\title{
11C-PIB-PET for the early diagnosis of Alzheimer's disease dementia and other dementias in people with mild cognitive impairment (MCI) (Review)
}

Zhang S, Smailagic N, Hyde C, Noel-Storr AH, Takwoingi Y, McShane R, Feng J

Zhang S, Smailagic N, Hyde C, Noel-Storr AH, Takwoingi Y, McShane R, Feng J.

${ }^{11}$ C-PIB-PET for the early diagnosis of Alzheimer's disease dementia and other dementias in people with mild cognitive impairment $(\mathrm{MCl})$.

Cochrane Database of Systematic Reviews 2014, Issue 7. Art. No.: CD010386.

DOI: 10.1002/14651858.CD010386.pub2. 
HEADER 1

ABSTRACT

PLAIN LANGUAGE SUMMARY

SUMMARY OF FINDINGS

BACKGROUND

OBJECTIVES

METHODS

RESULTS

Figure 1.

Figure 2.

Figure 3.

Figure 4.

Figure 5.

Figure 6.

Figure 7.

DISCUSSION

AUTHORS' CONCLUSIONS

ACKNOWLEDGEMENTS

REFERENCES

CHARACTERISTICS OF STUDIES

DATA

Test 1. 11C-PIB-PET AD dementia.

Test 2. 11C-PIB-PET All dementia.

ADDITIONAL TABLES

APPENDICES

CONTRIBUTIONS OF AUTHORS

DECLARATIONS OF INTEREST

SOURCES OF SUPPORT

INDEX TERMS

\section{TABLE OF CONTENTS}

1

2

3

6

${ }^{11} \mathrm{C}$-PIB-PET for the early diagnosis of Alzheimer's disease dementia and other dementias in people with mild cognitive impairment (MCI) (Review)

Copyright @ 2014 The Cochrane Collaboration. Published by John Wiley \& Sons, Ltd. 


\section{C-PIB-PET for the early diagnosis of Alzheimer's disease dementia and other dementias in people with mild cognitive impairment (MCI)}

Shuo Zhang ${ }^{1}$, Nadja Smailagic ${ }^{2}$, Chris Hyde ${ }^{3}$, Anna H Noel-Storr ${ }^{4}$, Yemisi Takwoingi ${ }^{5}$, Rupert McShane ${ }^{4}$, Juan Feng 6

1Department of Neurology, Shengjing Hospital, China Medical University, Shenyang, China. 2Institute of Public Health, University of Cambridge, Cambridge, UK. ${ }^{3}$ Institute of Health Research, University of Exeter Medical School, University of Exeter, Exeter, UK. ${ }^{4}$ Radcliffe Department of Medicine, University of Oxford, Oxford, UK. 5 Public Health, Epidemiology and Biostatistics, University of Birmingham, Birmingham, UK. ${ }^{6}$ Department of Neurology, Shengjing Hospital, China Medical University, Shenyang, China

Contact address: Shuo Zhang, Department of Neurology, Shengjing Hospital, China Medical University, 36 Shanhao Street, Shenyang, Liaoning, 110004, China. submission@126.com.

Editorial group: Cochrane Dementia and Cognitive Improvement Group. Publication status and date: New, published in Issue 7, 2014.

Citation: Zhang S, Smailagic N, Hyde C, Noel-Storr AH, Takwoingi Y, McShane R, Feng J. ${ }^{11} \mathrm{C}$-PIB-PET for the early diagnosis of Alzheimer's disease dementia and other dementias in people with mild cognitive impairment $(\mathrm{MCl})$. Cochrane Database of Systematic Reviews 2014, Issue 7. Art. No.: CD010386. DOI: 10.1002/14651858.CD010386.pub2.

Copyright $(2014$ The Cochrane Collaboration. Published by John Wiley \& Sons, Ltd.

\section{A B S T R A C T}

\section{Background}

According to the latest revised National Institute of Neurological and Communicative Disorders and Stroke and the Alzheimer's Disease and Related Disorders Association (now known as the Alzheimer's Association) (NINCDS-ADRDA) diagnostic criteria for Alzheimer's disease dementia, the confidence in diagnosing mild cognitive impairment $(\mathrm{MCl}$ ) due to Alzheimer's disease dementia is raised with the application of imaging biomarkers. These tests, added to core clinical criteria, might increase the sensitivity or specificity of a testing strategy. However, the accuracy of biomarkers in the diagnosis of Alzheimer's disease dementia and other dementias has not yet been systematically evaluated. A formal systematic evaluation of the sensitivity, specificity, and other properties of positron emission tomography (PET) imaging with the ${ }^{11} \mathrm{C}$-labelled Pittsburgh Compound-B (11C-PIB) ligand was performed.

\section{Objectives}

To determine the diagnostic accuracy of the ${ }^{11} \mathrm{C}$ - PIB-PET scan for detecting participants with $\mathrm{MCl}$ at baseline who will clinically convert to Alzheimer's disease dementia or other forms of dementia over a period of time.

\section{Search methods}

The most recent search for this review was performed on 12 January 2013. We searched MEDLINE (OvidSP), EMBASE (OvidSP), BIOSIS Previews (ISI Web of Knowledge), Web of Science and Conference Proceedings (ISI Web of Knowledge), PsycINFO (OvidSP), and LILACS (BIREME). We also requested a search of the Cochrane Register of Diagnostic Test Accuracy Studies (managed by the Cochrane Renal Group).

No language or date restrictions were applied to the electronic searches and methodological filters were not used so as to maximise sensitivity.

\section{Selection criteria}

We selected studies that had prospectively defined cohorts with any accepted definition of $\mathrm{MCI}$ with baseline ${ }^{11} \mathrm{C}-\mathrm{PIB}-\mathrm{PET}$ scan. In addition, we only selected studies that applied a reference standard for Alzheimer's dementia diagnosis for example NINCDS-ADRDA or Diagnostic and Statistical Manual of Mental Disorders-IV (DSM-IV) criteria.

${ }^{11} \mathrm{C}$-PIB-PET for the early diagnosis of Alzheimer's disease dementia and other dementias in people with mild cognitive impairment (MCI) 


\section{Data collection and analysis}

We screened all titles generated by electronic database searches. Two review authors independently assessed the abstracts of all potentially relevant studies. The identified full papers were assessed for eligibility and data were extracted to create two by two tables. Two independent assessors performed quality assessment using the QUADAS 2 tool. We used the hierarchical summary receiver operating characteristic (ROC) model to produce a summary ROC curve.

\section{Main results}

Conversion from $\mathrm{MCl}$ to Alzheimer's disease dementia was evaluated in nine studies. The quality of the evidence was limited. Of the 274 participants included in the meta-analysis, 112 developed Alzheimer's dementia. Based on the nine included studies, the median proportion converting was $34 \%$. The studies varied markedly in how the PIB scans were done and interpreted.

The sensitivities were between $83 \%$ and $100 \%$ while the specificities were between $46 \%$ and $88 \%$. Because of the variation in thresholds and measures of $11 \mathrm{C}$-PIB amyloid retention, we did not calculate summary sensitivity and specificity. Although subject to considerable uncertainty, to illustrate the potential strengths and weaknesses of ${ }^{11} \mathrm{C}$-PIB-PET scans we estimated from the fitted summary ROC curve that the sensitivity was $96 \%$ (95\% confidence interval $(\mathrm{Cl}) 87$ to 99$)$ at the included study median specificity of $58 \%$. This equated to a positive likelihood ratio of 2.3 and a negative likelihood ratio of 0.07 . Assuming a typical conversion rate of $\mathrm{MCl}$ to Alzheimer's dementia of $34 \%$, for every 100 PIB scans one person with a negative scan would progress and 28 with a positive scan would not actually progress to Alzheimer's dementia.

There were limited data for formal investigation of heterogeneity. We performed two sensitivity analyses to assess the influence of type of reference standard and the use of a pre-specified threshold. There was no effect on our findings.

\section{Authors' conclusions}

Although the good sensitivity achieved in some included studies is promising for the value of ${ }^{11}$ C-PIB-PET, given the heterogeneity in the conduct and interpretation of the test and the lack of defined thresholds for determination of test positivity, we cannot recommend its routine use in clinical practice. ${ }^{11} \mathrm{C}$-PIB-PET biomarker is a high cost investigation, therefore it is important to clearly demonstrate its accuracy and standardise the process of the ${ }^{11} \mathrm{C}-\mathrm{PIB}$ diagnostic modality prior to it being widely used.

\section{PLAIN LANGUAGE SUMMARY}

\section{${ }^{11}$ C-PIB-PET scan for early prediction of developing Alzheimer's disease or other dementia in people with mild cognitive impairment (MCl)}

The numbers of people with dementia and other cognitive problems are increasing globally. A diagnosis of the pre-dementia phase of disease is recommended but there is no agreement on the best approach. A range of tests have been developed which healthcare professionals can use to assess people with poor memory or cognitive impairment. Based on the published data, we have found that the ${ }^{11} \mathrm{C}-\mathrm{PIB}-\mathrm{PET}$ scan as a single test lacks the accuracy to identify those patients with $\mathrm{MCl}$ who would develop Alzheimer's disease dementia or other forms of dementia. The findings indicate that for every $100 \mathrm{PIB}$ scans, one person with a negative scan will progress to Alzheimer's disease dementia and 28 with a positive scan will not. Therefore, a positive PIB scan in patients with $\mathrm{MCl}$ is of no clinical value in the early prediction of Alzheimer's disease dementia developing. 


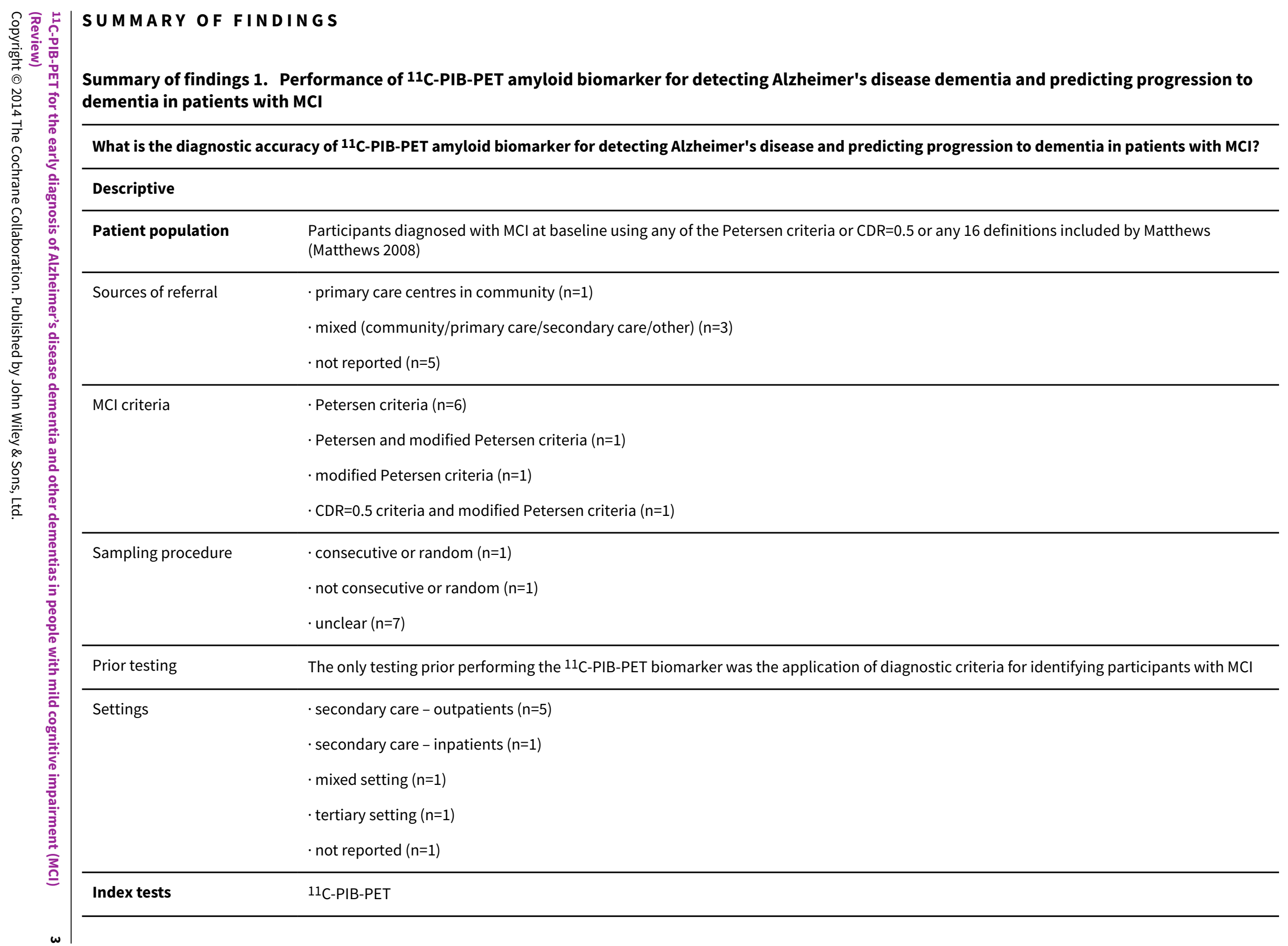




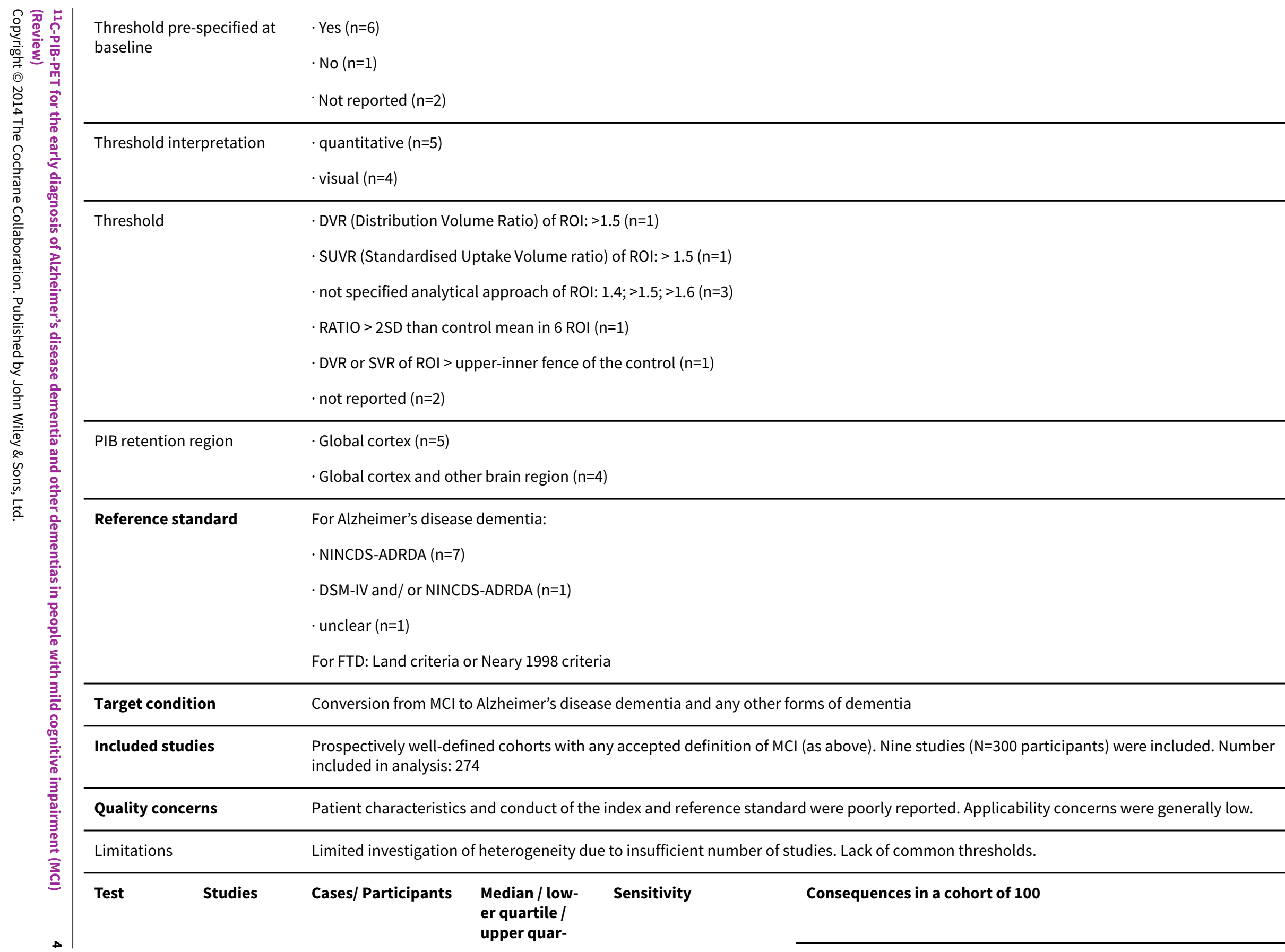




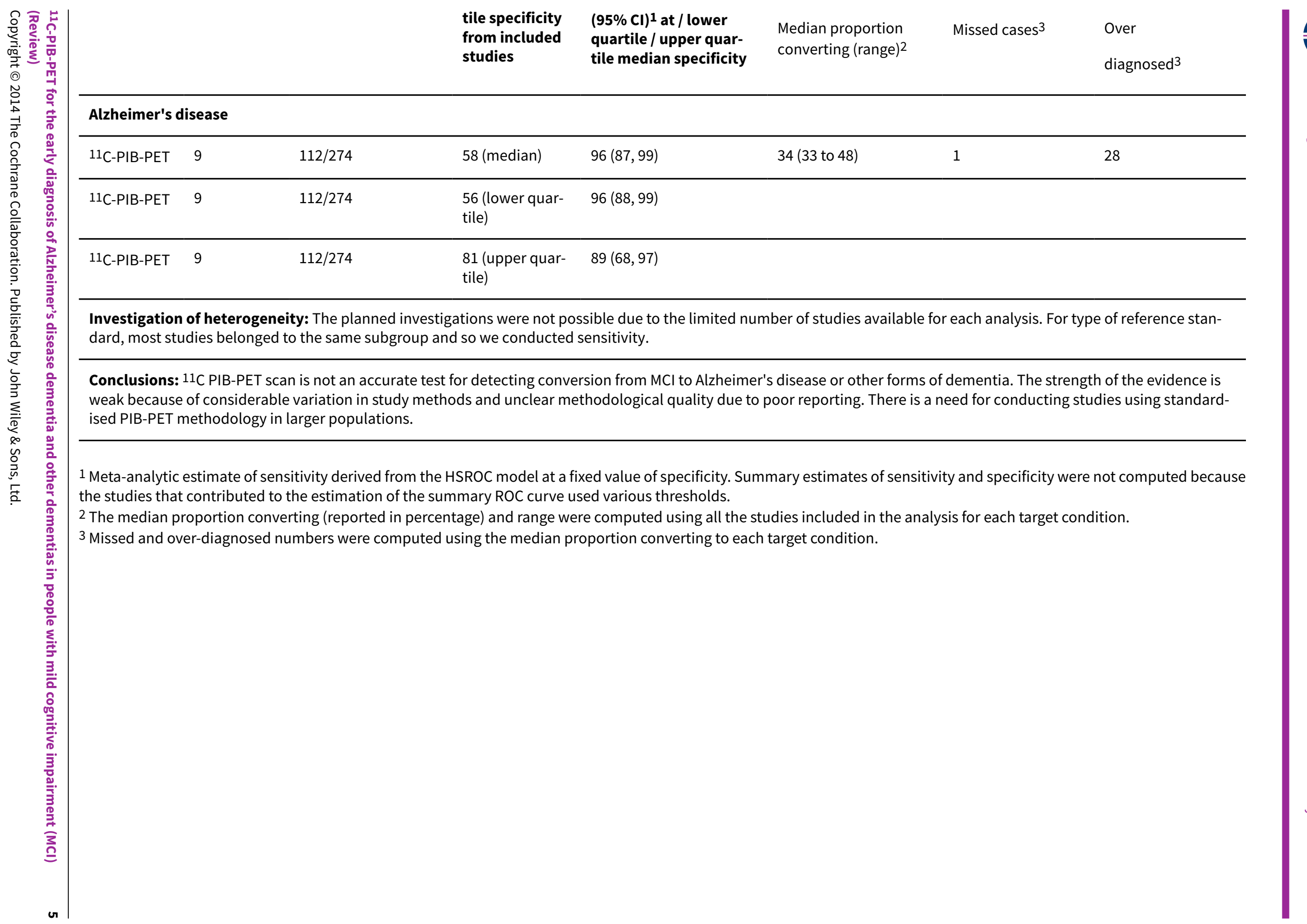




\section{B A C K G R O U N D}

The pathology of Alzheimer's disease is present in the majority of cases of dementia. As the dominant or sole pathology, it accounts for over $50 \%$ of dementia, afflicting $5 \%$ of men and $6 \%$ of women over the age of 60 years worldwide (World Health Organization 2002). However, the strength of the link between cognitive impairment and the pathological features of Alzheimer's disease varies with age and with each of the different pathological features. It has also been recognised that a significant number of individuals without clinical evidence of Alzheimer's disease have amyloid deposition at death (Dickson 1992). Indeed, epidemiological neuropathological studies have established that there is no significant relationship between amyloid plaque burden and cognitive impairment in those over the age of 90 years (Savva 2009).

The term 'Alzheimer's disease dementia' is used to describe those in whom the symptoms of cognitive impairment have gradually progressed to the point where the ability of the patient to perform everyday functions has been affected. Before this, there is a stage, known as mild cognitive impairment $(\mathrm{MCl})$, in which the patient has a degree of cognitive impairment which is greater than expected for age but he or she is not impaired in function. Before $\mathrm{MCl}$, there is a stage in which the pathology is present and increasing but has not yet affected cognitive function, known as 'preclinical Alzheimer's disease'.

$\mathrm{MCl}$ is a heterogeneous condition. In this review $\mathrm{MCl}$ refers to the clinical criteria defined by Petersen or the revised Petersen criteria (Petersen 1999; Petersen 2004; Winblad 2004), the Cognitive Dementia Rating (CDR $=0.5$ ) scale (Morris 1993), or to the 16 different classifications of $\mathrm{MCl}$ (Matthews 2008). There are four outcomes for those within an $\mathrm{MCl}$ population, progression to Alzheimer's disease dementia, progression to another dementia, maintaining stable $\mathrm{MCl}$, or recovery. At present, there is no clinical method to determine who of these patients will experience Alzheimer's disease dementia (ADD) or other forms of dementia.

The main concern of patients who present with worries about their cognitive function is whether there is a treatment which will either improve or delay progression of their symptoms. The rate at which patients cross the boundary between preclinical Alzheimer's disease and $\mathrm{MCl}$, and between $\mathrm{MCl}$ and Alzheimer's disease dementia, depends on several factors. Patients presenting to primary care are different from those in secondary care, who are different again from those in research settings. Those with the apolipoprotein E4 (ApoE4) genotype progress more rapidly. Within the ' $\mathrm{MCl}$ band', those with worse cognitive function also progress more rapidly. Studies indicate that an annual average of $5 \%$ to $15 \%$ of $\mathrm{MCl}$ patients progress to ADD (Petersen 1999; Bruscoli 2004; Mattsson 2009; Petersen 2009).

Alzheimer's disease pathology is associated with cerebral amyloidosis and the presence of amyloid-beta (Abeta) plaques and neurofibrillary tangles in brain tissues at autopsy has been considered a 'gold standard' for the definitive diagnosis of Alzheimer's disease (Mirra 1991; Newell 1999). However, Abeta plaques are present in conditions other than ADD (Villemagne 2008). Abeta amyloid deposits, measured with a Pittsburgh Compound-B (PIB) radioactive substance, are greater in congophilic angiopathy (Johnson 2007) and dementias other than ADD. PIB retention and Abeta imaging in vivo could indicate more accurate differential diagnosis of the dementias. For instance, PIB could differentiate Alzheimer's disease from frontotemporal dementia (FTD) (Rabinovici 2007; Rowe 2007; Drzezga 2008; Engler 2008). The role of the PIB positron emission tomography (PET) biomarker in dementia differential diagnostics is being evaluated in a number of separate Cochrane systematic reviews.

The U.S. Food and Drug Administration (FDA) position on recently licensed amyloid ligands is that such tests do not establish a positive diagnosis of Alzheimer's disease nor, if positive, predict progression from $\mathrm{MCl}$ to $\mathrm{ADD}$ (http://www.alzforum.org/news/research-news/fdaapproves-second-amyloid-imaging-agent; http://www.fda.gov/ newsevents/newsroom/pressannouncements/ucm372261.htm).

It is a reasonable assumption, and one on which this review is predicated, that if a patient has both $\mathrm{MCl}$ and the pathology of Alzheimer's disease and then goes on to develop clinical ADD then the cause of the initial $\mathrm{MCl}$ and of the ADD was the Alzheimer's pathology.

Our approach is an example of assessing diagnostic accuracy using delayed verification of diagnosis. Instead of the reference standard being based on pathology, however, it is based on a clinical standard, the progression from $\mathrm{MCl}$ to $\mathrm{ADD}$ or other dementias. Although, for the reasons stated above, this introduces a degree of unreliability it has the advantage of being based on what matters to patients, which is progression.

The PIB-PET biomarker results represent Abeta amyloid deposition in the brain. We looked at at the relation between ${ }^{11} \mathrm{C}$-PIB ligand binding in the brain and: i) conversion from $\mathrm{MCl}$ to $\mathrm{ADD}$; or ii) conversion from $\mathrm{MCl}$ to other forms of dementia.

\section{Target condition being diagnosed}

In this review there are two target conditions: i) Alzheimer's disease dementia (ADD); and ii) other forms of dementia, which are assessed at follow-up.

We compared the index test results obtained at baseline with the results of the reference standards obtained at follow-up (delayed verification).

\section{Index test(s)}

The ${ }^{11} \mathrm{C}$-PIB-PET scan is an index test for the detection of Abeta deposition in the brain region of interest (ROI). The ROI is a selected brain area that physicians create for futher study, in various anatomical areas of the brain.

${ }^{11} \mathrm{C}$-PIB is a molecular biomarker, a N-methyl-[11C]2-(4'methylaminophenyl)-6-hydroxybenzothyazole radiotracer derived from thioflavin T (Klunk 2004). Price 2005 fully evaluated quantitative ${ }^{11}$ C-PIB-PET data in order to identify a valid, simple and reliable PET quantisation method for the routine measure of brain amyloid retention in vivo.

- Criteria for ${ }^{11} \mathrm{C}-\mathrm{PIB}-\mathrm{PET}$ positivity: there are currently no generally accepted standards for ${ }^{11} \mathrm{C}$-PIB threshold, and therefore it was not possible to pre-specify it. We planned to use the criteria that were applied in each included primary study to classify participants as either test positive or test negative.

${ }^{11}$ C-PIB-PET for the early diagnosis of Alzheimer's disease dementia and other dementias in people with mild cognitive impairment (MCI) 
Positivity is a ${ }^{11} \mathrm{C}-\mathrm{PIB}-\mathrm{PET}$ uptake and retention exceeding a certain threshold.

- Measure of ${ }^{11} \mathrm{C}-\mathrm{PIB}$ amyloid retention (retention ratio): distribution volume ratio (DVR), standardized uptake value ratio (SUVR), or other ratios will be considered. DVR refers to the ratio of the ${ }^{11} \mathrm{C}$-PIB ligand distribution volume in the selected area (ROI) to the distribution volume in the reference area (usually cerebellum). SUVR is the measured activity in the ROI, which is normalised for body weight, surface area, and injected dose.

- Image analysis: not pre-specified (e.g. Statistical Parametric Mapping (SPM), MilxView medical image, and analysis software or other image analysis techniques).

- Time between ${ }^{11} \mathrm{C}$-PIB injection and PET acquisition: not prespecified (e.g. 40 minutes, 60 minutes, 50 to 70 minutes, 90 minutes).

- ${ }^{11 C} \mathrm{C}-\mathrm{PIB}$ injection dose: not pre-specified (e.g. $300 \mathrm{MBq}, 370$ $\mathrm{MBq})$.

- ${ }^{11} \mathrm{C}$-PIB retention detecting regions: not pre-specified ROI (e.g. global cortex, thalamus, frontal, parietal, temporal cortices or posterior cingulum, or a combination of these) (e.g. global cortex, caudate nucleus, putamen, thalamus, pons, etc.).

Although it is inevitable for included studies to use different imaging protocols and varied parameters, the amyloid PET data in these included studies should be technically adequate and should be acquired at a fully qualified and certified facility. The protocol for the qualitative read that determines positivity or negativity should be be standardized and should conform to a specific guideline.

\section{Clinical pathway}

Dementia develops over several years. There is a presumed period when people are asymptomatic but when pathology is accumulating. Individuals or their relatives may then notice subtle impairments of recent memory. Gradually more cognitive domains become involved and difficulty in planning complex tasks becomes increasingly apparent. In the UK, people usually present to their general practitioner, who may administer cognitive tests and refer the person to a hospital memory clinic. However, many people with dementia do not present until much later in the disorder and will follow a different pathway to diagnosis, for example being identified during an admission to a general hospital for a physical illness. Thus the pathway influences the accuracy of the diagnostic test. The accuracy of the test will vary with the experience of the administrator, and the accuracy of the subsequent diagnosis will vary with the history of referrals to the particular healthcare setting. Diagnostic assessment pathways may vary in other countries and diagnoses may be made by a variety of specialists including neurologists and geriatricians. We anticipated that the main way in which ${ }^{11}$ C-PIB-PET scans will be used is as an additive test to clinical signs and other tests.

\section{Alternative test(s)}

Alternative tests are not included in this review because there are currently no standard practice tests available for the diagnosis of dementia. The Cochrane Dementia and Cognitive Improvement Group ( $\mathrm{CDCIG}$ ) is in the process of conducting a series of diagnostic test accuracy reviews of biomarkers and scales (see list below). Although we are conducting reviews on individual tests compared to a reference standard, we plan to compare our results in an overview.
- 18F-FDG-PET (18F-2-fluoro-2-deoxy-D-glucose).

- Cerebrospinal fluid (CSF) analysis of Abeta and tau.

- Structural magnetic resonance imaging (SMRI).

- Neuropsychological tests (Mini-Mental State Examination (MMSE); MiniCOG; Montreal Cognitive Assessment (MoCA)).

- Informant interviews (Informant Questionnaire on Cognitive Decline in the Elderly (IQCODE); AD8).

- ApoE4.

- Fluoropropil-carbomethoxy-iodophenil-tropane single-photon emission tomography (FP-CIT SPECT).

\section{Rationale}

The new diagnostic criteria for Alzheimer's disease and $\mathrm{MCl}$ due to Alzheimer's disease (Dubois 2010; Albert 2011; McKhann 2011; Sperling 2011) incorporate add-on biomarkers based on imaging or CSF measures. These tests added on to core clinical criteria might increase the sensitivity or specificity of a testing strategy.

The ${ }^{11} \mathrm{C}$-PIB-PET scan might facilitate accurate identification of those patients with $\mathrm{MCl}$ who would convert to Alzheimer's disease or other forms of dementia. At the present time there is no 'cure' for dementia, but there are some treatments which can slow cognitive and functional decline, or reduce the associated behavioural and psychiatric symptoms of dementia (Birks 2006; McShane 2006). In addition, the accurate early diagnosis of dementia may improve opportunities for the use of newly-evolving interventions designed to delay or prevent progression to more debilitating stages of dementia (Oddo 2004).

The disappointing clinical trial result for Alzheimer's diseasemodifying therapies in people suggests that treatment should be targeted at earlier stages in the disease, such as $\mathrm{MCl}$ (Friedrich 2014). Abeta biomarkers such as PIB-PET imaging may be essential to allow for testing an Abeta immunotherapy drug on $\mathrm{MCl}$ patients with evidence of brain Abeta pathology, and seem to be useful in assessing the effects of pre-dementia phase preventive treatments of potential Alzheimer's disease on cortical fibrillar Abeta load in vivo (Rinne 2010; Blennow 2014; Salloway 2014).

It is crucial that the ${ }^{11}$ C-PIB-PET scan is assessed for its diagnostic accuracy in patients with $\mathrm{MCl}$ before being adopted as a routine add-on test in clinical practice.

\section{O B JECTIVES}

To determine the diagnostic accuracy of the ${ }^{11} \mathrm{C}$ - PIB-PET scan as the index test for detecting participants with mild cognitive impairment $(\mathrm{MCl})$ at baseline who would clinically convert to Alzheimer's disease dementia (ADD) or other forms of dementia at follow-up.

\section{Secondary objectives}

To investigate the heterogeneity of the test accuracy in the included studies.

${ }^{11}$ C-PIB-PET for the early diagnosis of Alzheimer's disease dementia and other dementias in people with mild cognitive impairment (MCI) 


\section{METHODS}

\section{Criteria for considering studies for this review}

\section{Types of studies}

We considered longitudinal studies that had prospectively defined cohorts with any accepted definition of $\mathrm{MCl}$ with baseline ${ }^{11} \mathrm{C}$-PIBPET scan and the reference standard results obtained at followup (see Index tests and Reference standards below). These studies necessarily employ delayed verification of conversion to dementia and are sometimes labelled as 'delayed verification cross-sectional studies' (Knotnerus 2002; Bossuyt 2008).

We included case control studies when they incorporated a delayed verification design. This occurred in the context of a cohort study, so these studies are invariably diagnostic nested case-control studies.

\section{Participants}

Participants recruited and clinically classified as those with $\mathrm{MCl}$ at baseline were eligible for this review. The diagnosis of $\mathrm{MCl}$ was established using the Petersen criteria or revised Petersen criteria (Petersen 1999; Petersen 2004; Winblad 2004), the Matthews 2008 criteria, or CDR $=0.5$ (Morris 1993), or a combination. These criteria include: subjective complaints; a decline in memory objectively verified by neuropsychological testing in combination with a history from the patient; a decline in other cognitive domains; no or minimal impairment of activities of daily living; not meeting the criteria for dementia. Therefore, the eligible participants had a number of tests, for example neuropsychological tests for cognitive deficit and checklists for activities of daily living, prior to study entry. Participants in some studies were defined as amnestic single domain, amnestic multiple domain, non-amnestic single domain, non-amnestic multiple domain, or non-specified $\mathrm{MCl}$ participants. We considered these studies for inclusion. We also considered studies without reference to a particular source of recruitment (participant setting) for inclusion.

We excluded studies that involved patients with $\mathrm{MCl}$ possibly caused by: i) current or a history of alcohol or drug abuse; ii) central nervous system (CNS) trauma (for example subdural haematoma), tumour, or infection; iii) other neurological conditions (for example Parkinson's or Huntington's diseases).

\section{Index tests}

\section{${ }^{11}$ C-PIB-PET imaging test}

We used the criteria that were applied in each included primary study to classify participants as either ${ }^{11} \mathrm{C}$-PIB positive or ${ }^{11} \mathrm{C}$-PIB negative. We considered positivity as ${ }^{11} \mathrm{C}-\mathrm{PIB}$ ligand uptake and retention exceeding a certain threshold.

\section{Target conditions}

There were two target conditions in this review:

1. Alzheimer's disease dementia (ADD) (conversion from $\mathrm{MCl}$ to ADD);

2. Any other forms of dementia (conversion from $\mathrm{MCl}$ to any other forms of dementia).

\section{Reference standards}

The reference standard was progression to the target conditions. For the purpose of this review, several definitions of ADD were acceptable. Included studies applied probable or possible National Institute of Neurological and Communicative Disorders and Stroke and the Alzheimer's Disease and Related Disorders Association (now known as the Alzheimer's Association) (NINCDSADRDA) criteria (McKhann 1984). The Diagnostic and Statistical Manual of Mental Disorders (DSM) (DSMIII 1987; DSMIV 1994) and International Classification of Diseases (ICD) (World Health Organization 2010) definitions for ADD were also acceptable.

Similarly, differing clinical definitions of other dementias were acceptable. For Lewy body dementia the reference standard is the McKeith criteria (McKeith 1996; McKeith 2005); for frontotemporal dementia (FTD) the Lund criteria (Neary 1988; Brun 1994; Boxer 2005), DSM (DSMIII 1987; DSMIV 1994), ICD (World Health Organization 2010); and for vascular dementia the National Institute of Neurological Disorders and Stroke and Association Internationale pour la Recherché et l'Enseignement en Neurosciences (NINDS ARIEN) criteria (Roman 1993), DSM (DSMIII 1987; DSMIV 1994), and ICD (World Health Organization 2010).

The time interval over which progression from $\mathrm{MCl}$ to $\mathrm{ADD}$ or other forms of dementia occurred is very important. We chose one year as the minimum period of delay in the verification of the diagnosis (that is the time between the assessment at which a diagnosis of $\mathrm{MCl}$ is made and the assessment at which the diagnosis of dementia is made). We planned to segment analyses into separate follow-up mean periods for the delay in verification: one year to less than two years; two to less than four years; and greater than four years. In this eventuality we planned to clearly note where the same included studies contributed to the analysis for more than one reference standard follow-up interval.

\section{Search methods for identification of studies}

\section{Electronic searches}

On 12 January 2013 we searched MEDLINE (OvidSP), EMBASE (OvidSP), BIOSIS Previews (ISI Web of Knowledge), Science Citation Index (ISI Web of Knowledge), PsycINFO (OvidSP), and LILACS (BIREME). See Appendix 1 for details of the sources searched, the search strategies used, and the number of hits retrieved. No language restriction was applied to the electronic searches.

\section{Searching other resources}

The reference lists of all relevant studies were checked for additional studies. Searches were also conducted in the MEDION database (Meta-analyses van Diagnostisch Onderzoek) (www.mediondatabase.nl), DARE (Database of Abstracts of Reviews of Effects) (www.york.ac.uk/ inst/crd/crddatabases.htm\#DARE), HTA Database (Health Technology Assessments Database) (www.york.ac.uk/inst/crd/ crddatabases.htm\#HTA), and ARIF database (Aggressive Research Intelligence Facility) (www.arif.bham.ac.uk) for other related systematic diagnostic accuracy reviews; and a dataset of systematic reviews of diagnostic studies from the International Federation of Clinical Chemistry and Laboratory Medicine Committee for Evidence-based Laboratory Medicine database (CEBLM) was sought. Reference lists of any relevant systematic reviews were checked for additional studies.

${ }^{11} \mathrm{C}-\mathrm{PIB}-\mathrm{PET}$ for the early diagnosis of Alzheimer's disease dementia and other dementias in people with mild cognitive impairment (MCI) 


\section{Data collection and analysis}

\section{Selection of studies}

The Cochrane Dementia and Cognitive Impairment Group (CDCIG) Trial Search Co-ordinator, a researcher with experience of diagnostic test accuracy systematic reviews, performed the first assessment of the search results in order to remove the obvious non-relevant studies. Two authors independently reviewed the remaining titles and abstracts for potentially eligible studies for full paper review. Two authors independently assessed the full manuscripts against the inclusion criteria. Where necessary, a third review author acted as arbitrator to resolve disagreements that the two review authors were not able to resolve through discussion.

Where a study did not present all relevant data for creating a 2 $x 2$ table, we contacted the authors directly to request further information. When the same data set was presented in more than one paper, we included as the primary paper the paper with the largest number of patients or with the most informative data.

\section{Data extraction and management}

We planned to extract the following data on study characteristics if reported.

Bibliographic details of primary paper:

- author, title of study, year, and journal.

Basic clinical and demographic details:

- number of participants;

- clinical diagnosis;

- MCl clinical criteria;

- age;

- gender;

- sources of referral;

- participant recruitment;

- sampling procedures.

Details of the index test:

- method of the PIB test administration, including who administered the test;

- thresholds used to define positive and negative tests;

- other technical aspects as seemed relevant to the review, e.g. brain areas.

Details of the reference standard:

- definition of ADD and other dementias used in reference standard;

- duration of follow-up from time of index test performed to defining ADD and other dementias by reference standard;

- prevalence or proportion of population developing ADD and other dementias, with severity if described.

We created $2 \times 2$ tables (cross-relating index test results of the reference standards) as shown in Appendix 2.

The numbers lost to follow-up were recorded for each included study.
We also extracted data necessary for the assessment of quality as defined below.

Data extraction was performed independently by two blinded review authors (NS, ZS). Disagreement in data extraction was resolved by discussion, with the potential to involve a third author $(\mathrm{CH})$ as arbitrator if necessary.

\section{Assessment of methodological quality}

We assessed the methodological quality of each study using the QUADAS-2 tool (Whiting 2011) as recommended by The Cochrane Collaboration. The tool is made up of four domains:

- patient selection;

- index test;

- reference standard;

- patient flow.

Two independent raters (NS, MW), blinded to each other's scores, performed the QUADAS-2 assessment. Disagreement was resolved by further review and discussion with the potential to involve a third author $(\mathrm{CH})$ as arbitrator if necessary.

We assessed each domain in terms of risk of bias, with the first three domains also considered in terms of applicability concerns. The components of each of these domains and a rubric which details how judgements concerning risk of bias were made are detailed in Appendix 3. Key areas important to quality assessment are participant selection, blinding, and missing data.

We did not use QUADAS-2 data to form a summary quality score. We produced a narrative summary describing the numbers of studies that were found to have high, low, or unclear risk of bias as well as concerns regarding applicability.

\section{Statistical analysis and data synthesis}

We evaluated test accuracy according to the target condition. There are no accepted thresholds to define PIB-PET positivity for ADD and other forms of dementia, and so the estimates of diagnostic accuracy reported in primary studies were likely to be based on data-driven threshold selection (Leeflang 2008) unless pre-specified. We conducted exploratory analyses by plotting estimates of sensitivity and specificity from each study on forest plots and in receiver operating characteristic (ROC) space. We meta-analysed pairs of sensitivity and specificity using the hierarchical summary ROC (HSROC) model (Rutter 2001) that allows for the possibility of variation in threshold between studies. Where adequate studies were available to estimate all parameters, we assumed a symmetrical shape to the summary ROC curve. Estimates of summary sensitivities and specificities are not clinically interpretable when studies with mixed thresholds are included in the HSROC model, and so we derived estimates of sensitivity and likelihood ratios at fixed values (lower quartile, median, and upper quartile) of specificity from the HSROC models. The analyses were performed using the NLMIXED procedure in the SAS software (version 9.2; SAS Institute 2011, Cary, NC).

\section{Investigations of heterogeneity}

We planned to investigate the effects of the following factors.

${ }^{11} \mathrm{C}$-PIB-PET for the early diagnosis of Alzheimer's disease dementia and other dementias in people with mild cognitive impairment (MCI) 
- Spectrum of patients (mean age, gender, MMSE score, APOE $\epsilon 4$ status). For age, we planned to separately examine any study that included $30 \%$ of patients below the age of 65 years.

- Referral centres: primary care, memory clinic, and hospital.

- Clinical criteria of $\mathrm{MCl}$ : Petersen criteria, revised Petersen criteria, $\mathrm{CDR}=0.5$ criteria, and different $\mathrm{MCl}$ classification (Matthews 2008).

- ${ }^{11} \mathrm{C}-\mathrm{PIB}$ retention ratio.

- Image analysis techniques.

- Time between ${ }^{11} \mathrm{C}-\mathrm{PIB}$ injection and PET acquisition.

- ${ }^{11} \mathrm{C}-\mathrm{PIB}$ injection dose.

- $11 \mathrm{C}-\mathrm{PIB}$ retention detecting regions.

- Reference standard(s) used: NINCDS-ADRDA, DSM, and ICD 10 for ADD.

- Duration of follow-up: 1 year to $<2$ years, 2 to $<4$ years, and $>4$ years.

- Aspects of study quality, particularly inadequate blinding and loss to follow-up: we considered separately those studies that had more than $20 \%$ dropouts.

- Conflict of interest.

In preliminary analyses, we visually examined forest plots of sensitivity and specificity, and summary ROC plots to explore the effect of each of these factors. If there were sufficient studies, we planned to perform meta-regression by including each potential source of heterogeneity as a covariate in the HSROC model.

\section{Sensitivity analyses}

We investigated the effect of pre-specification of threshold and PIB positivity on diagnostic accuracy by performing sensitivity analyses.

\section{Assessment of reporting bias}

We did not investigate reporting bias because of current uncertainty about how it operates in test accuracy studies and the interpretation of existing analytical tools such as funnel plots.

\section{RES U L T S}

\section{Results of the search}

The total number of records identified by the searches for this review was 14,951. After de-duplication, a small team of assessors performed a first-assess on the remaining records. The PRISMA diagram (Figure 1) shows the flow of studies through the screening and selection processes. In total, 103 studies (94 full text papers and 11 conference publications) were assessed for eligibility. We included nine studies and one was identified as an ongoing study. We excluded 93 studies. Nineteen studies were multiple publications and 11 did not have extractable data for constructing $2 \times 2$ tables (see Characteristics of excluded studies). The remaining 63 studies were excluded as they did not meet the inclusion criteria: i) not $\mathrm{MCl}$ participants at baseline $(n=10)$; ii) not a delayed verification study $(n=40)$; iii) index test not PIB-PET scan $(n=1)$; iv) discussion papers ( $n=3)$; and v) conference publications and no reply when authors were contacted $(n=9)$ (Okello 2007; Ellis 2011; Maruff 2011; Perrotin 2011; Rentz 2011; Villain 2011; Villemagne 2011a; Hatashita 2012; Mosconi 2012). No extra studies were found through reference checking. Usable data were obtained for three studies (Jack 2010; Ossenkoppele 2012; Ossenkoppele 2012a) by contacting the authors of the studies.

${ }^{11}$ C-PIB-PET for the early diagnosis of Alzheimer's disease dementia and other dementias in people with mild cognitive impairment (MCI) 
Figure 1. Study flow diagram.

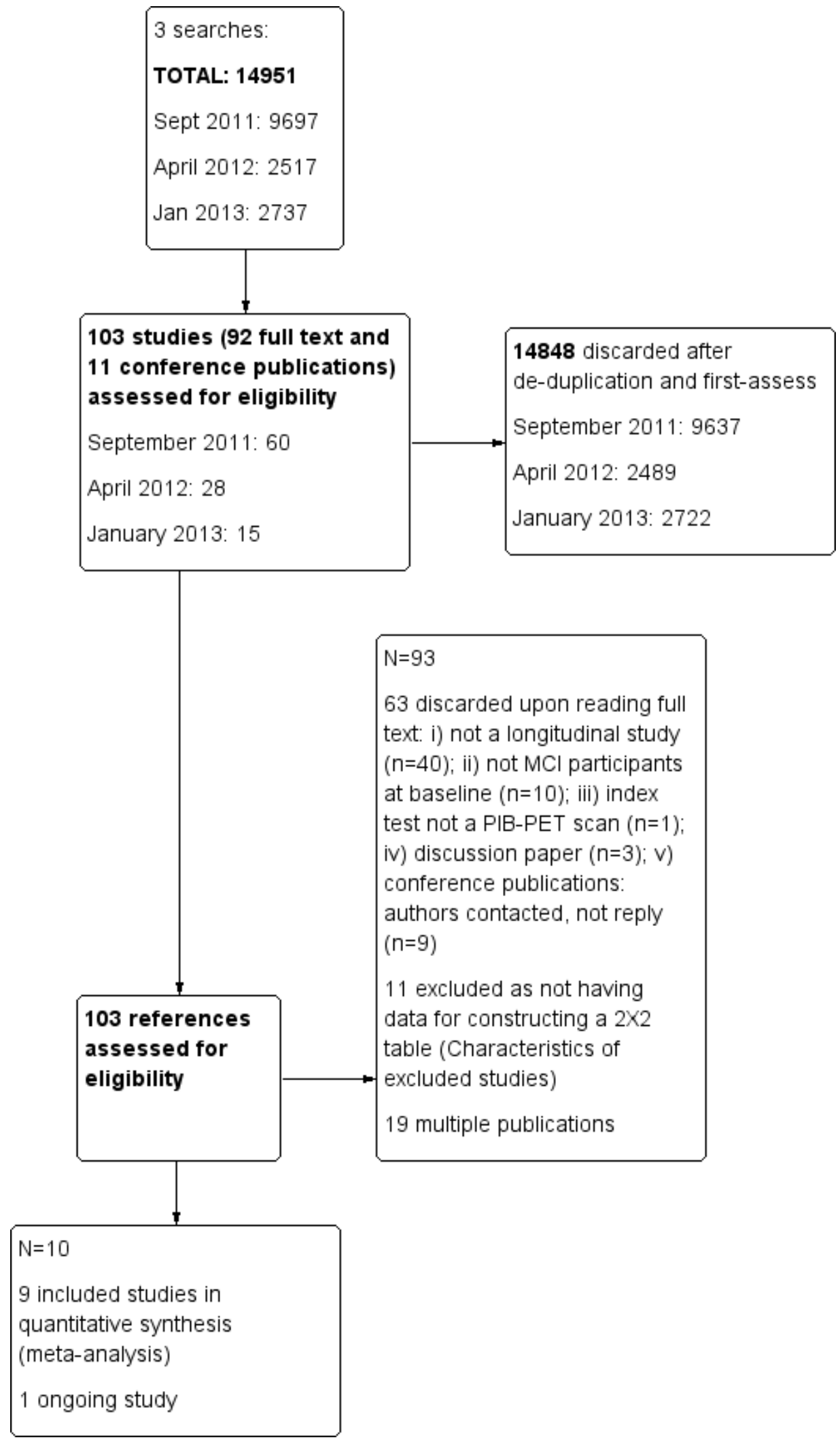

${ }^{11} \mathrm{C}$-PIB-PET for the early diagnosis of Alzheimer's disease dementia and other dementias in people with mild cognitive impairment (MCI) 


\section{Included studies}

The Characteristics of included studies table lists the characteristics of the nine included studies containing a total of 300 participants with $\mathrm{MCl}$ at baseline.

Of the 274 participants with analysable data, 112 developed Alzheimer's dementia and nine non-Alzheimer's dementia. The remaining 26 participants were reported to be lost to follow-up. The majority $(n=18)$ of participants were missing from a single study (Ossenkoppele 2012a). All the studies were published in recent years (2009 to 2013). Most of them (6/9) were conducted in Europe (two in the Netherlands, one in the UK and Finland, one in Finland alone, one in Sweden, one in Germany); two in the USA; and one in Australia. All included studies used one version or another of the Petersen criteria for MCl. Eight studies applied NINCDS-ADRDA criteria as a reference standard for ADD; Koivunen 2011 also used DSM-IV criteria; Ossenkoppele 2012a did not explicitly state what reference standard was used at follow-up.

Demographic and patient characteristics are summarised in Table 1. Study sizes were small and ranged from 15 to 67. Four papers reported a mean age of over 70 years (Jack 2010; Koivunen 2011; Villemagne 2011; Wolk 2009) while five papers reported a mean age below 70 years (Okello 2009; Forsberg 2010; Ossenkoppele 2012; Ossenkoppele 2012a; Grimmer 2013). The youngest study population was aged $64 \pm 9$ years (Ossenkoppele 2012a) and the oldest study population was aged $73.4 \pm 8.5$ years (Villemagne 2011). Gender, APOE $\varepsilon 4$ carriers, years of education, and sampling procedure were poorly reported. Participants were mainly recruited from secondary care (five studies from outpatient clinics and one study from inpatient department), one study recruited the participants from a tertiary setting (Wolk 2009), one from a mixed setting (Jack 2010), and one did not report the sources of recruitment (Ossenkoppele 2012).
Table 2 and Table 3 summarise the data regarding the threshold used, the measure of PIB amyloid retention, image analysis, PIB dose and the time between PIB injection and performing a PET scan, and PIB retention detecting region of interest (ROI). The studies applied different analytic approaches to PET data, ranging from quantitative binding potentials (BPs) or distribution volume ratios (DVRs) using invasive arterial sampling to semi-quantitative standardized uptake value ratios (SUVR). Seven studies used seven different thresholds and two studies did not report the threshold used. Six different measures were used for PIB retention and six different ROIs were investigated for detecting PIB retention in nine included studies. The timing of the scans and data acquisition (dynamic versus static) also varied greatly across studies. Duration of follow-up was reported as the mean and SD, median, or maximum duration, or it was not reported at all. Duration of followup varied substantially but was mostly within the 18 to 36 months range. PIB positivity ranged from $42 \%$ (Ossenkoppele 2012) to $72 \%$ (Koivunen 2011). Conversion to ADD ranged from 22\% (Wolk 2009) to 59\% (Koivunen 2011). The included studies varied markedly in how the PIB scans were done and interpreted.

\section{Excluded studies}

Eleven studies were excluded as they failed on the inclusion criteria for participants, index test, or target condition (Characteristics of excluded studies).

\section{Methodological quality of included studies}

Methodological quality was assessed using the QUADAS 2 tool (Whiting 2011). Review authors' judgements about each methodological quality item for each included study are presented in the Characteristics of included studies table and Figure 2. The overall methodological quality of the studies is summarised in Figure 3.

${ }^{11} \mathrm{C}$-PIB-PET for the early diagnosis of Alzheimer's disease dementia and other dementias in people with mild cognitive impairment (MCI) 
Figure 2. Risk of bias and applicability concerns summary: review authors' judgements about each domain for each included study

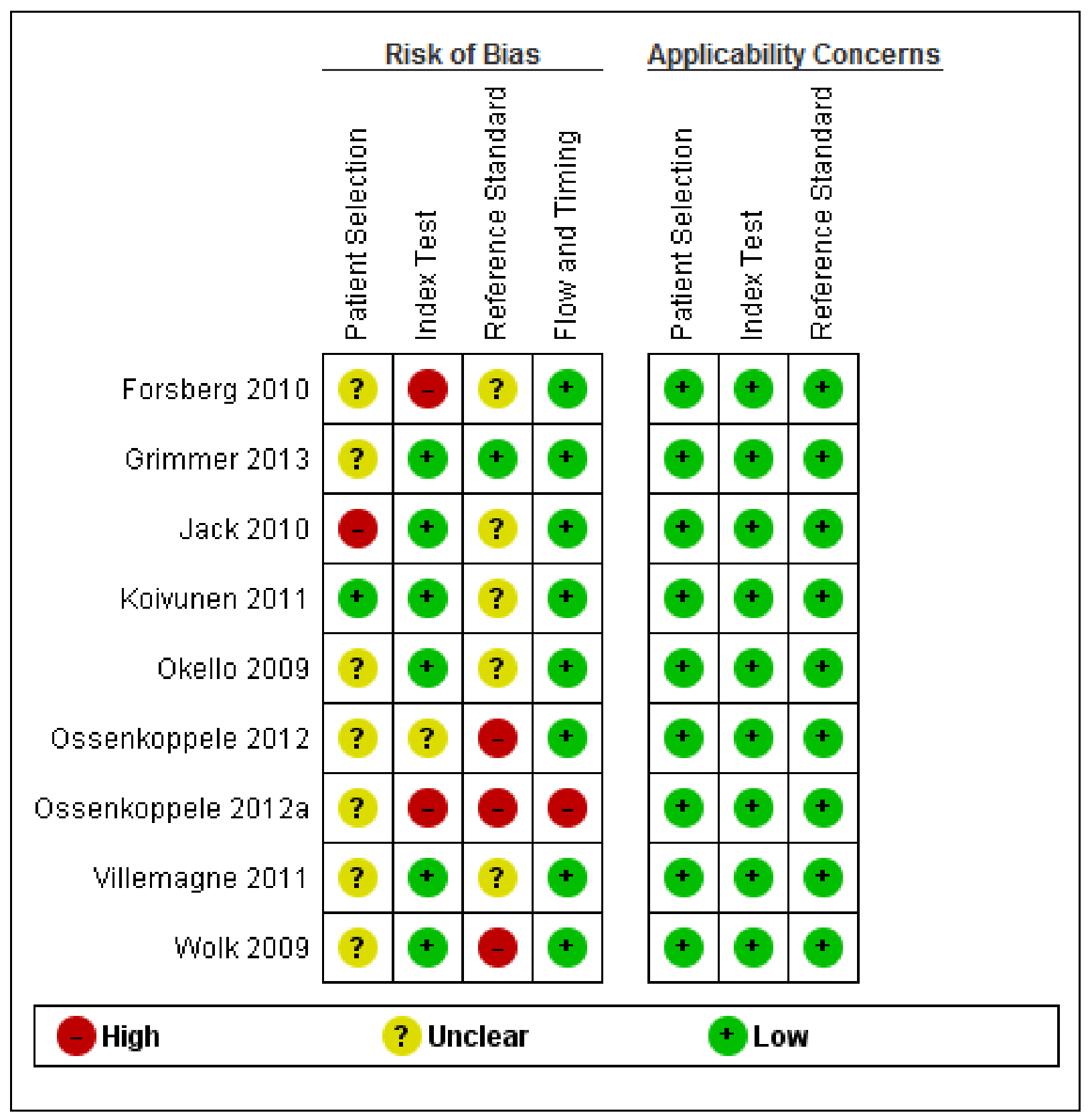

${ }^{11} \mathrm{C}-\mathrm{PIB}-\mathrm{PET}$ for the early diagnosis of Alzheimer's disease dementia and other dementias in people with mild cognitive impairment (MCI) 
Figure 3. Risk of bias and applicability concerns graph: review authors' judgements about each domain presented as percentages across included studies.

\begin{tabular}{|l|llllll|}
\hline $\begin{array}{r}\text { Patient Selection } \\
\text { Index Test }\end{array}$ & & & & & & \\
Reference Standard \\
Flow and Timing
\end{tabular}

In the patient selection domain, we considered seven studies (78\%) to be at unclear risk of bias due to poor reporting on sampling procedures and exclusion criteria. We stated that all included studies avoided a case-control design because we only considered data on performance of the index test to discriminate between patients with $\mathrm{MCl}$ who converted to dementia and those who remained stable. We considered two remaining studies to be at high (Jack 2010) and low (Koivunen 2011) risk of bias because the participants were not systematically enrolled or were consecutively or randomly enrolled, respectively.

In the index test domain, we considered six studies (67\%) at low risk of bias because the threshold used was pre-specified and the index test results were interpreted without knowledge of the results of the reference standard. We considered two studies (Forsberg 2010; Ossenkoppele 2012a) to be at high risk of bias because the threshold used was not pre-specified and the optimal cut-off level was determined from ROC analyses; therefore, the accuracy of the ${ }^{11} \mathrm{C}$-PIB biomarker that was reported in these studies appeared to be overestimated. We considered the remaining one study (Ossenkoppele 2012) to be at unclear risk of bias due to poor reporting.

In the reference standard domain, we considered five studies (55\%) to be at unclear risk of bias because it was not reported whether the clinicians conducting follow-up were aware of the initial ${ }^{11} \mathrm{C}$ PIB biomarker analysis results. We were not able to obtain the information about how the reference standard was obtained and by whom due to poor reporting. We considered three studies to be at high risk of bias (Wolk 2009; Ossenkoppele 2012; Ossenkoppele 2012a) and one study (Grimmer 2013) to be at low risk of bias.

In the flow and timing domain, we judged eight studies (89\%) to be of low concern for risk of bias because all patients were accounted for in the analysis or the reasons for missing data were given, and the time interval between the index test and reference standard was appropriate (duration of follow-up was longer than one year). Shorter durations of follow-up may yield low conversion rates and this might have an effect on the diagnostic accuracy of the index test; therefore, these scores might be overstated and should be interpreted with caution. We considered one remaining study (Ossenkoppele 2012a) to be at high risk of bias because a large number of patients were excluded from the analyses.

For assessment of applicability, there was no concern that the included patients and setting, the conduct and interpretation of the index test, and the target condition (as defined by the reference standard) in each of the included studies did not match the review question.

It should be noted that the lack of concern about the applicability of the three domains mentioned above was based on the inclusion criteria that were set for the review. Considering the level of heterogeneity with respect to the nature of the index test (Table 2; Table 3), it appeared that the judgement about applicability may be overstated.

\section{Findings}

The key characteristics of each study are summarised in Table 1 and Table 2. The summary of main results for nine included studies is presented in the Summary of findings 1 .

\section{C-PIB-PET for Alzheimer's disease dementia (ADD)}

Individual study estimates of sensitivity and specificity, and the threshold used to define test positivity, are shown in Figure 4 for each of the nine studies (112 cases and 162 non-cases) that evaluated ADD. The sensitivities were between $83 \%$ and $100 \%$ while the specificities were between $46 \%$ and $88 \%$. The criteria for ${ }^{11}$ C-PIB positivity varied between studies: five studies used a quantitative threshold while the remaining four studies used visual inspection. The nine studies used different measures of ${ }^{11} \mathrm{C}$-PIB amyloid retention (ROI to cerebellar ratio, average neocortical to cerebellar ratio, posterior cingulate to cerebellar ratio, or visual inspection of parametric nondisplaceable binding potential (BP $\mathrm{ND}_{\text {) }}$ images or SUVR images). The mode of image analysis also varied between studies. 
Figure 4. Forest plot of ${ }^{11}$ C-PIB-PET AD dementia.

\begin{tabular}{|c|c|c|c|c|c|c|c|c|c|c|}
\hline Study & TP & FP & FN & TN & Threshold type & Threshold pre-specified & Sensitivity (95\% Cl) & Specificity (95\% Cl) & Sensitivity (95\% Cl) & Specificity (95\% Cl) \\
\hline Forsberg 2010 & 7 & 4 & 0 & 10 & quantitative & No & $1.00[0.59,1.00]$ & $0.71[0.42,0.92]$ & & \\
\hline Grimmer 2013 & 9 & 8 & 0 & 11 & quantitative & Yes & $1.00[0.66,1.00]$ & $0.58[0.33,0.80]$ & & \\
\hline Jack 2010 & 15 & 19 & 3 & 16 & quantitative & Yes & $0.83[0.59,0.96]$ & $0.46[0.29,0.63]$ & & \\
\hline Koivunen 2011 & 16 & 5 & 1 & 7 & quantitative & Yes & $0.94[0.71,1.00]$ & $0.58[0.28,0.85]$ & & \\
\hline Villemagne 2011 & 30 & 15 & 1 & 19 & quantitative & Yes & $0.97[0.83,1.00]$ & $0.56[0.38,0.73]$ & & \\
\hline Okello 2009 & 14 & 3 & 1 & 13 & visual inspection & Yes & $0.93[0.68,1.00]$ & $0.81[0.54,0.96]$ & — & \\
\hline Ossenkoppele 2012 & 4 & 1 & 0 & 7 & visual inspection & Not reported & $1.00[0.40,1.00]$ & $0.88[0.47,1.00]$ & & \\
\hline Ossenkoppele 2012a & 6 & 1 & 0 & 5 & visual inspection & Yes & $1.00[0.54,1.00]$ & $0.83[0.36,1.00]$ & & $=$ \\
\hline Wolk 2009 & 5 & 8 & 0 & 10 & visual inspection & Yes & $1.00[0.48,1.00]$ & $0.56[0.31,0.78]$ & & \\
\hline
\end{tabular}

The summary ROC curve summarising the accuracy of PIB-PET across the nine studies is shown in Figure 5. Because of the variation in thresholds and measures of ${ }^{11} \mathrm{C}$-PIB amyloid retention, we did not estimate summary sensitivity and specificity. However, we derived estimates of sensitivity and likelihood ratios at fixed values of specificity (see Table 4) from the model we fitted to produce a summary ROC curve. At the median specificity of $58 \%$, the estimated sensitivity was $96 \%(95 \% \mathrm{Cl} 87$ to 99$)$, the positive likelihood ratio was 2.29 (95\% $\mathrm{Cl} 2.17$ to 2.41$)$, and the negative likelihood ratio was 0.07 ( $95 \% \mathrm{Cl} 0.02$ to 0.24$)$.

${ }^{11} \mathrm{C}$-PIB-PET for the early diagnosis of Alzheimer's disease dementia and other dementias in people with mild cognitive impairment (MCI) 
Figure 5. Summary ROC plot of ${ }^{11}$ C-PIB-PET AD dementia.

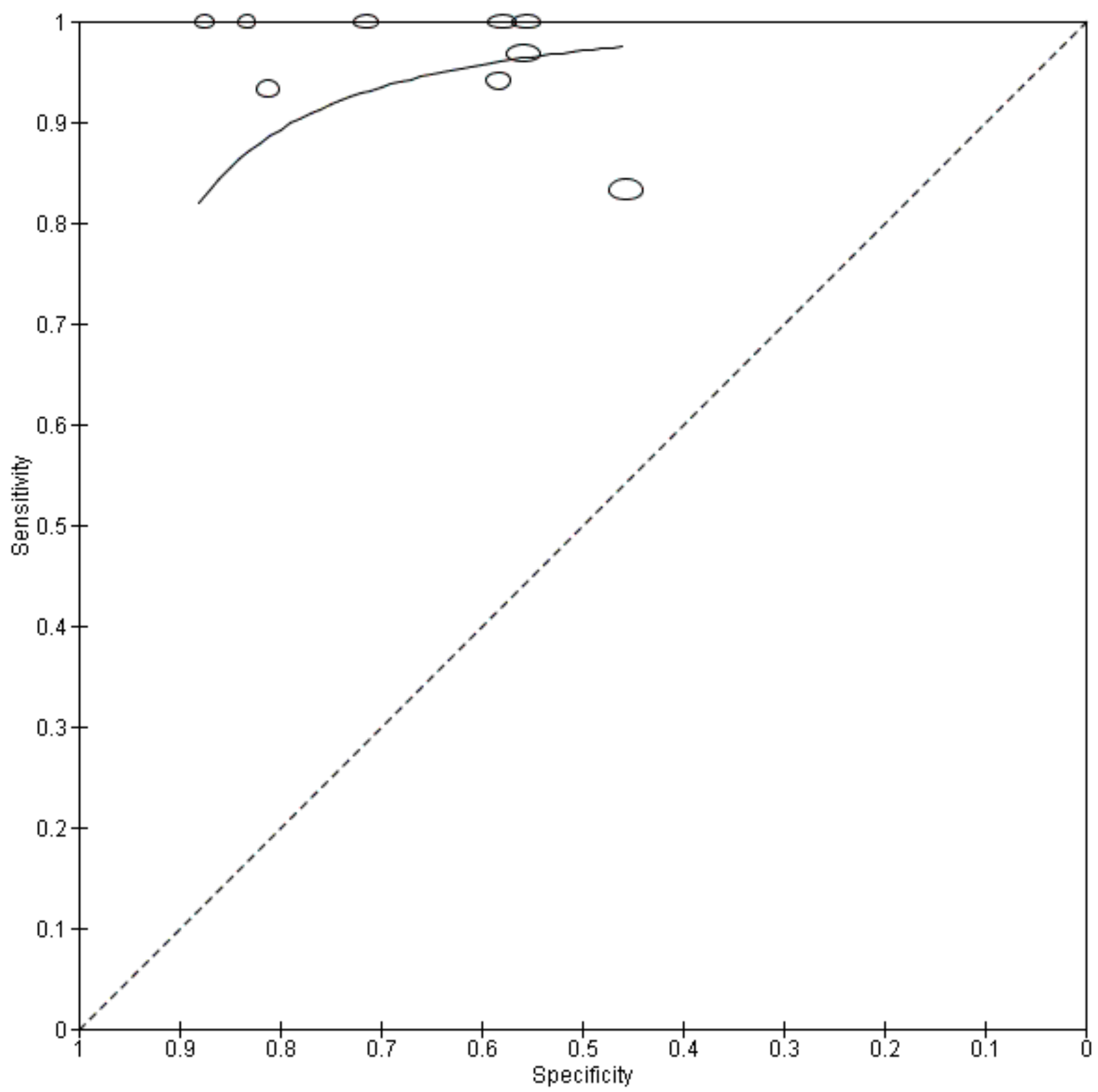

${ }^{11}$ C-PIB-PET for all types of dementia (combined Alzheimer's disease and non-ADD)

Four studies (59 cases and 58 non-cases) evaluated the accuracy of PIB-PET for all types of dementia (Figure 6) in addition to evaluating ADDa. The sensitivities were between $75 \%$ and $86 \%$ while the specificities were between $50 \%$ and $86 \%$. Two studies used a quantitative threshold while the other two used visual inspection to determine test positivity. Meta-analysis was not performed because the studies were few and small, and there was considerable heterogeneity. Figure 7 shows study specific estimates of sensitivity and specificity in the ROC space together with their $95 \% \mathrm{Cls}$.

${ }^{11}$ C-PIB-PET for the early diagnosis of Alzheimer's disease dementia and other dementias in people with mild cognitive impairment (MCI) 
Figure 6. Forest plot of ${ }^{11}$ C-PIB-PET All dementia.

\begin{tabular}{|c|c|c|c|c|c|c|c|c|c|}
\hline Study & TP & FP & FN & TN & Threshold type & Sensitivity (95\% Cl) & Specificity (95\% Cl) & Sensitivity (95\% Cl) & Specificity (95\% Cl) \\
\hline Grimmer 2013 & 9 & 8 & 3 & 8 & quantitative & $0.75[0.43,0.95]$ & $0.50[0.25,0.75]$ & & \\
\hline Villemagne 2011 & 30 & 15 & 5 & 15 & quantitative & $0.86[0.70,0.95]$ & $0.50[0.31,0.69]$ & & \\
\hline Ossenkoppele 2012 & 4 & 1 & 1 & 6 & visual inspection & $0.80[0.28,0.99]$ & $0.86[0.42,1.00]$ & & \\
\hline Ossenkoppele 2012a & 6 & 1 & 1 & 4 & visual inspection & $0.86[0.42,1.00]$ & $0.80[0.28,0.99]$ & & \\
\hline
\end{tabular}

Figure 7. Summary ROC Plot of 11C-PIB-PET All dementia. Each point represents a pair of sensitivity and specificity for each study, and the cross hairs correspond to their $95 \% \mathrm{Cls}$.

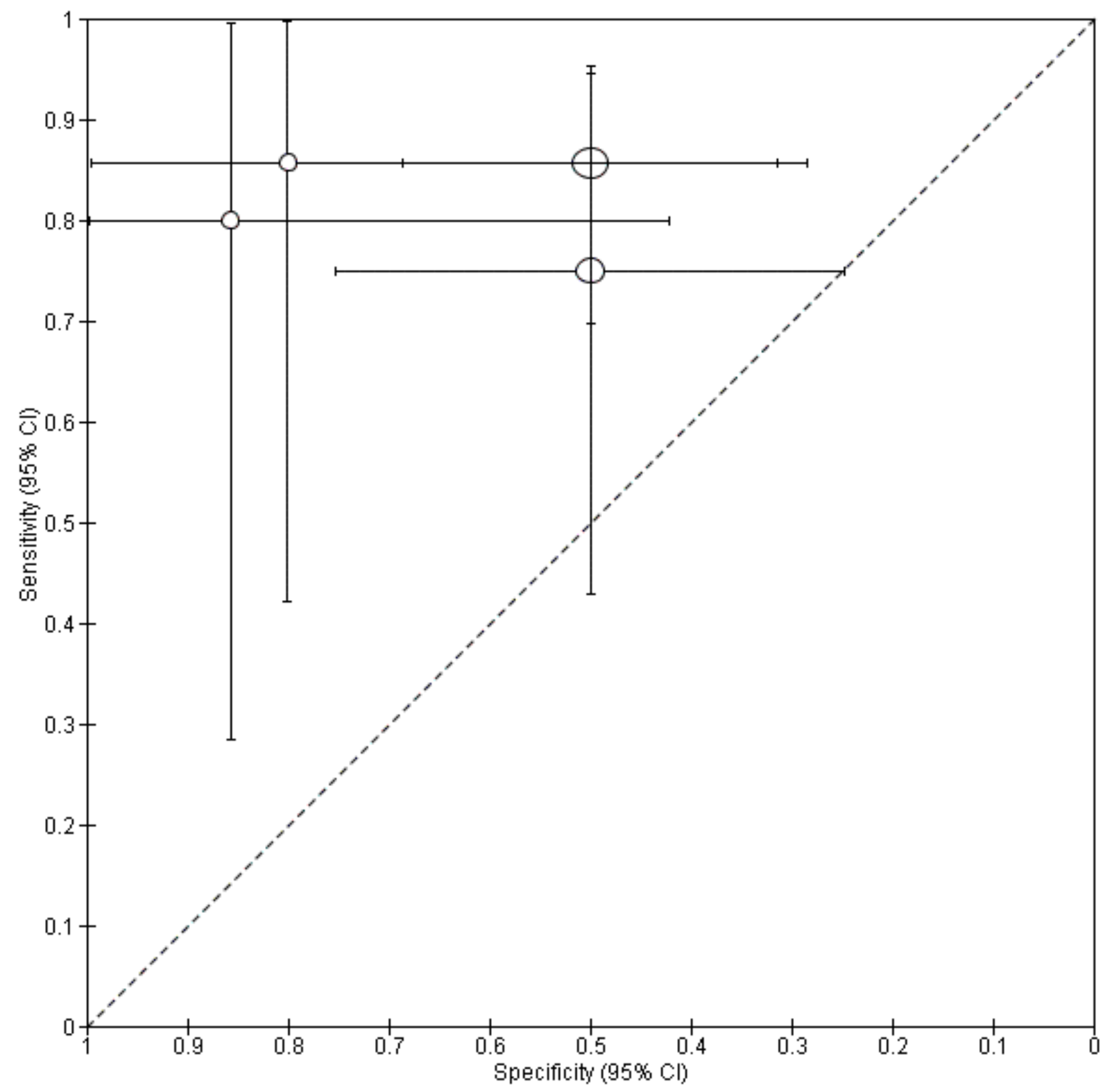

${ }^{11} \mathrm{C}$-PIB-PET for the early diagnosis of Alzheimer's disease dementia and other dementias in people with mild cognitive impairment (MCI) 


\section{Investigation of heterogeneity}

The planned investigations were not possible due to the limited number of studies available for each analysis. For type of reference standard, seven of the nine studies used NINCDSADRDA. Therefore, we conducted sensitivity analyses restricting the analysis to only studies that used NINCDS-ADRDA as the reference standard.

\section{Sensitivity analyses}

Due to the limited number of studies evaluating ${ }^{11}$ C-PIB-PET for all dementia, we performed sensitivity analyses only for studies of ADD.

\section{Type of reference standard}

Of the nine studies that evaluated ${ }^{11}$ C-PIB-PET for ADD, seven used NINCDS-ADRDA as the reference standard. To explore the impact of type of reference standard on the summary estimates, we excluded one study (Koivunen 2011) that used NINCDS-ADRDA and DSM IV as the reference standard and another study (Ossenkoppele 2012a) where the reference standard used was unclear. There was no impact on our findings (Table 4).

\section{Threshold pre-specified}

Seven studies pre-specified thresholds for test positivity. The two studies that did not pre-specify the threshold (Forsberg 2010) or did not report whether or not thresholds were pre-specified (Ossenkoppele 2012) were excluded in this analysis. There was no impact on our findings (Table 4).

\section{DISCUSSION}

\section{Summary of main results}

The volume and quality of evidence on the diagnostic accuracy of ${ }^{11}$ C-PIB-PET for early diagnosis of ADD and other dementias in patients with $\mathrm{MCl}$ was limited. The results are summarised in Summary of findings 1 . Due to variations in thresholds and the measurement of ${ }^{11} \mathrm{C}$-PIB amyloid retention, we estimated a summary ROC curve for studies that evaluated conversion from $\mathrm{MCl}$ to $\mathrm{AD}$ dementia; we did not estimate a summary sensitivity and specificity on the curve because with mixed thresholds a summary point lacks a clnically meaningful interpretation. At the median specificity of $58 \%$ the estimated sensitivity of ${ }^{11}$ C-PIB-PET for identifying patients with $\mathrm{MCl}$ that will convert to $A D$, derived from the summary ROC curve, was $96 \%$ (95\% Cl $87 \%$ to $99 \%$ ).

Data were not pooled for the four studies that evaluated conversion from $\mathrm{MCl}$ to all types of dementia; the sensitivities were between $75 \%$ and $86 \%$, and the specificities were between $50 \%$ and $86 \%$.

\section{C-PIB-PET for Alzheimer's disease dementia (ADD)}

PIB had high sensitivity for predicting conversion to Alzheimer's disease but poor specificity. In other words, the high false positive rate suggested that amyloid imaging was not only an imaging biomarker for Alzheimer's disease but perhaps also for other neurodegenerative diseases and 'asymptomatic' neurological disease, even in healthy people (Chen 2014). It has been demonstrated that PIB binds to amyloid in vessel walls (Bacskai 2007; Johnson 2007), in particular to cerebral amyloid

${ }^{11} \mathrm{C}$-PIB-PET for the early diagnosis of Alzheimer's disease dementia and other dementias in people with mild cognitive impairment (MCI) angiopathy. Therefore, vascular Abeta could be another major contributor to the in vivo PIB signal.

A recent study (Ducharme 2013) reported that a patient met clinical criteria for probable Alzheimer's DD but had a higher than expected burden of white matter disease on magnetic resonance imaging (MRI). A ${ }^{11} \mathrm{C}$-PIB-PET scan was highly positive in typical Alzheimer's disease distribution. Six months after the assessment the patient died of an intracerebral haemorrhage and an autopsy revealed cerebral amyloid angiopathy (CAA) in the complete absence of amyloid plaques or neurofibrillary tangles (NFT). So it is suggested that an uncertain percentage of cognitively normal individuals or with clinical $\mathrm{MCl}$ who have positive amyloid PET imaging (Sperling 2011) in fact could have CAA rather than AD. On the other hand, we did not estimate a summary specificity and so far there is no large-scale ${ }^{11} \mathrm{C}$-PIB-PET study with $\mathrm{MCl}$ pathology, therefore it is unknown whether there are 'false positives' that may in fact be vascular $\mathrm{MCl}$ due to CAA in some of the included studies. We would also speculate that the final pathological diagnosis of some patients with clinical probable AD may be vascular dementia secondary to CAA.

${ }^{11}$ C-PIB-PET may not be able to detect more soluble species of Abeta-42 or other atypical amyloid deposits (Leinonen 2008) thus producing false negative results. This is rare, however, and it is more likely that these patients present with an AD-like phenotype that originates from non-amyloidogenic neuropathology. Indeed, multiple contradictory PIB binding results in humans have been reported and a study demonstrating that PIB brain accumulation may be at least in part mediated by PIB sulfation via estrogen sulfotransferase (Cole 2010) has cast doubts on the purported human amyloid specificity of PIB. This phenomenon emphasizes the potential that there might be types of Abeta deposits that PIB does not detect (Shin 2011). Another study (Shin 2010) demonstrated that NFTs, rather than amyloid plaques, were predominantly accumulated in the hippocampal formation in some patients with ADD. PIB can only be bound to senile plaques specifically, but not tangles, sp we can speculate that NFTs might be more pronounced or have happened earlier than amyloid plaques in some PIB negative $\mathrm{MCl}$ converters. The notion about NFT pathology has been further strengthened by some neuropathologic studies with autopsy data from ADD. The data from cohort research (Serrano-Pozo 2013) indicated that plaques and tangles independently contribute to cognitive impairment in $A D$ pathology without any other primary neuropathologic diagnosis. Furthermore, NFT formation must be either unrelated to amyloid plaques formation or a temporally distinct process, or both. (Royall 2014).

Another hypothesis that can explain false negative results is that those with probable ADD may have multiple brain pathologies, most commonly $A D$ with macroscopic infarcts, followed by $A D$ with neocortical Lewy body disease. Similar to $A D$, the pathology underlying $\mathrm{MCl}$ is heterogeneous (Schneider 2007; Schneider 2009). Until now, it is unknown whether the complicated and mixed pathology can have an effect on imaging and diagnosis with ${ }^{11} \mathrm{C}$ PIB-PET, but we speculate that mixed neuropathology of probable Alzheimer's disease and $\mathrm{MCl}$ may play a role in PIB negative $\mathrm{MCl}$ converters.

Duration of follow-up is also important in predicting conversion to ADD. Although the mean, median, or maximum follow-up period of 
the included studies was more than one year, the variability in the duration of follow-up was considerable. The reported conversion rate of $\mathrm{MCl}$ to $\mathrm{AD}$ is between $8 \%$ and $16 \%$ per year (Mitchell 2009), and the cumulative conversion rate ranged from $22 \%$ to $69 \%$, but unfortunately we were not able to calculate conversion rate per year of each of the included studies because of insufficient data. Conversion rates of $\mathrm{MCl}$ could have influenced the test results in our review. We took it for granted that given a long follow-up period, a high percentage of patients with baseline $\mathrm{MCl}$ would progress to Alzheimer's disease thus affecting the predictive accuracy of ${ }^{11} \mathrm{C}$ PIB-PET. However, there was not a positive correlation between follow-up time and percentage of conversions. For example, the cumulative conversion rate of $\mathrm{MCl}$ in Villemagne 2011 was $68.9 \%$, which was the highest among these included studies, but the maximum follow-up period did not exceed two years in this study. The range of follow-up in Ossenkoppele 2012 was from two to four years, whereas the corresponding cumulative conversion rate did not exceed $34 \%$ (Table 2). The differences are significant among these studies. As a consequence, we were not able to investigate the effect of duration of follow-up on the conversion rate due to a high level of heterogeneity and the small number of included studies.

The length of follow-up duration also may have a direct effect on diagnostic accuracy for progression of $\mathrm{MCl}$ to dementia. So far the results of the longest follow-up study with two times for ${ }^{11} \mathrm{C}$ PIB-PET scans (two and five years), conducted by Kemppainen (Kemppainen 2014) and only including $10 \mathrm{MCl}$ participants, were consistent with a $100 \%$ specificity of a positive ${ }^{11 C}$-PIB-PET scan for predicting five year $\mathrm{MCl}$ to Alzheimer's disease conversion. This differs from our review, which reports $46 \%$ to $88 \%$ specificity of PIB PET for predicting one to four 4 year conversion. Furthermore, the estimated $75 \%$ sensitivity of baseline ${ }^{11}$ C-PIB PET scans for predicting $\mathrm{MCl}$ to Alzheimer's disease conversion in Kemppainen 2014 is in turn lower than the reported $83 \%$ to $100 \%$ sensitivity in our review. The inconsistent estimates might be explained by the longer duration of the follow-up period. Additionally, only one $\mathrm{MCl}$ participant was diagnosed with Alzheimer's disease at the time of the two year scan, while the others converted between the two year and five year scans. The interval between the two scans and inconsistent accuracy thus reflect the fact that a complete understanding of the role of ${ }^{11} \mathrm{C}$-PIB-PET in the prediction of decline in $\mathrm{MCl}$ will not only require both short and long-term periods of observation but will also need to clarify inter-individual variation in the cerebral amyloid load in $\mathrm{MCl}$, and in the course of amyloid accumulation in relation to the clinical diagnosis of disorders associated with cognitive impairment.

Some demographic and $\mathrm{MCl}$ characteristics may be other underlying factors that can increase the conversion rate. More and more attention has been paid to the relationship between $\mathrm{MCl}$ subtypes and conversion to dementia. The largest ever longitudinal study, with results from the follow-up of $550 \mathrm{MCl}$ patients, indicated that the $\mathrm{MCl}$ subtype, presence of storage memory impairment, multiple domain condition, and presence of APOE $\epsilon 4$ allele increased the risk of conversion to dementia. Multivariate survival and Kaplan-Meier analyses showed that amnestic $\mathrm{MCl}$ with storage memory impairment had the most and closest risk of conversion to dementia (Espinosa 2013). In our review the only longitudinal study with $\mathrm{MCl}$ subtypes (Wolk 2009) found that both amnestic $\mathrm{MCl}$ and non-amnestic $\mathrm{MCl}$ subtype were associated with a significant proportion of amyloid positive scans and, in particular, there were no obvious differences in the distribution of PIB retention between the two groups (Wolk 2009). None of the included studies had analysed the underlying correlation or relationship between ${ }^{11} \mathrm{C}$ PIB-PET imaging with conversion rate and clinical classification of $\mathrm{MCl}$. In addition, some 'high risk factors' such as positive family history of dementia, presence of Abeta and tau protein in cerebrospinal fluid, and the APOE $\epsilon 4$ allele may also contribute to a faster conversion rate to dementia. Although some studies had reported the status of 'risk factors' of $\mathrm{MCl}$ at baseline, these were not fully described to include in the meta-regression. In conclusion, further updated reviews that include high quality research and can provide more detailed data about the characteristics of $\mathrm{MCl}$ are required to not only explore the underlying mechanisms but also to elucidate the causal pathways that link PIB positivity of diverse $\mathrm{MCl}$ subtypes and disease progression.

\section{C-PIB-PET for any other forms of dementia (non-Alzheimer's disease dementia (non-ADD))}

We were not able to evaluate the accuracy of the index test for conversion from $\mathrm{MCl}$ to non-ADD. Only four included studies (Villemagne 2011; Ossenkoppele 2012; Ossenkoppele 2012a; Grimmer 2013) reported a small number (nine) of converters to non-ADD. As a result of the information available from these four studies, we evaluated the target condition ${ }^{11} \mathrm{C}$-PIB-PET for all types of dementia (combined Alzheimer's disease and non-ADD) (Figure 6; Figure 7).

${ }^{11}$ C-PIB-PET positive scans are regularly observed in patients with non-ADD and patients with $\mathrm{MCl}$ who progress to non-ADD, especially FTD and dementia with Lewy bodies (DLB) (Rabinovici 2011; Albin 2013).

Both DLB and Parkinson's disease dementia (PDD) are characterised at autopsy by the presence of subcortical or cortical Lewy bodies, or both. Patients with DLB frequently have levels of PIB uptake above that of controls and occasionally equivalent to Alzheimer's disease (Rowe 2007). Most studies have found higher amyloid plaques in DLB than in PDD or non-demented Parkinson's disease patients, and in some studies PIB positivity was associated with greater cognitive deficits and more rapid disease progression (Foster 2010). Shimada et al (Shimada 2013) reported that amyloid deposits are associated with AD-like atrophy in patients with DLB and PDD. Patients with DLB have higher levels of amyloid deposits than patients with PD and PDD. There was one autopsy-based study of a patient with DLB with a positive PIB scan due to CAA, but the concurrent pathological evidence of amyloid plaques and NFTs complicated this case (Bacskai 2007), while Lewy bodies themselves contributed little if at all to the overall PIB-PET signal, and $\alpha$-synuclein and A $\beta-42$ increased each other's toxicity (Masliah 2001). Amyloid deposits have been linked to cognitive impairment in DLB (Gomperts 2012) and Parkinson's disease without dementia (Gomperts 2013), which may contribute to the timing of the onset of dementia relative to that of Parkinsonism in DLB.

Frontotemporal lobe degeneration (FTLD) is an umbrella term used for disorders associated with neurodegeneration of the frontal and anterior temporal lobes. Clinical syndromes that are in the FTLD spectrum include the behavioural variant of frontotemporal dementia (bvFTD), semantic dementia (SD), and progressive non-fluent aphasia (PNFA). A study of PIB retention in patients with FTD reported that most patients with FTD displayed no PIB retention and that ${ }^{11} \mathrm{C}$-PIB-PET could potentially aid in differentiating FTD and Alzheimer's disease (Engler 2008). However,

${ }^{11}$ C-PIB-PET for the early diagnosis of Alzheimer's disease dementia and other dementias in people with mild cognitive impairment (MCI) 19 (Review)

Copyright $\odot 2014$ The Cochrane Collaboration. Published by John Wiley \& Sons, Ltd. 
FTD cases have occasionally demonstrated PIB positive scans and it remains unclear whether these cases represent mixed FTLD and Alzheimer's disease, Alzheimer's disease manifesting clinically as FTD, or false-positive cases of FTD (Rabinovici 2007), which may suggest the mimicking of Alzheimer's disease pathology; SD and PNFA are less likely to demonstrate PIB uptake, and it is known from postmortem studies that about $15 \%$ to $20 \%$ of clinical FTD patients actually have Alzheimer's disease (Forman 2006). Four out of nine included studies (Villemagne 2011; Ossenkoppele 2012; Ossenkoppele 2012a; Grimmer 2013) reported that five $\mathrm{MCl}$ participants converted to FTD during the course of the study. All five ${ }^{11} \mathrm{C}$-PIB-PET scans of those with $\mathrm{MCl}$ were negative suggesting the test is insufficient to evaluate the early diagnostic value for progression from $\mathrm{MCl}$ to FTD.

Data for all types of dementia are limited in this systematic review. Although high PIB retention is common in $\mathrm{MCl}$ and is a powerful predictor of subsequent conversion to Alzheimer's disease, the current available data suggest that PIB may play a similar role in all dementia; at baseline, imaging Abeta may seem bland but deleterious effects emerge as patients with $\mathrm{MCl}$ decline cognitively over time to dementia.

\section{Strengths and weaknesses of the review}

Our review was planned and conducted following the criteria and methods set out in our published protocol. Our searches were comprehensive and sensitive. We used major electronic databases and wide search terms, and also checked the reference lists of systematic review databases for additional studies. Our searches were not limited by language. We contacted study authors and usable data were obtained for three studies (Jack 2010; Ossenkoppele 2012; Ossenkoppele 2012a). Our methodological quality assessment and data syntheses were based on recommended methods. To increase the reliability of our findings, we included only studies that fulfilled delayed verification of conversion to dementia.

Our review has some limitations. The clinical diagnosis of ADD or other forms of dementia is imperfect, therefore the findings from studies with postmortem confirmation of the diagnosis are more convincing than those from studies with clinical diagnosis in the evaluation of the accuracy of PET imaging in the early detection of the dementia process in $\mathrm{MCl}$.

Considerable attention should be paid to risk stratification of $\mathrm{MCl}$ participants (Holland 2012). The stratification of biomarker and risk factors could enable potentially informative $\mathrm{MCl}$ subgroup analyses to emerge, which is helpful for ${ }^{11} \mathrm{C}$-PIB-PET to detect the progression in $\mathrm{MCl}$. Besides amyloid positive imaging, several predisposing factors have been recognized such as FDG-PET hypometabolism, cognitive task-associated changes in functional $\mathrm{MRI}$, abnormality in structural MRI, presence of APOE $\epsilon 4$ allele, $\mathrm{MCl}$ subtypes, age and abnormal cerebrospinal fluid findings that conferred increased risk for progression to dementia in $\mathrm{MCl}$ participants. Most included studies provided some raw data on $\mathrm{MCl}$ at baseline, nevertheless there are still not enough details reported by included studies for stratifying $\mathrm{MCl}$ individuals based on risk factors. For instance, only one study (Wolk 2009) performed the $\mathrm{MCl}$ subtypes analysis. A clear classification and stratification of $\mathrm{MCl}$ may reduce a potential bias in the procedure of patient sampling (Hampel 2012). As a result of poorly standardized $\mathrm{MCl}$, we suggest that international collaboration should introduce a standardization grading scale or system, with or without ${ }^{11}$ C-PIB-PET, to more accurately reflect the conversion risk for 'various types' of $\mathrm{MCl}$.

\section{Applicability of findings to the review question}

There was no applicability concern that the included patients and setting, the conduct and interpretation of the index test, and the target condition (as defined by the reference standard) in each of the included studies did not match the review question: Could the ${ }^{11} \mathrm{C}$-PIB biomarker identify those $\mathrm{MCI}$ participants with Alzheimer's disease pathology at baseline who would convert clinically to dementia at follow up? However, due to the limited number of included studies and levels of heterogeneity with respect to the three domains mentioned above, it was difficult to determine to what extent the findings from this meta-analysis could be applied to clinical practice.

The diagnostic utility of ${ }^{11}$ C-PIB-PET scans for identifying Alzheimer's disease pathology and identifying those patients with $\mathrm{MCl}$ who would convert to ADD could be affected by a number of factors that have not been determined so far. First, PIB binds to both plaques and cerebral amyloid angiopathy, and the relative contribution of each to the in vivo signal is unknown. Second, it is not yet clear whether the ${ }^{11} \mathrm{C}$-PIB-PET scan should be interpreted as a dichotomous test (that is positive versus negative) or whether the degree and spatial distribution of binding offer additional diagnostic information. Third, it has not yet been established whether the ${ }^{11} \mathrm{C}$-PIB threshold should be adjusted based on demographic factors such as age, education, or genetic variables such as the ApoE $\epsilon 4$ genotype, although the relationship between amyloid and dementia is significantly weaker in older versus younger individuals.

The ${ }^{11 C} \mathrm{C}$-PIB-PET biomarker is a high cost investigation, therefore it is important to clearly demonstrate its accuracy prior to recommending its adoption in clinical practice.

\section{AUTHORS' CONCLUSIONS}

\section{Implications for practice}

At present, a ${ }^{11}$ C-PIB-PET scan is not indicated in patients with $\mathrm{MCl}$ except in clinical trials and research studies (Albert 2011). However, the Amyloid Imaging Task Force, the Society of Nuclear Medicine and Molecular Imaging, and the Alzheimer's Association have proposed the usage of amyloid PET in patients with persistent or progressive unexplained $\mathrm{MCl}$ (Johnson 2013). The diagnostic accuracy of a ${ }^{11}$ C-PIB-PET scan as determined in this review suggests that the diagnostic modality has been expected to be a potentially valuable technique for prediction of progression in people with $\mathrm{MCl}$ and the detection method used in clinical practice in the near future.

However, given the heterogeneity in the conduct and interpretation of the test, the lack of defined thresholds for determination of test positivity and the inconsistency of length of follow-up, we cannot recommend the routine use of ${ }^{11} \mathrm{C}-\mathrm{PIB}-\mathrm{PET}$ in clinical practice. The ${ }^{11} \mathrm{C}-\mathrm{PIB}-\mathrm{PET}$ biomarker is a high cost investigation, therefore it is important to clearly demonstrate its accuracy and to standardize the process for the ${ }^{11} \mathrm{C}$-PIB diagnostic modality prior to it being widely used.

${ }^{11}$ C-PIB-PET for the early diagnosis of Alzheimer's disease dementia and other dementias in people with mild cognitive impairment (MCI) 


\section{Implications for research}

Although the National Institute on Aging and the Alzheimer's Association workgroup had recommended that the diagnostic criteria for $\mathrm{MCl}$ due to Alzheimer's disease in research settings and clinical trials should incorporate the use of biomarkers based on imaging, such as ${ }^{11}$ C-PIB-PET (Albert 2011), there is a lack of a generally accepted standardization process and diagnostic criteria for ${ }^{11} \mathrm{C}$-PIB-PET for detecting the amyloid image in participants with $\mathrm{MCl}$. We recommend better standardization of image analysis, the threshold, and other ${ }^{11} \mathrm{C}$-PIB-PET parameters in research studies. Moreover, the procedure for acquisition and analysis of the sample need to be established to implement ${ }^{11} \mathrm{C}$-PIB-PET criteria on a broad scale. Although we consider biomarkers as 'negative' or 'positive' for the purposes of classification, it is recognized that varying severities of an abnormality may confer different likelihoods or prognoses, which is currently difficult to quantify accurately for broad application in research.

Since neurodegenerative diseases are complex disorders with occasionally multiple and overlapping pathophysiological processes, multitracer imaging may be helpful in combining metabolic, inflammation, or apoptosis markers with those labelling typical protein aggregations seen in the progression of $\mathrm{MCl}$ to Alzheimer's disease. In future, various PET imaging modalities are needed to evaluate the usefulness of the various PET tracers as predictors of conversion to Alzheimer's disease in $\mathrm{MCl}$ studies with clinical follow-up. There is a hypothesis that amyloid deposition is an early event in Alzheimer's disease that reaches a relative plateau even at the $\mathrm{MCl}$ stage, while downstream biomarkers measure neuronal loss and dysfunction, and cognitive measures are more dynamic at the symptomatic disease stage. Based on this hypothesis, the combination of structural imaging, functional imaging, and cognitive tests may be better predictors of when an individual will convert. Some studies (Ossenkoppele 2012a; Zhang 2012; Trzepacz 2014) of clinical relevance have shown that the combination of biomarker modalities, such as PIB-PET, FDGPET, and structural MR, is likely to provide the best additional neuroimaging information over that of single imaging. Some comparative studies (Jack 2008; Trzepacz 2014) suggest that structural MRI combined with ${ }^{11} \mathrm{C}$-PIB-PET produces the highest accuracy for the prediction of conversion from $\mathrm{MCl}$ to Alzheimer's disease and is superior to using either in isolation. Moreover, the combined use of ${ }^{11} \mathrm{C}-\mathrm{PIB}$ and ${ }^{18} \mathrm{~F}-\mathrm{FDG}$ plus PET provided beneficial information for $\mathrm{MCl}$ due to non-ADD (Banzo 2014).

It is worth mentioning the greater consistency in sensitivity as an aspect of the results in our review, suggesting potential value of the test as a rule-out test. This needs to be confirmed in larger studies with standardized PIB-PET techniques. We were not able to fully explore the causes of heterogeneity in specificity, so understanding the variability in specificity (if it persists when PIB-PET has been standardized) should also be an objective of further research. The above implications suggest that well designed studies and standardization through international collaboration are required.

\section{ACK N O WLEDGEMENTS}

Marie Westwood, Kleijnen Systematic Reviews, York, performed QUADAS 2 assessment.

Steven Martin, University of Cambridge, performed QUADAS 2 assessment.

${ }^{11} \mathrm{C}$-PIB-PET for the early diagnosis of Alzheimer's disease dementia and other dementias in people with mild cognitive impairment (MCI) 
R E F E R E N C E S

\section{References to studies included in this review}

Forsberg 2010 \{published data only\}

* Forsberg A, Almkvist O, Engler H, Wall A, Langstrom B, Nordberg A. High PIB retention in Alzheimer's disease in early event with complex relationship with CSF biomarkers and functional parameters. Current Alzheimer Research 2010;7:56-66.

Forsberg A, Engler H, Almkvist O, Blomquist G, Hagman G, Wall $A$, et al. PET imaging of amyloid deposition in patients with mild cognitive impairment. Neurobiology of Aging 2008;29:1456-65.

Forsberg A, Engler H, Blomquist G, Almkvist O, Hagman G, Wall $\mathrm{A}$, et al. PET imaging of amyloid depositions in $\mathrm{MCl}$ patients using PIB. Journal of Cerebral Blood Flow and Metabolism 2007; Vol. 27 Suppl 1:B003-01.

Nordberg A, Carter SF, Rinne J, Drzezga A, Brooks DJ, Vandenberghe R, et al. A European multicentre PET study of fibrillar amyloid in Alzheimer's disease. European Journal of Nuclear Medicine and Molecular Imaging 2013;40(1):104-14.

\section{Grimmer 2013 \{published data only\}}

* GrimmerT, Wutz C, Drzezga A, Forster S, Forstl H, Ortner M, et al. The usefulness of amyloid imaging in predicting the clinical outcome after two years in subjects with mild cognitive impairment. Current Alzheimer Research 2013;10:82-5.

\section{Jack 2010 \{published data only\}}

Beckett 2010. The Alzheimer's Disease Neuroimaging Initiative: Annual change in biomarkers and clinical outcomes. Alzheimer's \& Dementia 2010;3:257-64.

Burns L, Berman R, Guo Z, Soares H, Kaplita S, Yoo B, et al. The relationship between cerebral spinal fluid (CSF) biomarkers and Pittsburgh compound B (PIB) positron emission tomography $(P E T)$ in predicting Alzheimer's disease (AD) [Conference: Alzheimer's Association International Conference, AAIC 11 Paris France. Conference Start: 20110716 Conference End: 20110721. Conference Publication: (var.pagings)]. Alzheimer's \& Dementia 2011; Vol. 7, issue 4 Suppl 1:S206.

Ewers M, Aisen P, Jagust W, Schuff N, Weiner M, Trojanowski J, et al. CSF biomarker and PIB-PET-derived beta-amyloid signature predicts brain metabolism grey matter and cognitive changes in non-demented subjects [Conference: Alzheimer's Association International Conference, AAIC 11 Paris France. Conference Start: 20110716 Conference End: 20110721. Conference Publication: (var.pagings)]. Alzheimer's \& Dementia 2011; Vol. 7, issue 4 Suppl 1:S102.

Ishii K, Sakata M, Oda K, Toyohara J, Ishiwata K, Senda M, et al. Age, ApoE e4, and ethnic effect on [C-11] PIB in multinational ADNI studies: Direct comparison of J-ADNI, US-ADNI and AIBL data [Conference: Alzheimer's Association International Conference, AAIC 11 Paris France. Conference Start: 20110716 Conference End: 20110721. Conference Publication: (var.pagings)]. Alzheimer's \& Dementia 2011; Vol. 7, issue 4 Suppl 1:S233.
Jack 2009. Serial PIB and MRI in normal, mild cognitive impairment and Alzheimer's disease: implications for sequence at pathological events in Alzheimer's disease. Brain 2009;132:1355-65.

* Jack CR, Wiste HJ, Vemuri P, Weigand SD, Sejnem ML, Zeng G at al. Brain beta-amyloid measures and magnetic resonance imaging athrophy both predict time-to-progression from mild cognitive impairment to Alzheimer's disease. Brain 2010;133:3336-48.

Landau S, Petersen R, Aisen P, Jagust W. Change in amyloid deposition is related to concurrent cognitive change in $\mathrm{MCl}$ [Conference: Alzheimer's Association International Conference, AAIC 11 Paris France. Conference Start: 20110716 Conference End: 20110721. Conference Publication: (var.pagings)]. Alzheimer's \& Dementia 2011; Vol. 7, issue 4 Suppl 1:S28.

Mormino EC, Kluth JT, Madison CM, Rabinovici GD, Baker SL, Miller BL, et al. Episodic memory loss is related to hippocampalmediated beta-amyloid deposition in elderly subjects. Brain 2009; Vol. 132, issue 5:1310-23.

Riddle WR, Shokouhi S, Donlevy SC. Monitoring brain changes in mild cognitive impairment and a biomarker for structural changes and correlations with serial PET-FDG scans, PET-PIB scans, and MMSE scores. European Journal of Neurology 2012; Vol. 19 Suppl 1:110.

Toledo JB, Vanderstichele H, Figurski M, Aisen PS, Petersen RC, Weiner MW, et al. Factors affecting A plasma levels and their utility as biomarkers in ADNI. Acta Neuropathologica 2011; Vol. 122 , issue 4:401-13.

Tosun D, Schuff N, Mathis C, A, Jagust W, Weiner M, et al. Spatial patterns of brain amyloid-beta burden and atrophy rate associations in mild cognitive impairment. Brain 2011;134(4):1077-88.

Tosun D, Schuff N, Weiner M. Predicting brain amyloid-b burden with atrophy in $\mathrm{MCl}$ [Conference: Alzheimer's Association International Conference, AAIC 11 Paris France. Conference Start: 20110716 Conference End: 20110721. Conference Publication: (var.pagings)]. Alzheimer's \& Dementia 2011; Vol. 7, issue 4 Suppl 1:S236.

Walhovd K, B, Fjell A, M, Brewer J, McEvoy L, et al. Combining MR imaging, positron-emission tomography, and CSF biomarkers in the diagnosis and prognosis of Alzheimer disease. American Journal of Neuroradiology 2010; Vol. 31, issue 2:347-54.

\section{Koivunen 2011 \{published data only\}}

Koivunen J, Karrasch M, Scheinin NM, Aalto S, Vahlberg T, Nagren K, et al. Cognitive decline and amyloid accumulation in patients with mild cognitive impairment. Dementia and Geriatric Cognitive Disorders 2012; Vol. 34, issue 1:31-7.

Koivunen J, Pirttila T, Kemppainen N, Aalto S, Herukka SK, Jauhianen AM, et al. PET amyloid ligand [11C]PIB uptake and cerebrospinal fluid beta-amyloid in mild cognitive impairment.

${ }^{11} \mathrm{C}$-PIB-PET for the early diagnosis of Alzheimer's disease dementia and other dementias in people with mild cognitive impairment (MCI) 
Dementia and Geriatric Cognitive Disorders 2008; Vol. 26, issue 4:378-83.

* Koivunen J, ScheininN, Virta JR, et al. Amyloid PET imaging in patients with mild cognitive impairment: A 2-year follow-up study. Neurology 2011;76:1085-90.

Nordberg A, Carter SF, Rinne J, Drzezga A, Brooks DJ, Vandenberghe R, et al. A European multicentre PET study of fibrillar amyloid in Alzheimer's disease. European Journal of Nuclear Medicine and Molecular Imaging 2013;40(1):104-14.

\section{Okello 2009 \{published data only\}}

Nordberg A, Carter SF, Rinne J, Drzezga A, Brooks DJ, Vandenberghe R, et al. A European multicentre PET study of fibrillar amyloid in Alzheimer's disease. European Journal of Nuclear Medicine and Molecular Imaging 2013; Vol. 40, issue 1:104-14.

* Okello A, Koivunen J, Edison P, et al. Conversion of amyloid positive and negative $\mathrm{MCl}$ to $\mathrm{AD}$ over 3 years. Neurology 2009;73:754-60.

\section{Ossenkoppele 2012 \{published data only\}}

* Ossenkoppele R, Tolboom N, Foster-Dingley JC, Adriaanse SF, Boellaard R, Yaqub M, et al. Longitudinal imaging of Alzheimer pathology using [11C]PIB, [18F]FDDNP and [18F]FDG PET. European Journal of Nuclear Medicine and Molecular Imaging 2012;9(6):990-1000.

\section{Ossenkoppele 2012a \{published data only\}}

* Ossenkoppele R, Prins ND, Pijnenburg YA, Lemstra AW, van der Flier WM, Adriaanse SF, et al. Impact of molecular imaging on the diagnostic process in a memory clinic. Alzheimer's \& Dementia 2012;9(4):414-21.

\section{Villemagne 2011 \{published data only\}}

Villain N, Chetelat G, Grassiot B, Bourgeat P, Jones G, Ellis KA, et al. Regional dynamics of amyloid-beta deposition in healthy elderly, mild cognitive impairment and Alzheimer's disease: A voxelwise PiB-PET longitudinal study. Brain 2012; Vol. 135, issue 7:2126-39.

* Villemagne VL, Pike KE, Chetelat G, Ellis KA, Mulligan RS, Bourgeat $P$, et al. Longitudinal assessment of $A \beta$ and cognition in a Alzheimer disease. Annals of Neurology 2011;69:181-92.

Wolk 2009 \{published data only\}

* Wolk DA, Price JC, Saxton JA, Snitz BE, James JA, Lopez OL, et al. Amyloid imaging in mild cognitive impairment subtypes. Annals of Neurology 2009;65:557-68.

\section{References to studies excluded from this review}

\section{Choo 2011 \{published data only\}}

Choo H, Lee DY, Seo EH, Kim YK, Yoon EJ, Lee DS, et al. PIB retention changes in cognitively normal, mild cognitive impairment and Alzheimer's disease: One year follow-up study IL [Conference: Alzheimer's Association International Conference, AAIC 11 Paris France. Conference Start: 20110716 Conference End: 20110721. Conference Publication: (var.pagings)]. Alzheimer's \& Dementia 2011; Vol. 7, issue 4 Suppl 1:S208-9.

\section{Driscoll 2011 \{published data only\}}

Driscoll I, Zhou Y, An Y, Sojkova J, Davatzikos C, Kraut MA, et al. Lack of association between 11C-PIB longitudinal brain atrophy in non-demented older individuals. Neurobiology of Aging 2011;32:2123-30.

Ellis 2010 \{published data only\}

Ellis KA, Rowe CC, Villemagne VL, Martins RN, Masters CL, Salvado O, et al. addressing population aging and Al;zheimer's disease through the Australian imaging biomarkers and lifestyle study: collaboration with the Alzheimer's Disease Neuroimaging Initiative. Alzheimer's \& Dementia 2010;6:291-6.

Fagan 2007 \{published data only\}

Fagan AM, Roe CM, Xiong C, Mintun M, et al. Cerebrospinal fluid tau/beta-amyloid $<$ sub $>42</$ sub $>$ ratio as a prediction of cognitive decline in nondemented older adults. Archives of Neurology 2007; Vol. 64, issue 3:343-9.

\section{Kadir 2012 \{published data only\}}

Kadir A, Alkmvist O, Forsberg A, Wall A, Engler H, Langstrom B at al. Dynamic changes in PET amyloid and FDG imaging at diffetrent stages of Alzheimer's disease. Neurobiology of Aging 2012;33:198.e1-198.e14.

\section{Kadir 2012a \{published data only\}}

Kadir A, Almkvist O, Forsberg A, Wall A, Engler H, Langstrom B, et al. Dynamic changes in PET amyloid and FDG imaging at different stages of Alzheimer's disease. Neurobiology of Aging 2012; Vol. 33, issue 1:198.e1-14.

\section{Resnick 2010 \{published data only\}}

Resnick SM, Sojkova J, Zhou J, An Y, Ye W, Holt DP, et al. Longitudinal cognitive decline is associated with fibrillar amyloid-beta measured by 11C-PIB. Neurology 2010;74(10):807-15.

\section{Rowe 2010 \{published data only\}}

Rowe CC, Ellis KA, Rimajova M, Bourgeat P, Pike KE, Jones G, et al. Amyloid imaging results from the Australian Imaging Biomarkers and Lifestyle (AIBL) study of aging. Neurobiology of Aging 2010;31:1275-83.

\section{Shinotoh 2011 \{published data only\}}

Shinotoh H, Shimada H, Hirano S, Tanaka N, Sato K, Kiyoshi F, et al. Longitudinal [11C]PIB PET study in healthy elderly persons, patients with mild cognitive impairment, and Alzheimer's disease [Conference: Alzheimer's Association International Conference, AAIC 11 Paris France. Conference Start: 20110716 Conference End: 20110721. Conference Publication: (var.pagings)]. Alzheimer's \& Dementia 2011; Vol. 7, issue 4 Suppl 1:S224.

\section{Sojkova 2008 \{published data only\}}

Sojkova J, Beason-Held L, Zhou Y, An Y, Kraut MA, et al. Longitudinal cerebral blood flow and amyloid deposition: An emerging pattern?. Journal of Nuclear Medicine 2008; Vol. 49, issue 9:1465-71.

${ }^{11} \mathrm{C}-\mathrm{PIB}-\mathrm{PET}$ for the early diagnosis of Alzheimer's disease dementia and other dementias in people with mild cognitive impairment (MCI) 
Sojkova 2011 \{published data only\}

Sojkova J, Zhou Y, An Y, Kraut MA, Ferrucci L, Wong D, et al. Longitudinal patterns of beta-amyloid deposition in nondemented older adults. Archives of Neurology 2011;68(5):644-9.

\section{References to ongoing studies}

DeKosky 2006 \{published data only\}

Dekosky ST, Mathis CA, Price JC, Lopresti BJ, Meltzer CC, Ziolko SK, et al. Human amyloid-imaging studies with Pittsburgh compound-B in mild cognitive impairment $(\mathrm{MCl})$ : Is $\mathrm{MCl}$ the critical period of amyloid plaque deposition?. Neurology 2006; Vol. 66, issue 5:A60.

\section{Additional references}

\section{Albert 2011}

Albert MS, DeKosky ST, Dickson D, Dubois B, Feldman HH, Fox NC, et al. The diagnosis of mild cognitive impairment due to Alzheimer's disease: recommendations from the National Institute on Aging-Alzheimer's Association workgroups on diagnostic guidelines for Alzheimer's disease. Alzheimer's \& Dementia 2011;7(3):270-9. [DOI: 10.1016/j.jalz.2011.03.008]

\section{Albin 2013}

Albin RL, Burke JF, Koeppe RA, Giordani B, Gilman S, Frey KA. Assessing mild cognitive impairment with amyloid and dopamine terminal molecular imaging. Journal of Nuclear Medicine 2013;54(6):887-93.

\section{Bacskai 2007}

Bacskai BJ, Frosch MP, Freeman SH, Raymond SB, Augustinack JC, Johnson KA, et al. Molecular imaging with Pittsburgh compound B confirmed at autopsy: a case report. Archives of Neurology 2007;64(3):431-4.

\section{Banzo 2014}

Banzo I, Jimenez-Bonilla J, Ortega-Nava F, Quirce R, MartinezRodriguez I, de Arcocha-Torres $\mathrm{M}$, et al. Amyloid imaging with (11)C-PIB PET/CT and glucose metabolism with (18)FFDG PET/CT in a study on cognitive impairment in the clinical setting. Nuclear Medicine Communications 2014;35(3):238-44. doi:10.1097/MNM.0000000000000042.

\section{Birks 2006}

Birks J. Cholinesterase inhibitors for Alzheimer's disease. Cochrane Database of Systematic Reviews 2006, Issue 1. [DOI: 10.1002/14651858.CD005593]

\section{Blennow 2014}

Blennow K, Hampel H, Zetterberg H. Biomarkers in amyloid- $\beta$ immunotherapy trials in Alzheimer's disease. Neuropsychopharmacology 2014;39(1):189-201. doi: 10.1038/ npp.2013.154. Epub 2013 Jun 25.PMID: 23799530.

\section{Bossuyt 2008}

Bossuyt PM, Leeflang MM. Chapter 6: Developing criteria for including studies. Cochrane Handbook for Systematic Reviews of Diagnostic Test Accuracy Version 0.42008.

\section{Boxer 2005}

Boxer AL, Miller L. Clinical features of frontotemporal dementia. Alzheimer's Disease and Associated Disorders 2005;19 Suppl 1:S3-6.

\section{Brun 1994}

Brun A, Englund B, Gustafson L, et al. Clinical and neuropathological criteria for frontotemporal dementia. The Land and Manchester Group. Journal of Neurology, Neurosurgery, and Psychiatry 1994;57:416-8.

\section{Bruscoli 2004}

Bruscoli M, Lovestone S. Is MCI really just early dementia? A systematic review of conversion studies. International Psychogeriatrics 2004;16:129-40.

\section{Chen 2014}

Chen X, Li M, Wang S, Zhu H, Xiong Y, Liu X. Pittsburgh compound $B$ retention and progression of cognitive status - $a$ meta-analysis. European Journal of Neurology 2014:doi:10.1111/ ene.12398.

\section{Cole 2010}

Cole GB. Keum G, Liu J, Small GW, Satyamurthy N, Kepe V, Barrio JR. Specific estrogen sulfotransferase (SULT1E1) substrates and molecular imaging probe candidates. Proceedings of the National Academy of Sciences of the United States of America 2010;107(14):6222-7.

\section{Dickson 1992}

Dickson DW, Crystal HA, Mattiace LA, Masur DM, Blau AD, Davies $P$, et al. Identification of normal and pathological aging in prospectively studied nondemented elderly humans. Neurobiology of Aging 1992;13(1):179-89.

\section{Drzezga 2008}

Drzezga A. Basic pathologies of neurodegenerative dementias and their relevance for state-of-the-art molecular imaging studies. European Journal of Nuclear Medicine and Molecular Imaging 2008;35:S4-11.

\section{DSMIII 1987}

American Psychiatric Association. Diagnostic and Statistical Manual of Mental Disorders. 3rd revised edition. Washington, DC: American Psychiatric Association 1987.

\section{DSMIV 1994}

American Psychiatric Association. Diagnostic and Statistical Manual of Mental Disorders. 4th edition. Washington, DC: American Psychiatric Association 1994.

\section{Dubois 2010}

Dubois B, Feldman HH, Jacova C, Cummings JL, Dekosky ST, Barberger-Gateau P, et al. Revising the definition of Alzheimer's disease: a new lexicon. Lancet Neurology 2010;9(11):1118-27.

\section{Ducharme 2013}

Ducharme S, Guiot MC, Nikelski J, Chertkow H. Does a positive Pittsburgh compound B scan in a patient with dementia equal Alzheimer disease?. JAMA Neurology 2013;70(7):912-4.

${ }^{11} \mathrm{C}$-PIB-PET for the early diagnosis of Alzheimer's disease dementia and other dementias in people with mild cognitive impairment (MCI) 


\section{Ellis 2011}

Ellis KA, Rowe C, Masters C, Szoeke C, Taddei K, Martins R, et al. Predictors of cognitive decline at 18 month follow up among 1112 participants in the australian imaging, biomarkers and lifestyle flagship study of ageing (AIBL) [Conference: Alzheimer's Association International Conference, AAIC 11 Paris France. Conference Start: 20110716 Conference End: 20110721. Conference Publication: (var.pagings)]. Alzheimer's \& Dementia 2011; Vol. 7, issue 4 Suppl 1:S158.

\section{Engler 2008}

Engler H, Santillo AF, Wang SX, Lindau M, Savitcheva I, Nordberg A, et al. In vivo amyloid imaging with PET in frontotemporal dementia. European Journal of Nuclear Medicine and Molecular Imaging 2008;35(1):100-6.

\section{Espinosa 2013}

Espinosa A, Alegret M, Valero S, Vinyes-Junque G, Hernandez I, Mauleon A, et al. A longitudinal follow-up of 550 mild cognitive impairment patients: evidence for large conversion to dementia rates and detection of major risk factors involved. Journal of Alzheimer's Disease 2013;34(3):769-80.doi:10.3233/JAD-122002.

\section{Forman 2006}

Forman MS, Farmer J, Johnson JK, Clark CM, Arnold SE, Coslett HB, et al. Frontotemporal dementia: clinicopathological correlations. Annals of Neurology 2006;59(6):952-62. doi:10.1002/ana.20873.

\section{Foster 2010}

Foster ER. Campbell MC, Burack MA, Hartlein J, Flores HP, Cairns NJ, et al. Amyloid imaging of Lewy body-associated disorders. Movement Disorders 2010;25(15):2516-23.

\section{Friedrich 2014}

Friedrich MJ. Researchers test strategies to prevent Alzheimer disease. JAMA 2014;311(16):1596-8. doi:10.1001/ jama.2014.3891.

\section{Geslani 2005}

Geslani DM, Tierney MC, Herrmann N, Szalai JP. Mild cognitive impairment: an operational definition and its conversion rate to Alzheimer's disease. Dementia and Geriatric Cognitive Disorders 2005;19(5-6):383-9.

\section{Gomperts 2012}

Gomperts SN, Locascio JJ, Marquie M, Santarlasci AL, Rentz DM, Maye J, et al. Brain amyloid and cognition in Lewy body diseases. Movement Disorders 2012;27(8):965-73.

\section{Gomperts 2013}

Gomperts SN, Locascio JJ, Rentz D, Santarlasci A, Marquie M, Johnson K.A, et al. Amyloid is linked to cognitive decline in patients with Parkinson disease without dementia. Neurology 2013;801(1):85-91.

\section{Hampel 2012}

Hampe H, Lista S, Khachaturian ZS. Development of biomarkers to chart all Alzheimer's disease stages: the royal road to cutting the therapeutic Gordian knot. Alzheimer's \& Dementia 2012;8(4):312-36. doi:10.1016/j.jalz.2012.05.2116.

\section{Hatashita 2012}

Hatashita S, Yamasaki H. PET biomarkers of beta-amyloid deposition and neuronal injury in mild cognitive impairment due to Alzheimer's disease. European Journal of Nuclear Medicine and Molecular Imaging 2012; Vol. 39:S407.

\section{Holland 2012}

Holland D, McEvoy LK, Desikan RS, Dale AM. Enrichment and stratification for predementia Alzheimer disease clinical trials. PLoS One 2012;7(10):e47739. doi:10.1371/ journal.pone.0047739.

\section{Jack 2008}

Jack CR, Lowe VJ, Senjem ML, Weigand SD, Kemp BJ, Shiung MN, et al. 11CPIB and structural MRI provide complementary information in imaging of Alzheimer's disease and amnestic mild cognitive impairment. Brain 2008;131:665-80.

\section{Johnson 2007}

Johnson KA, Gregas M, Becker JA, Kinnecom C, Moran DH, Smith EK, et al. Imaging of amyloid burden and distribution in cerebral amyloid angiopathy. Annals of Neurology 2007;62:229-34.

\section{Johnson 2013}

Johnson KA, Minoshima S, Bohnen NI, Donohoe KJ, Foste NL, Herscovitch P, et al. Update on appropriate use criteria for amyloid PET imaging: dementia experts, mild cognitive impairment, and education. Amyloid Imaging Task Force of the Alzheimer's Association and Society for Nuclear Medicine and Molecular Imaging. Alzheimer's \& Dementia 2013;9(4):e106-9. doi:10.1016/j.jalz.2013.06.001.

\section{Kemppainen 2014}

Kemppainen NM, Scheinin NM, Koivunen J, Johansson J, Toivonen JT, Nagren K, et al. Five-year follow-up of 11C-PIB uptake in Alzheimer's disease and $\mathrm{MCl}$. European Journal of Nuclear Medicine and Molecular Imaging 2014;41(2):283-9. doi:10.1007/s00259-013-2562-0.

\section{Klunk 2004}

Klunk WE, Engler H, Nordberg A, Wang Y, Blomqvist G, Holt DP, et al. Imaging brain amyloid in Alzheimer's disease with Pittsburgh Compound-B. Ann Neurol 2004;55(3):306-19.

\section{Knotnerus 2002}

Knotnerus A, van Weel C, Muris JWM. Evaluation of diagnostic procedures. BMJ 2002;324:477-80.

\section{Leeflang 2008}

Leeflang MM, Moons KG, Reitsma JB, Zwinderman AH. Bias in sensitivity and specificity caused by data-driven selection of optimal cutoff values: mechanisms, magnitude, and solutions. Clinical Chemistry 2008;54(4):729-37.

\section{Leinonen 2008}

Leinonen V, Alafuzoff I, Aalto S, Suotunen T, Savolainen S, Nagren K, et al. Assessment of beta-amyloid in a frontal cortical brain biopsy specimen and by positron emission tomography

${ }^{11} \mathrm{C}-\mathrm{PIB}-\mathrm{PET}$ for the early diagnosis of Alzheimer's disease dementia and other dementias in people with mild cognitive impairment (MCI) 
with carbon 11-labeled Pittsburgh compound B. Archives of Neurology 2008;65(10):1304-9.

\section{Maruff 2011}

Maruff P, Ellis K, Harrington K, Gale J, Fredrickson A, Darby D, et al. Determining rate of decline in prealzheimer's and Alzheimer's disease AIBL participants using a regular brief cognitive assessment [Conference: Alzheimer's Association International Conference, AAIC 11 Paris France. Conference Start: 20110716 Conference End: 20110721. Conference Publication: (var.pagings)]. Alzheimer's \& Dementia 2011; Vol. 7 , issue 4 Suppl 1:S255.

\section{Masliah 2001}

Masliah E, Rockenstein E, Veinbergs I, Sagara Y, Mallory M, Hashimoto M, et al. Beta-amyloid peptides enhance alphasynuclein accumulation and neuronal deficits in a transgenic mouse model linking Alzheimer's disease and Parkinson's disease. Proceedings of the National Academy of the Sciences of the United States of America 2001;98(21):12245-50.

\section{Matthews 2008}

Matthews FE, Stephan BC, McKeith IG, Bond J, Brayne C, Medical Research Council Cognitive Function and Ageing Study. Two-year progression from mild cognitive impairment to dementia: to what extent do different definitions agree? Journal of the American Geriatrics Society 2008;56(8):1424-33.

\section{Mattsson 2009}

Mattsson N, Zetterberg H, Hansson O, Andreasen N, Parnetti L, Jonsson $\mathrm{M}$, et al. CSF biomarkers and incipient Alzheimer disease in patients with mild cognitive impairment. JAMA 2009;302(4):385-93.

\section{McKeith 1996}

McKeith IG, Galasko D, Kosaka K, Perry EK, Dickson DW, Hansen LA, et al. Consensus guidelines for the clinical and pathologic diagnosis of dementia with Lewy bodies (DLB): report of the Consortium on DLB international workshop. Neurology 1996;47(5):1113-24.

\section{McKeith 2005}

McKeith IG, Dickson DW, Lowe J, Emre M, O'Brien JT, Feldman H, et al. Diagnosis and management of dementia with Lewy bodies: third report of the DLB Consortium. Neurology 2005;65:1863-72.

\section{McKhann 1984}

McKhann GM, Drachman D, Folstein M, Katzman R, Price D, Stadlan EM. Clinical diagnosis of Alzheimer's disease: report of the NINCDS-ADRDA Work Group under the auspices of Department of Health and Human Services Task Force on Alzheimer's Disease. Neurology 1984;34(7):939-44.

\section{McKhann 2011}

McKhann GM, Knopman DS, Chertkow H, Hyman BT, Clifford RJ, Kawas $\mathrm{CH}$, et al. The diagnosis of dementia due to Alzheimer's disease: recommendation from the National Institute on Ageing and Alzheimer's Association workgroup. Alzheimer's \& Dementia 2011; Vol. 7, issue 3:263-9.

\section{McShane 2006}

McShane R, Areosa Sastre A, Minakaran N. Memantine for dementia. Cochrane Database of Systematic Reviews 2006, Issue 2. [DOI: 10.1002/14651858.CD003154.pub5]

\section{Mirra 1991}

Mirra SS, Heyman A, McKeel D, Sumi SM, Crain BJ, Brownlee LM, et al. The Consortium to Establish a Registry for Alzheimer's Disease (CERAD). Part II. Standardization of the neuropathologic assessment of Alzheimer's disease. Neurology 1991;41(4):479-86.

\section{Mitchell 2009}

Mitchell AJ, Shiri-Feshki M. Rate of progression of mild cognitive impairment to dementia--meta-analysis of 41 robust inception cohort studies. Acta Psychiatrica Scandinavica 2009;119(4):252-65.

\section{Morris 1993}

Morris JC. The Clinical Dementia Rating (CDR): current version and scoring rules. Neurology 1993;43:2412-4.

\section{Mosconi 2012}

Mosconi L, Matthews D, Schmidt M, Andrews R. Characterizing brain amyloid changes using PIB-PET: Progression, clinical correlates, PIB status and optimized sampling [Conference: Alzheimer's Association International Conference 2012 Vancouver, BC Canada. Conference Start: 20120714 Conference End: 20120719. Conference Publication: (var.pagings)]. Alzheimer's \& Dementia 2012.

\section{Neary 1988}

Neary D, Snowden JS, Gustafson L, Passant U, Stuss D, Black S, et al. Frontotemporal lobar degeneration: a consensus on clinical diagnostic criteria. Neurology 1998;51:1546-54.

\section{Newell 1999}

Newell KL, Hyman BT, Growdon JH, Hedley-Whyte ET. Application of the National Institute on Aging (NIA)-Reagan Institute criteria for the neuropathological diagnosis of Alzheimer disease. Journal of Neuropathology and Experimental Neurology 1999;58(11):1147-55.

\section{Oddo 2004}

Oddo S, Billings L, Kesslak JP, Cribbs DH, LaFerla FM. Abeta immunotherapy leads to clearance of early, but not late, hyperphosphorylated tau aggregates via the proteasome. Neuron 2004;43(3):321-32.

\section{Okello 2007}

Okello A, Edison P, Archer H, Hinz R, Fox N, Kennedy A, et al. Amyloid deposition and cerebral glucose metabolism in mild cognitive impairment: a longitudinal 11c-PIB and 18f-FDG PET study. Journal of Neurology, Neurosurgery, and Psychiatry 2007; Vol. 78, issue 2:219-20.

\section{Perrotin 2011}

Perrotin A, Desgranges B, Duval C, La Joie R, Mezenge F, Landeau $B$, et al. The imap project: How does the awareness of memory deficits evolve in the course of Alzheimer's disease? Insights from its relationships to PET b-amyloid

${ }^{11 C-P I B-P E T ~ f o r ~ t h e ~ e a r l y ~ d i a g n o s i s ~ o f ~ A l z h e i m e r ' s ~ d i s e a s e ~ d e m e n t i a ~ a n d ~ o t h e r ~ d e m e n t i a s ~ i n ~ p e o p l e ~ w i t h ~ m i l d ~ c o g n i t i v e ~ i m p a i r m e n t ~(M C I) ~}$ 
and metabolism measurements [Conference: Alzheimer's Association International Conference, AAIC 11 Paris France. Conference Start: 20110716 Conference End: 20110721. Conference Publication: (var.pagings)]. Alzheimer's \& Dementia 2011; Vol. 7, issue 4 Suppl 1:S742-3.

\section{Petersen 1999}

Petersen RC, Smith GE, Waring SC, Ivnik RJ, Tangalos EG, Kokmen E. Mild cognitive impairment: clinical characterization and outcome. Archives of Neurology 1999;56:303-8.

\section{Petersen 2004}

Petersen RC. Mild cognitive impairment as a diagnostic entity. Journal of Internal Medicine 2004;256:183-94.

\section{Petersen 2009}

Petersen R, Knopman D, Boeve B, Geda YE, Ivnik RJ, Smith GE, et al. Mild cognitive impairment: ten years later. Archives of Neurology 2009;66:1447-55.

\section{Price 2005}

Price JC, Klunk WE, Loprestil BJ, Lu X, Hoge JA, Ziolko SK, et al. Kinetic modelling of amyloid binding in humans using PET imaging and Pittsburgh compound-B. Journal of Cerebral Blood Flow and Metabolism 2005;25:1528-47.

\section{Quinn 2014}

Quinn TJ, Fearon P, Noel-Storr AH, Young C, McShane R, Stott DJ. Informant Questionnaire on Cognitive Decline in the Elderly (IQCODE) for the diagnosis of dementia within community dwelling populations. Cochrane Database of Systematic Reviews 2014, Issue Issue 4. Art. No.: CD010079. DOI: 10.1002/14651858.CD010079.pub2.

\section{Rabinovici 2007}

Rabinovici GD, Furst AJ, O'Neil JP, Racine CA, Mormino EC, Baker SL, et al. 11C-PIB PET imaging in Alzheimer disease and frontotemporal lobar degeneration. Neurology 2007;68(15):1205-12.

\section{Rabinovici 2011}

Rabinovici GD, Rosen HJ, Alkalay A, Kornak J, Furst AJ, Agarwal N, et al. Amyloid vs FDG-PET in the differential diagnosis of AD and FTLD. Neurology 2011;77(23):2034-42.

\section{Rentz 2011}

Rentz D, Betensky R, Becker A, England R, Maye J, Gidicsin C, et al. Amyloid deposition in non-demented elderly predicts longitudinal cognitive decline [Conference: Alzheimer's Association International Conference, AAIC 11 Paris France. Conference Start: 20110716 Conference End: 20110721. Conference Publication: (var.pagings)]. Alzheimer's \& Dementia 2011; Vol. 7, issue 4 Suppl 1:S221.

\section{Rinne 2010}

Rinne JO, Brooks DJ, Rossor MN, Fox NC, Bullock R, Klunk WE, et al. 11C-PiB PET assessment of change in fibrillar amyloidbeta load in patients with Alzheimer's disease treated with bapineuzumab: a phase 2, double-blind, placebo-controlled, ascending-dose study. Lancet Neurology 2010;9(4):363-72. doi:10.1016/S1474-4422(10)70043-0.

\section{Roman 1993}

Roman GC, Tatemichi TK, Erkinjuntti T, Cummings JL, Masdeu JC, Garcia JH, et al. Vascular dementia: diagnostic criteria for research studies. Report of the NINDS-AIREN International Workshop. Neurology 1993;43(2):250-60.

\section{Rowe 2007}

Rowe CC, Ng S, Ackermann U, Gong SJ, Pike K, Savage G, et al. Imaging beta-amyloid burden in aging and dementia. Neurology 2007;68(20):1718-25.

\section{Royall 2014}

Royall DR, Palmer RF. The temporospatial evolution of neuritic plaque-related and independent tauopathies: implications for dementia staging. Journal of Alzheimer's Disease 2014;40(3):541-9. doi:10.3233/JAD-131733.

\section{Rutter 2001}

Rutter CA, Gatsonis CA. A hierarchical regression approach to meta-analysis of diagnostic test accuracy evaluations. Statistics in Medicine 2001;20:2865-84.

\section{Salloway 2014}

Salloway S, Sperling R, Fox NC, Blennow K, Klunk W, Raskind M, et al. Two phase 3 trials of bapineuzumab in mild-to-moderate Alzheimer's disease. New England Journal of Medicine 2014;370(4):322-33. doi:10.1056/NEJMoa1304839.

\section{SAS Institute 2011}

SAS Institute Inc. 2011. SAS/OR ${ }^{\circledR} 9.3$ User’s Guide: Mathematical Programming. Cary, NC: SAS Institute Inc. SAS/OR ${ }^{\circledR} 9.3$ User's Guide: Mathematical Programming Copyright ( 2011. SAS Institute Inc., Cary, NC, USA http://support.sas.com/ documentation/cdl/en/ormpug/63975/PDF/default/ormpug.pdf (access 18 January 2013) .

\section{Savva 2009}

Savva GM, Wharton SB, Ince PG, Forster G, Matthews FE, Brayne C, et al. Age, neuropathology, and dementia. New England Journal of Medicine 2009;360(22):230-9.

\section{Schneider 2007}

Schneider JA, Arvanitakis Z, Bang W, Bennett DA. Mixed brain pathologies account for most dementia cases in communitydwelling older persons. Neurology 2007;69(24):2197-204. doi:01.wnl.0000271090.28148.24 [pii].

\section{Schneider 2009}

Schneider JA, Arvanitakis Z, Leurgans SE, Bennett DA. The neuropathology of probable Alzheimer disease and mild cognitive impairment. Annals of Neurology 2009;66(2):200-8. doi:10.1002/ana.21706.

\section{Serrano-Pozo 2013}

Serrano-Pozo A, Qian J, Monsell SE, Frosch MP, Betensky RA, Hyman BT. Examination of the clinicopathologic continuum of Alzheimer disease in the autopsy cohort of the National Alzheimer Coordinating Center. Journal of Neuropathology and Experimental Neurology 2013;72(12):1182-92. doi:10.1097/ NEN.0000000000000016.

${ }^{11} \mathrm{C}-\mathrm{PIB}-\mathrm{PET}$ for the early diagnosis of Alzheimer's disease dementia and other dementias in people with mild cognitive impairment (MCI) 


\section{Shimada 2013}

Shimada H, Shinotoh H, Hirano S, Miyoshi M, Sato K, Tanaka N, et al. Beta-amyloid in Lewy body disease is related to Alzheimer's disease-like atrophy. Movement Disorders 2013;28(2):169-75.

\section{Shin 2010}

Shin J, Lee SY, Kim SJ, Kim SH, Cho SJ, Kim YB. Voxelbased analysis of Alzheimer's disease PET imaging using a triplet of radiotracers: PIB, FDDNP, and FDG. Neurolmage 2010;52(2):488-96.

\section{Shin 2011}

Shin J, Kepe V, Small GW, Phelps ME, Barrio JR. Multimodal imaging of Alzheimer pathophysiology in the brain's default mode network. International Journal of Alzheimer's Disease 2011:doi:10.4061/2011/687945.

\section{Sperling 2011}

Sperling RA, Aisen PS, Beckett LA, Bennett DA, Craft S, Fagan AM, et al. Toward defining the preclinical stages of Alzheimer's disease: recommendation from the National Institute on Ageing-Alzheimer's Association workgroups on diagnostic guidelines for Alzheimer's disease. Alzheimer's \& Dementia 2011;7:1-10.

\section{Trzepacz 2014}

Trzepacz PT, Yu P, Sun J, Schuh K, Case M, Witte MM. Comparison of neuroimaging modalities for the prediction of conversion from mild cognitive impairment to Alzheimer's dementia. Neurobiology of Aging 2014;35(1):143-51. doi:10.1016/j.neurobiolaging.2013.06.018. S0197-4580(13)00279-0 [pii].

\section{Villain 2011}

Villain N, Chetelat G, Grassiot B, Bourgeat P, Jones G, Ellis K, et al. Dynamic of beta-amyloid deposition in healthy elderly, mild cognitive impairment and Alzheimer's disease: A PIBPET longitudinal study [Conference: Alzheimer's Association International Conference, AAIC 11 Paris France. Conference Start: 20110716 Conference End: 20110721. Conference Publication: (var.pagings)]. Alzheimer's \& Dementia 2011; Vol. 7, issue 4 Suppl 1:S226-7.

\section{Villemagne 2008}

Villemagne VL, Pike KE, Darby D, Maruff P, Savagee G, Ng S, et al. Aâ deposits in older non-demented individuals with cognitive decline are indicative of preclinical Alzheimer's disease. Neuropsychologia 2008;46:1688-97.

\section{Villemagne 2011a}

Villemagne V, Ellis K, Chetelat G, Bourgeat P, Jones G, Martins R, et al. $A B$ accumulation correlates with cognitive decline: Results from the longitudinal aibl study [Conference: Alzheimer's Association International Conference, AAIC 11 Paris France. Conference Start: 20110716 Conference End: 20110721. Conference Publication: (var.pagings)]. Alzheimer's \& Dementia 2011; Vol. 7, issue 4 Suppl 1:S39.

\section{Visser 2006}

Visser PJ, Kester, Jolles J, Verhey F. Ten-year risk of dementia in subjects with mild cognitive impairment. Neurology 2006;67(7):1201-7.

\section{Whiting 2011}

Whiting PF, Rutjes AWS, Westwood ME, Mallet S, Deeks JJ, Reitsma JB. QUADAS-2: a revised tool for the quality assessment of diagnostic accuracy studies. Annals of Internal Medicine 2011;155:529-36.

\section{Winblad 2004}

Winblad B, Palmer K, Kivipelto M, Jelic V, Fratiglioni L, Wahlund LO, et al. Mild cognitive impairment - beyond controversies, towards a consensus: report of the International Working Group on Mild Cognitive Impairment. Journal of Internal Medicine 2004;256(3):240-6.

\section{Wolk 2009}

Wolk DA, Price JC, Saxton JA, Snitz BE, James JA, Lopez OL, et al. Amyloid imaging in mild cognitive impairment subtypes. Annals of Neurology 2009;65(5):557-68.

\section{World Health Organization 2002}

World Health Organization. Mental Health. Alzheimer's Disease. http://www.afro.who.int/mentalhealth/related_disease/ alyheimer_disease.html. Last updated 18 September 2002 (archives, accessed 4 March 2004).

\section{World Health Organization 2010}

World Health Organization. International Statistical Classification of Diseases and Related Health Problems (ICD-10 Version: 2010). http://apps.who.int/classifications/icd10/ browse/2010/en (accessed 9 January 2013).

\section{Zhang 2012}

Zhang S, Han D, Tan X, Feng J, Guo Y, Ding Y. Diagnostic accuracy of 18 F-FDG and 11 C-PIB-PET for prediction of shortterm conversion to Alzheimer's disease in subjects with mild cognitive impairment. International Journal of Clinical Practice 2012;66(2):185-98. doi:10.1111/j.1742-1241.2011.02845.x.

* Indicates the major publication for the study

\section{CHARACTERISTICS OF STUDIES}

Characteristics of included studies [ordered by study ID]

${ }^{11} \mathrm{C}$-PIB-PET for the early diagnosis of Alzheimer's disease dementia and other dementias in people with mild cognitive impairment (MCI) 
Forsberg 2010

\section{Study characteristics}

Patient sampling Twenty-one patients with $\mathrm{MCl}$ and 37 patients with mild AD were recruited from Department of Geriatric Medicine at University Hostpital. No further details of recruitment were reported. Participants were referred from the primary care centres in the community (Forsberg 2008).

We only included data on performance of the index test to discriminate between patients with $\mathrm{MCl}$ who convert to dementia and those who remained stable.

No exclusion criteria were reported

Patient characteristics and setting

$21 \mathrm{MCl}$ participants diagnosed by the modified Petersen criteria (Winblad 2004) at baseline (Forsberg 2008). All subjects lived independently in the community and a majority of the subjects below 65 years of age had still a professional job

Gender: 8 male; 13 female

AGE: mean: $63.3 \pm 7.8$ years (range $50-78$ ); MCI-AD: $63.4 \pm 7.9$ years; $\mathrm{MCI}-\mathrm{MCl}: 62.6 \pm 8.4$ years

APOE $\underline{\epsilon}$ carrier: 14 (67\%) (8 MCI-MCl; $6 \mathrm{MCl}-\mathrm{AD})$

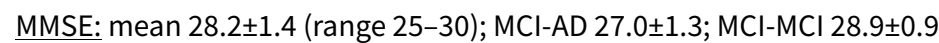

Sources of referral: primary care centres in community

Setting: secondary care - outpatients (Department of Geriatric Medicine clinic)

Index tests

The PET examination with ${ }^{11} \mathrm{C}$-PIB was performed at Uppsala PET centre/Uppsala Imanet AB in Uppsala, Sweden. Production of ${ }^{11} \mathrm{C}-\mathrm{PIB}$, tracer doses, and scanner protocol for transmissions, emissions and reconstructions have been described in detail previously (Klunke 2004)

Time between PIB injection and PET acquisition: 60 minutes

PIB administration dose: $300 \mathrm{MBq}$

Quantitative data on ${ }^{11} \mathrm{C}$-PIB retention were generating giving late scan ratio data for ${ }^{11} \mathrm{C}$-PIB retention (Forsberg 2008). ROIs (regions of interest) included the frontal, parietal and temporal cortices divided right and left, posterior cingulate, striatum, primary visual cortex and thalamus

Threshold: ROI to-cerebellar ratio >1.6 (PIB retention detecting regions: global cortex and thalamus). Threshold determined at follow-up.

Index test was conducted at baseline

Target condition and ref- Target condition: Alzheimer's disease dementia (conversion from MCI to AD)

erence standard(s)

Reference standard: NINCDS-ADRDA criteria

Details of follow-up procedures were not specified. Unclear whether clinicians conducting follow-up were aware of PIB-PET analysis results

Flow and timing

All participants received the same reference standard

Duration of follow-up: within $8.1 \pm 0.5$ months (2-16 months) after their PET scans $7 \mathrm{MCI}$ patients converted to $\mathrm{AD}$; after $45.5 \pm 8.5$ months of clinical follow-up 14 patients remained $\mathrm{MCl}$ stable; mean duration for all participants was not reported; average: $33.3 \pm 19.3$ months (the data was calculated by ZS)

Number included in analysis: $21 \mathrm{MCl}: 11 \mathrm{MCl}$ with positive PIB test: 7 converted to $A D$ and 4 remained stable; $10 \mathrm{MCl}$ with negative PIB test remained stable

$T P=7 ; F P=4 ; F N=0 ; T N=10$

Loss to follow-up: data appeared to have been reported for all 21 participants

${ }^{11} \mathrm{C}-\mathrm{PIB}-\mathrm{PET}$ for the early diagnosis of Alzheimer's disease dementia and other dementias in people with mild cognitive impairment (MCI) 
Forsberg 2010 (Continued)

Comparative

Notes

Methodological quality

\begin{tabular}{llll}
\hline Item & Authors' judgement & Risk of bias & Applicability concerns \\
\hline
\end{tabular}

DOMAIN 1: Patient Selection

Was a consecutive or ran- Unclear

dom sample of patients

enrolled?

\begin{tabular}{ll}
$\begin{array}{l}\text { Was a case-control de- } \\
\text { sign avoided? }\end{array}$ & Yes \\
\hline $\begin{array}{l}\text { Did the study avoid inap- } \\
\text { propriate exclusions? }\end{array}$ & Unclear \\
\hline
\end{tabular}

\begin{tabular}{l}
\hline Unclear $\quad$ Low \\
\hline DOMAIN 2: Index Test All tests \\
\hline $\begin{array}{l}\text { Were the index test re- Yes } \\
\text { sults interpreted without } \\
\text { knowledge of the results } \\
\text { of the reference stan- } \\
\text { dard? }\end{array}$
\end{tabular}

If a threshold was used, No

was it pre-specified?

High

Low

\section{DOMAIN 3: Reference Standard}

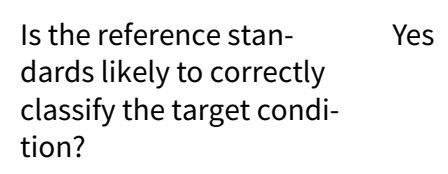

Were the reference stan- Unclear dard results interpreted without knowledge of the results of the index tests?

\begin{tabular}{l}
\hline Unclear \\
\hline DOMAIN 4: Flow and Timing \\
\hline Was there an appropriate Yes \\
interval between index \\
test and reference stan- \\
dard?
\end{tabular}

${ }^{11 C-P I B-P E T ~ f o r ~ t h e ~ e a r l y ~ d i a g n o s i s ~ o f ~ A l z h e i m e r ' s ~ d i s e a s e ~ d e m e n t i a ~ a n d ~ o t h e r ~ d e m e n t i a s ~ i n ~ p e o p l e ~ w i t h ~ m i l d ~ c o g n i t i v e ~ i m p a i r m e n t ~(M C I) ~}$ 30 


\section{Forsberg 2010 (Continued)}

Did all patients receive the same reference standard?

\section{Yes}

Were all patients includ- Yes ed in the analysis?

Low

\section{Grimmer 2013}

\section{Study characteristics}

Patient sampling

Participants had been referred for the diagnostic evaluation by general practitioners, specialists, or other institutions. No further details of recruitment were reported

Exclusion criteria: psychotropic medication, substance misuse, major abnormalities in routine blood testing, or other neurological or psychiatric disorders

Patient characteristics and setting

$28 \mathrm{MCl}$ participants diagnosed by the modified Petersen criteria (Winblad 2004) and CDR=0.5 (Morris 1993) criteria at baseline

Gender: 14 male; 14 female

AGE: mean: $67.9 \pm 7.4$ years (range $50-79$ )

$\underline{\mathrm{APOE}} \underline{\underline{4}} \underline{\text { carrier: }}$ not reported

MMSE: mean 26.0 \pm 3.19 (range 15-30)

Education: $11.8 \pm 2.2$ years (range $8-17$ )

Sources of referral: mixed: primary and secondary care, and other institutions

Setting: secondary care - outpatients (Psychiatry and Psychotherapy Department clinic)

Index tests $\quad$ Time between PIB injection and PET acquisition: 40-60 minutes

PIB administration dose: $628 \mathrm{MBq}$ (range 385 to $723 \mathrm{MBq}$

Threshold: PIB-PET findings at baseline were dichotomised into amyloid positive or amyloid-negative using a cerebrum to cerebellar vermis ratio threshold of 1.4 as cut-off using proposed methods described above (Jack 2008).

Threshold determined at baseline.

Index test was conducted at baseline.

Target condition and reference standard(s)

Target condition: Alzheimer's disease dementia and other forms of dementia

Reference standard: NINCDS-ADRDA criteria for Alzheimer's disease dementia and the Land criteria (Brun 1994) for FTD

Clinicians conducting follow-up were blinded for the baseline PIB-PET findings

Flow and timing

All participants received the same reference standard

Duration of follow-up: mean was $31.2 \pm 7.8$ months

${ }^{11 C-P I B-P E T ~ f o r ~ t h e ~ e a r l y ~ d i a g n o s i s ~ o f ~ A l z h e i m e r ' s ~ d i s e a s e ~ d e m e n t i a ~ a n d ~ o t h e r ~ d e m e n t i a s ~ i n ~ p e o p l e ~ w i t h ~ m i l d ~ c o g n i t i v e ~ i m p a i r m e n t ~(M C I) ~}$

Copyright @ 2014 The Cochrane Collaboration. Published by John Wiley \& Sons, Ltd. 
Grimmer 2013 (Continued)

Number included in analysis: $28 \mathrm{MCl}: 17 \mathrm{MCl}$ with PIB positive test: 9 converted to AD and 8 remained stable; $11 \mathrm{MCl}$ with PIB negative test: 3 converted to non-AD (2 FTD; 1 dementia not specified), 7 remained stable and 1 reverted to normal

Conversion from $\mathrm{MCl}$ to $\mathrm{AD}$ dementia:

$T P=9 ; F P=8 F N=0 ; T N=11$

Conversion from $\mathrm{MCl}$ to all dementia:

$\mathrm{TP}=9 ; \mathrm{FP}=8 \mathrm{FN}=3 ; \mathrm{TN}=8$

Loss to follow-up: data appeared to have been reported for all 28 participants

\section{Comparative}

Notes

\section{Methodological quality}

\begin{tabular}{|c|c|c|c|}
\hline Item & Authors' judgement & Risk of bias & Applicability concerns \\
\hline \multicolumn{4}{|l|}{ DOMAIN 1: Patient Selection } \\
\hline $\begin{array}{l}\text { Was a consecutive or random } \\
\text { sample of patients enrolled? }\end{array}$ & Unclear & & \\
\hline $\begin{array}{l}\text { Was a case-control design avoid- } \\
\text { ed? }\end{array}$ & Yes & & \\
\hline \multirow[t]{2}{*}{$\begin{array}{l}\text { Did the study avoid inappropriate } \\
\text { exclusions? }\end{array}$} & Yes & & \\
\hline & & Unclear & Low \\
\hline
\end{tabular}

\section{DOMAIN 2: Index Test All tests}

Were the index test results interpreted without knowledge of the results of the reference standard?

If a threshold was used, was it Yes pre-specified?

\begin{tabular}{lll}
\hline & Low & Low \\
\hline
\end{tabular}

\section{DOMAIN 3: Reference Standard}

Is the reference standards like- Yes ly to correctly classify the target condition?

Were the reference standard results interpreted without knowledge of the results of the index tests? 
Grimmer 2013 (Continued)

DOMAIN 4: Flow and Timing

Was there an appropriate interval Yes

between index test and reference

standard?

Did all patients receive the same Yes

reference standard?

Were all patients included in the Yes

analysis?

\section{Study characteristics}

Patient sampling $218 \mathrm{MCl}$ participants were selected from the Alzheimer's Disease Neuroimaging Initiative (ADNI) (retrospective study). No discussion on when patients were recruited. 53 participants assessed by PIBPET imaging and 165 by cerebrospinal fluid $A \beta 42$ methods. No sampling criteria specified.

We only included data on performance of the PIB-PET index test to discriminate between patients with $\mathrm{MCl}$ who convert to dementia and those who remained stable at follow-up.

No exclusion criteria were reported

Patient characteristics and setting
$53 \mathrm{MCl}$ participants diagnosed by the Petersen 2001 criteria. Demographic data reported on 218 participants

Gender: $72(33 \%)$ female

AGE: 75 year

$\underline{\mathrm{APOE}} \underline{\underline{4}} \underline{\text { carrier not reported: }}$

MMSE: median (IQR) $27(25,29)$

Education: median duration (IQR) $16(14,18)$

Sources of referral: mixed: the local Alzheimer's Disease Research Center (ADRC), memory clinics, newspaper ads, radio and other public media campaigns

Setting: mixed (ADNI participants at 13 different sites)

Index tests

A global cortical PIB PET retention summary was formed by combining the prefrontal, orbitofrontal, parietal, temporal, anterior cingulate and posterior cingulate/precuneus values for each subject, using a weighted average of these regions of interest values

Larger regions of interest were given greater weight. PIB PET ratio values calculated by dividing the median value in each target cortical region of by the median value in the cerebellar grey matter region of interest of the atlas

Time between PIB injection and PET acquisition: 50-70 minutes

PIB administration dose: not reported

Threshold: mean neocortical distribution volume ratio (DVR) $>1.5$ (PIB retention detecting regions: global cortex). Threshold determined at baseline.

${ }^{11} \mathrm{C}$-PIB-PET for the early diagnosis of Alzheimer's disease dementia and other dementias in people with mild cognitive impairment (MCI) 
Jack 2010 (Continued)

Index test was conducted at baseline

Target condition and refer- Target condition: Alzheimer's disease (conversion from MCI to AD)

ence standard(s)

Reference standard: NINCDS-ADRDA criteria

Unclear whether clinicians conducting follow-up were aware of PIB-PET analysis results

Flow and timing

No discussion on when patients were recruited

All participants received the same reference standard

Duration of follow-up: a median progression-free follow-up time of 1.7 years

Number included in analysis: $53 \mathrm{MCl}: 34 \mathrm{MCl}$ with PIB positive test: 15 converted to AD and 19 remained stable; $19 \mathrm{MCI}$ with PIB negative test: 3 converted to $A D$ and 16 remained stable

$\mathrm{TP}=15 ; \mathrm{FP}=19 ; \mathrm{FN}=3 ; \mathrm{TN}=16$

Loss to follow-up: data appeared to have been reported for all 53 participants

\section{Comparative}

\begin{tabular}{ll}
\hline Notes & The trial investigators contacted; they provided requested data tor the $2 \times 2$ table to be completed; \\
email from Dr Weigand on $11 / 5 / 12$
\end{tabular}
email from Dr Weigand on $11 / 5 / 12$

\section{Methodological quality}

\begin{tabular}{lll}
\hline Item & Authors' judgement & Risk of bias
\end{tabular}

\section{DOMAIN 1: Patient Selection}

Was a consecutive or ran- No

dom sample of patients en-

rolled?

Was a case-control design Yes avoided?

Did the study avoid inap- Unclear propriate exclusions?

High Low

\section{DOMAIN 2: Index Test All tests}

Were the index test results Yes interpreted without knowledge of the results of the reference standard?

If a threshold was used, was Yes it pre-specified?

Low Low

\section{DOMAIN 3: Reference Standard}

${ }^{11} \mathrm{C}-\mathrm{PIB}-\mathrm{PET}$ for the early diagnosis of Alzheimer's disease dementia and other dementias in people with mild cognitive impairment (MCI) 
Jack 2010 (Continued)

Is the reference standards likely to correctly classify the target condition?

\section{Were the reference stan- Unclear} dard results interpreted without knowledge of the results of the index tests?

\begin{tabular}{lll}
\hline & Unclear Low \\
\hline
\end{tabular}

\section{DOMAIN 4: Flow and Timing}

Was there an appropriate Unclear interval between index test and reference standard?

Did all patients receive the Yes
same reference standard?

Were all patients included Yes in the analysis?

Low

\section{Koivunen 2011}

\section{Study characteristics}

Patient sampling

Twenty-nine consecutive $\mathrm{MCl}$ patients seen at the memory clinic and who volunteered for PET scanning, and thirteen healthy controls were included in the study. We only included data on performance of the index test to discriminate between patients with $\mathrm{MCl}$ who convert to dementia and those who remained stable.

No inclusion or exclusion criteria described setting
Patient characteristics and

29 participants diagnosed by Petersen 2004 criteria: all patients had subjective memory impairment that was confirmed in neuropsychological testing, and some patients had mild decline in other cognitive domains. Clinical Dementia Rating (CDR) was 0.5 , global cognition was normal, activities of daily living were not impaired, and no subject had dementia at baseline

Gender: 11 women, 18 men

Age: total sample $71.3 \pm 6.4$ years; $\mathrm{MCl}$ converters $73.6 \pm 7.2$ years; non- $\mathrm{MCl}$ converters $70.8 \pm 4.9$ years $\underline{\mathrm{APOE}} \underline{\epsilon 4} \underline{\text { carrier: }}$ total sample $17 ; \mathrm{MCl}$ converters 14; non- $\mathrm{MCl}$ converters 3

MMSE: total sample 26.9 $\pm 1.6 ; \mathrm{MCl}$ converters $26.2 \pm 1.5$; non- $\mathrm{MCl}$ converters $27.9 \pm 1.3$

Sources of referral: not reported

Setting: secondary care - outpatients (memory clinic)

Index tests

An Advance PET scanner was used in the 3D scanning mode.ROls were drawn on the anterior and posterior cingulate, lateral frontal cortex, caudate nucleus, putamen, thalamus, lateral temporal cortex, parietal cortex, medial temporal lobe, and pons. Average regional ratio values of 11C-PIB uptake were calculated using these ROIs from spatially normalised parametric ratio images

${ }^{11} \mathrm{C}$-PIB-PET for the early diagnosis of Alzheimer's disease dementia and other dementias in people with mild cognitive impairment (MCI) 
Koivunen 2011 (Continued)

Time between PIB injection and PET acquisition: 90 minutes.

PIB administration dose: not reported

Threshold: region-to-cerebellum ratio $\geq 1.5$ (PIB retention detecting regions: global cortex, caudate nucleus, putamen, thalamus, pons). Threshold determined at baseline

Index test was conducted at baseline

Target condition and ref- Target condition: Alzheimer's disease dementia (conversion from $\mathrm{MCl}$ to AD) erence standard(s)

Reference standard: NINCDS-ADRDA criteria; DSM-IV criteria

Unclear whether clinicians conducting follow-up were aware of PIB-PET analysis results

Flow and timing

It was not clear whether all participants received the both reference standards

Duration of follow-up: 2 years

Number included in analysis: $29 \mathrm{MCl}: 17 \mathrm{MCl}$ converted to $A D$ and 12 remained stable

1) Anterior cingulate: sensitivity $=82 \%$; specificity $=58 \%$

$\mathrm{TP}=14 ; \mathrm{FP}=5 ; \mathrm{FN}=3 ; \mathrm{TN}=7$

2) Posterior cingulate: sensitivity $=94 \%$; specificity $=58 \%$

$\mathrm{TP}=16 ; \mathrm{FP}=5 ; \mathrm{FN}=1 ; \mathrm{TN}=7$

3) Lateral frontal cortex: sensitivity $=65 \%$; specificity $=67 \%$

$\mathrm{TP}=11 ; \mathrm{FP}=4 ; \mathrm{FN}=6 ; \mathrm{TN}=8$

4) Parietal cortex: sensitivity $=41 \%$; specificity $=67 \%$

$\mathrm{TP}=7 ; \mathrm{FP}=4 ; \mathrm{FN}=11 ; \mathrm{TN}=8$

5) Temporal cortex: 53\%; specificity $=67 \%$

$\mathrm{TP}=9 ; \mathrm{FP}=4 ; \mathrm{FN}=8 ; \mathrm{TN}=8$

Loss to follow-up: data appear to have been included for all 29 participants

\section{Comparative}

\section{Notes}

\section{Methodological quality}

\begin{tabular}{llll}
\hline Item & Authors' judgement & Risk of bias & Applicability concerns \\
\hline
\end{tabular}

DOMAIN 1: Patient Selection

Was a consecutive or ran- Yes dom sample of patients enrolled?

Was a case-control design Yes
avoided?

Did the study avoid inap- Unclear propriate exclusions?

${ }^{11}$ C-PIB-PET for the early diagnosis of Alzheimer's disease dementia and other dementias in people with mild cognitive impairment (MCI) 36 (Review)

Copyright (c) 2014 The Cochrane Collaboration. Published by John Wiley \& Sons, Ltd. 
Koivunen 2011 (Continued)

\section{DOMAIN 2: Index Test All tests}

Were the index test re- Yes

sults interpreted without

knowledge of the results

of the reference standard?

\section{If a threshold was used, Yes} was it pre-specified?

\section{Low}

Low

\section{DOMAIN 3: Reference Standard}

Is the reference standards Yes

likely to correctly classify

the target condition?

\section{Were the reference stan- Unclear}

dard results interpreted

without knowledge of the

results of the index tests?

\section{DOMAIN 4: Flow and Timing}

Was there an appropriate Yes

interval between index

test and reference stan-

dard?

\section{Did all patients receive the Unclear}

same reference standard?

\section{Were all patients included Yes}

in the analysis?

\section{Low}

\section{Okello 2009}

\section{Study characteristics}

Patient sampling Thirty-one participants were recruited from UK and Finnish Hospitals. No further details of recruitment were reported

Patients with significant white matter disease in the view of an experienced radiologist were excluded from the study. No further exclusion criteria were reported

Patient characteristics and setting
$31 \mathrm{MCl}$ participants diagnosed by the Petersen 2001 criteria: subjective memory complaint by the patient, preferably corroborated by an informant; objective memory impairment as assessed by performance below age-matched normals on at least one neuropsychological measure of memory; rela-

${ }^{11} \mathrm{C}-\mathrm{PIB}-\mathrm{PET}$ for the early diagnosis of Alzheimer's disease dementia and other dementias in people with mild cognitive impairment (MCI) 
Okello 2009 (Continued)

tively normal performance in other cognitive domains; intact activities of daily living; no dementia. A strict cut-off score was not applied for the definition of objective memory impairment

Gender: 19 male, 12 female

Age: total sample $69.4 \pm 7.9$ years; $\mathrm{MCl}$ converters $71.6 \pm 6.3$ years; non- $\mathrm{MCl}$ converters $67.9 \pm 9.0$ years

$\underline{\text { APOE }} \underline{\underline{4}} \underline{\text { carrier: }}$ not reported

MMSE: total sample $27.5 \pm 1.5 ; \mathrm{MCl}$ converters $27.1 \pm 1.5$; non- $\mathrm{MCl}$ converters $27.9 \pm 1.3$

Sources of referral: not reported

Setting: secondary - inpatients (three UK hospitals and one Finland hospital)

Index tests

All UK participants were scanned using a Siemens ECAT EXACT HR+ camera in 3-dimensional acquisition mode. The Finland sample were scanned with a GE advance camera, using previously described protocol (Kemppainen 2006)

Time between PIB injection and PET acquisition: 90 minutes for DVR; 40-60 minutes for SUVR

PIB administration dose: $367 \pm 25$ MBq in UK; $487 \pm 44$ MBq in Finland

Threshold: region to cerebellum ratio $\geq 2$ SD greater than the control mean in all 6 ROIs (regions of interest). PIB retention ratio values for each $\mathrm{MCl}$ participant were compared to that of the control mean of their scanning site (visual assessment)

Threshold determined at baseline

Index test was conducted at baseline

Target condition and refer- Target condition: Alzheimer's dementia (conversion from $\mathrm{MCl}$ to Alzheimer's dementia)

ence standard(s)

Reference standard: NINCDS-ADRDA criteria

Unclear whether clinicians conducting follow-up were aware of PIB-PET analysis results

Flow and timing All participants received the same reference standard

Duration of follow-up: total sample: mean $2.68 \pm 0.6$ years (32.2 \pm 7.2 months), range $1-3$ years; mean $2.9 \pm 0.5$ years in converters; $2.5 \pm 0.7$ years in non-converters

At follow-up: $15 \mathrm{MCl}$-converters and $17 \mathrm{MCl}$-nonconverters

Number included in analysis=31: 17 with positive PIB tests: $14 \mathrm{MCl}-\mathrm{AD}, 3 \mathrm{MCl}-\mathrm{MCl}$; 14 with negative PIB tests: $1 \mathrm{MCl}-\mathrm{AD}, 13 \mathrm{MCl}-\mathrm{MCl}$

$\mathrm{TP}=14 ; \mathrm{FP}=3 ; \mathrm{FN}=1 ; \mathrm{TN}=13$

Loss to follow-up: data appeared to have been reported for all 31 participants

Comparative

Notes

\section{Methodological quality}

\begin{tabular}{llll}
\hline Item & Authors' judgement & Risk of bias & Applicability concerns \\
\hline
\end{tabular}

DOMAIN 1: Patient Selection

${ }^{11} \mathrm{C}-\mathrm{PIB}-\mathrm{PET}$ for the early diagnosis of Alzheimer's disease dementia and other dementias in people with mild cognitive impairment (MCI) 
Okello 2009 (Continued)

Was a consecutive or ran- Unclear dom sample of patients enrolled?

Was a case-control design Yes avoided?

Did the study avoid inap- Unclear propriate exclusions?

Unclear

Low

\section{DOMAIN 2: Index Test All tests}

Were the index test results Yes

interpreted without knowl-

edge of the results of the

reference standard?

If a threshold was used, was Yes

it pre-specified?

Low Low

\section{DOMAIN 3: Reference Standard}

Is the reference standards Yes

likely to correctly classify

the target condition?

Were the reference stan- Unclear

dard results interpreted

without knowledge of the

results of the index tests?

Unclear

Low

\section{DOMAIN 4: Flow and Timing}

Was there an appropriate Yes

interval between index test

and reference standard?

Did all patients receive the Yes

same reference standard?

Were all patients included Yes

in the analysis?

Low

Ossenkoppele 2012

\section{Study characteristics}

${ }^{11} \mathrm{C}$-PIB-PET for the early diagnosis of Alzheimer's disease dementia and other dementias in people with mild cognitive impairment (MCI)

Copyright @ 2014 The Cochrane Collaboration. Published by John Wiley \& Sons, Ltd. 
Ossenkoppele 2012 (Continued)

Patient sampling

At baseline 15 participants were included in each group: $\mathrm{MCl}, \mathrm{AD}$ and controls. No further details of patient sampling and recruitment were reported.

We only included data on performance of the index test to discriminate between patients with $\mathrm{MCl}$ who convert to dementia and those who remained stable

Exclusion criteria were a history of major psychiatric or neurological illness (other than AD) and the use of nonsteroidal antiinflammatory drugs Patients with severe vascular events during the follow-up period, such as stroke or haemorrhage, were also excluded

Patient characteristics and setting

15 participants diagnosed by the Petersen 1999 criteria

Gender: male 9; female 3

Age: $67 \pm 7$

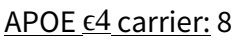

MMSE: $27 \pm 3$

Education: median (range): 6 (3-7)

Sources of referral: not reported

Setting: not reported

Index tests

A dynamic emission scan in three-dimensional acquisition mode was used

Time between PIB injection and PET acquisition: 90 minutes

PIB administration dose: $351 \pm 82 \mathrm{MBq}$

Threshold: Visual assessment. ${ }^{11}$ CPIB scans were classified as either positive or negative, based on visual inspection of parametric BPND images by a trained nuclear medicine physician. Not reported when threshold was determined

Index test was conducted at baseline

Target condition and reference standard(s)
Target condition: conversion from $\mathrm{MCl}$ to $\mathrm{AD}$ or other type of dementia

Reference standards: NINCDS-ADRDA criteria for AD (McKhann 1984); Reference standard for the clinical criteria for FTD not reported

Flow and timing

Duration of follow-up: 2.5 years (range $2.0-4.0$ years)

Number included in analysis: $12 \mathrm{MCl}$ : 5 PIB+: 4 MCl-AD, 1MCl-non-converter: 7 PIB-: 1 MCI-FTD; 6 MCInon-converters

Conversion from $\mathrm{MCl}$ to $\mathrm{AD}$ : $5 \mathrm{PIB}+: 4 \mathrm{MCl}$-converters and $1 \mathrm{MCl}$-non-converter; $7 \mathrm{PIB}$-: $0 \mathrm{MCl}$-converters and $7 \mathrm{MCl}$-non-converters (6 $\mathrm{MCl}-\mathrm{MCl} ; 1 \mathrm{MCl}-\mathrm{FTD})$

$T P=4 ; F P=1 ; F N=0 ; T N=7$

Conversion from $\mathrm{MCl}$ to all dementia: $5 \mathrm{PIB}+: 4 \mathrm{MCl}$-converters and $1 \mathrm{MCl}$ non-converter; $7 \mathrm{PIB}$-: 1 $\mathrm{MCl}$-converter and $6 \mathrm{MCl}$ - non-converters. Two out of seven $\mathrm{MCl}$-non-converters converted to 'cognitively improved' and five remained stable

$\mathrm{TP}=4 ; \mathrm{FP}=1 ; \mathrm{FN}=1 ; \mathrm{TN}=6$

Loss to follow-up: $3 \mathrm{MCI}$ patients refused to participate in the follow-up study due to lack of motivation

Comparative

${ }^{11} \mathrm{C}-\mathrm{PIB}-\mathrm{PET}$ for the early diagnosis of Alzheimer's disease dementia and other dementias in people with mild cognitive impairment (MCI)

Copyright @ 2014 The Cochrane Collaboration. Published by John Wiley \& Sons, Ltd. 
Ossenkoppele 2012 (Continued)

Notes

The trial investigators contacted; they provided requested data tor the $2 \times 2$ table to be completed and confirmed there are no overlapping patients with the Ossencoppele 2012a study; email from Dr

Ossenkopele on $5 / 3 / 13$

\section{Methodological quality}

\begin{tabular}{llll}
\hline Item & Authors' judgement & Risk of bias & Applicability concerns \\
\hline
\end{tabular}

DOMAIN 1: Patient Selection

\section{Was a consecutive or random Unclear}

sample of patients enrolled?

Was a case-control design Yes
avoided?

\section{Did the study avoid inappro- Yes}

priate exclusions?

Unclear Low

\section{DOMAIN 2: Index Test All tests}

Were the index test results in- Yes terpreted without knowledge of the results of the reference standard?

If a threshold was used, was Unclear it pre-specified?

Unclear

\section{DOMAIN 3: Reference Standard}

\section{Is the reference standards Unclear}

likely to correctly classify the

target condition?

Were the reference standard results interpreted without knowledge of the results of the index tests?

\section{Unclear}

\begin{tabular}{lll}
\hline & High & Low \\
\hline
\end{tabular}

DOMAIN 4: Flow and Timing

Was there an appropriate in- Yes

terval between index test and

reference standard?

Did all patients receive the Yes
same reference standard?

Were all patients included in No

the analysis?

${ }^{11} \mathrm{C}-\mathrm{PIB}-\mathrm{PET}$ for the early diagnosis of Alzheimer's disease dementia and other dementias in people with mild cognitive impairment (MCI)

Copyright @ 2014 The Cochrane Collaboration. Published by John Wiley \& Sons, Ltd. 


\section{Ossenkoppele 2012a}

\section{Study characteristics}

Patient sampling

154 participants included from the outpatient memory clinic of the VU University Medical centre for assessing the impact of molecular imaging on the diagnostic process. Among those participants there were $30 \mathrm{MCl}$ participants. No further details of patient sampling and recruitment were reported.

We only included data on performance of the index test to discriminate between patients with $\mathrm{MCl}$ who convert to dementia and those who remained stable.

Exclusion criteria: major clinical and psychiatric disorders, recent vascular events and excessive substance abuse

Patient characteristics and setting
$30 \mathrm{MCl}$ participants diagnosed by the Petersen 2001 criteria

Gender: male 23; female 7

Age: $64 \pm 9$

$\underline{A P O E} \in \underline{4}$ carrier: not reported

MMSE: $27 \pm 2$

Sources of referral: not reported

Setting: secondary care - outpatients (memory clinic)

Index tests

A dynamic emission scan in three-dimensional acquisition mode was used

Time between PIB injection and PET acquisition: 90 minutes

PIB administration dose: $367 \pm 43 \mathrm{MBq}$ at baseline

Threshold: Visual assessment: [11C]PIB PET scans were rated as either PIB-positive (PIB1; binding in more than one cortical brain region; i.e., frontal, parietal, temporal, or occipital) or PIB-negative (PIB2, predominantly white matter binding), based on visual inspection of parametric BPND images by a trained nuclear medicine physician. Not reported when threshold was determined.

Index test was conducted at baseline and at follow up. It was not reported whether the index test baseline results were interpreted without knowledge of the results of the reference standard.

Outcome measures were changes in clinical diagnosis and confidence in that diagnosis before and after disclosing PET results. The main focus of this study was not 'conversion from $\mathrm{MCl}$ to dementia; however, the author provided us with the relevant information for creating $2 \times 2$ table and, therefore, this study has been included.

\section{Target condition and} reference standard(s)

\section{Target condition: conversion from MCI to AD or other type of dementia}

Reference standards: not explicitly stated, although NINCDS-ADRDA criteria for AD (McKhann 1984), Neary 1998 criteria for FTD were baseline diagnostic criteria

Flow and timing

Number included in analysis: $12 \mathrm{MCl}: 7 \mathrm{PIB}+: 6 \mathrm{MCl}-\mathrm{AD}$ and $1 \mathrm{MCl}-\mathrm{MCl}$; $5 \mathrm{PIB}-: 1 \mathrm{MCl}-\mathrm{FTD}$ and $2 \mathrm{MCl}-\mathrm{MCl}$ and $1 \mathrm{MCl}$-cognitively improved and $1 \mathrm{MCl}$-psychiatric disorder

${ }^{11} \mathrm{C}$-PIB-PET for the early diagnosis of Alzheimer's disease dementia and other dementias in people with mild cognitive impairment (MCI) 
Ossenkoppele 2012a (Continued)

Conversion from $\mathrm{MCl}$ to $\mathrm{AD}: 7 \mathrm{PIB}+: 6 \mathrm{MCl}$-converters and $1 \mathrm{MCl}$-non-converter; $5 \mathrm{PIB}$-: $0 \mathrm{MCl}$-converters and $5 \mathrm{MCl}$-non-converters

$T P=6 ; F P=1 ; F N=0 ; T N=5$

Conversion from $\mathrm{MCl}$ to all dementia: $7 \mathrm{PIB}+: 6 \mathrm{MCl}$-converters and $1 \mathrm{MCl}$ non-converter; $5 \mathrm{PIB}$-: $1 \mathrm{MCl}$-converter and $4 \mathrm{MCl}$ - non-converters.

$T P=6 ; F P=1 ; F N=1 ; T N=4$

Loss to follow-up: $18 \mathrm{MCl}$ patients. No further information

\section{Comparative}

Notes

The trial investigators contacted; they provided requested data tor the $2 \times 2$ table to be completed and confirmed there are no overlapping patients with the Ossencoppele 2012 study; email from Dr Ossenkopele on $5 / 3 / 13$

\section{Methodological quality}

\begin{tabular}{llll}
\hline Item & Authors' judgement & Risk of bias & Applicability concerns \\
\hline
\end{tabular}

DOMAIN 1: Patient Selection

\begin{tabular}{l}
$\begin{array}{l}\text { Was a consecutive or } \\
\text { random sample of pa- } \\
\text { tients enrolled? }\end{array}$ \\
\hline $\begin{array}{ll}\text { Was a case-control de- Yes } \\
\text { sign avoided? }\end{array}$ \\
$\begin{array}{l}\text { Did the study avoid in- } \\
\text { appropriate exclusions? }\end{array}$ \\
\hline
\end{tabular}

\section{DOMAIN 2: Index Test All tests}

\section{Were the index test re- Unclear}

sults interpreted with-

out knowledge of the

results of the reference

standard?

If a threshold was used, Unclear was it pre-specified?

High Low

\section{DOMAIN 3: Reference Standard}

Is the reference stan- Unclear
dards likely to correctly
classify the target con-
dition?

Were the reference Unclear

standard results inter-

preted without knowl-

${ }^{11} \mathrm{C}$-PIB-PET for the early diagnosis of Alzheimer's disease dementia and other dementias in people with mild cognitive impairment (MCI)

Copyright ( 2014 The Cochrane Collaboration. Published by John Wiley \& Sons, Ltd. 
Ossenkoppele 2012a (Continued)

edge of the results of

the index tests?

\begin{tabular}{lll}
\hline & High & Low \\
\hline
\end{tabular}

\section{DOMAIN 4: Flow and Timing}

Was there an appropri- Yes

ate interval between in-

dex test and reference

standard?

\section{Did all patients receive Unclear}

the same reference

standard?

Were all patients in-

No

cluded in the analysis?

High

\section{Villemagne 2011}

\section{Study characteristics}

Patient sampling $\quad \mathrm{MCl}$ and DAT participants were recruited from the Austin Health Memory Disorders Clinic. Controls were recruited by advertisement and from the Melbourne Healthy Aging Study. We only included data on performance of the index test to discriminate between patients with $\mathrm{MCl}$ who convert to dementia and those who remained stable..

No further details on recruitment are presented. No inclusion or exclusion criteria are described

Patient characteristics and setting
$67 \mathrm{MCl}$ participants diagnosed by the Petersen 1999 criteria. Demographic data were reported for $65 \mathrm{MCl}$ participants who were further classified as a amnestic $\mathrm{MCl}(n=53)$ or nonamnestic $\mathrm{MCl}$ (4 nonamnestic single domain and 8 nonamnestic multiple domain)

Gender: 36 male, 29 female

Age: $73.4 \pm 8.5$ years

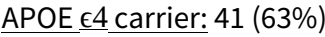

MMSE: $26.5 \pm 2.9$

Years of education: $12.2 \pm 4.3$

Sources of referral: mixed: advertisements and the Melbourne Healthy Aging Study

Setting: secondary care - outpatients (memory clinic)

Index tests
Standardized uptake values (SUVS) for PiB were calculated for all brain regions examined and SUV ratios (SUVRS) were generated by dividing all regional SUVs by the cerebellar cortex SUV. ROI measurements were averaged across both hemispheres. Neocortical Ab burden was expressed as the average SUVR of the area-weighted mean of frontal, and posterior cingulate regions

Time between PIB injection and PET acquisition: 40 minutes

PIB administration dose: $370 \mathrm{MBq}$

${ }^{11}$ C-PIB-PET for the early diagnosis of Alzheimer's disease dementia and other dementias in people with mild cognitive impairment (MCI) 
Villemagne 2011 (Continued)

Threshold: neocortical standardised uptake values ratio (SUVR) > 1.5 (PIB retention detecting regions: global cortex). To define a PiB SUVR cut-off, a hierarchical cluster analysis was performed on all healthy controls. Threshold determined at baseline and was consistent with cutoff values used in previous PIBPET studies (Bourgeat 2010; Jack 2008)

Index test was conducted at baseline

Target condition and reference standard(s)
Target condition: Alzheimer's disease dementia and other forms of dementia

Reference standard: NINCDS-ADRDA criteria for Alzheimer's disease dementia. Neurologist and a neuropsychologist conducting follow-up blind to PIB status

Reference standards for VD and FTD not reported

Flow and timing Duration of follow-up: mean was $20 \pm 3$ months.

All participants received the same reference standard

Number included in analysis: $65 \mathrm{MCl}: 45$ 'amyloid positive': $30 \mathrm{MCl}-\mathrm{AD}, 15 \mathrm{MCl}-\mathrm{MCl} ; 20$ 'amyloid negative': 5 converters (1 MCI-AD; 1 MCI-VD; 1 MCI-FTD; 2 LBD); 15 non-converters (13 MCl-MCl; 2 MCl-HC)

Conversion from MCl to AD: $45 \mathrm{PIB}+: 30 \mathrm{MCl}$-converters (MCl-AD) and $15 \mathrm{MCl}$-non-converter (MCl-MCl); 20 PIB-: $1 \mathrm{MCl}$-converter (MCI-AD) and 19 MCl-non-converters (1 MCI-VD; $1 \mathrm{MCl}-\mathrm{FTD} ; 2$ LBD; $13 \mathrm{MCl}-\mathrm{MCl}$; $2 \mathrm{MCl}$ $\mathrm{HC})$

$\mathrm{TP}=30 ; \mathrm{FP}=15 ; \mathrm{FN}=1 ; \mathrm{TN}=19$

Conversion from $\mathrm{MCl}$ to all dementia: $45 \mathrm{PIB}+: 30 \mathrm{MCl}$-converters and $15 \mathrm{MCl}$ non-converter; $20 \mathrm{PIB}$-: $5 \mathrm{MCl}$ converters (1 MCI-AD; $1 \mathrm{MCI}-\mathrm{VD} ; 1 \mathrm{MCI}-\mathrm{FTD} ; 2 \mathrm{LBD}$ ) and $15 \mathrm{MCl}$ - non-converters. Two out of seven MCI-nonconverters converted to 'cognitively improved' and five remained stable

$\mathrm{TP}=30 ; \mathrm{FP}=15 ; \mathrm{FN}=5 ; \mathrm{TN}=15$

Loss to follow-up: $2 \mathrm{MCl}$ participants: 1 participant was withdrawn by their caregivers and 1 participant was not contactable

Comparative

Notes

\section{Methodological quality}

\begin{tabular}{llll}
\hline Item & Authors' judgement & Risk of bias & Applicability concerns
\end{tabular}

\section{DOMAIN 1: Patient Selection}

Was a consecutive or Unclear
random sample of patients enrolled?

\section{Was a case-control de- Yes}

sign avoided?

Did the study avoid in- Unclear

appropriate exclusions?

Unclear

Low

\section{DOMAIN 2: Index Test All tests}

${ }^{11} \mathrm{C}$-PIB-PET for the early diagnosis of Alzheimer's disease dementia and other dementias in people with mild cognitive impairment (MCI) 
Villemagne 2011 (Continued)

Were the index test re-

Yes sults interpreted without knowledge of the results of the reference standard?

If a threshold was used, Yes was it pre-specified?

\begin{tabular}{l}
\hline Low \\
\hline DOMAIN 3: Reference Standard \\
\hline $\begin{array}{l}\text { Is the reference stan- } \\
\text { dards likely to correctly } \\
\text { classify the target con- } \\
\text { dition? }\end{array}$ \\
$\begin{array}{l}\text { Were the reference } \\
\text { standard results inter- } \\
\text { preted without knowl- } \\
\text { edge of the results of } \\
\text { the index tests? }\end{array}$ \\
\hline
\end{tabular}

\section{DOMAIN 4: Flow and Timing}

Was there an appropri- Yes

ate interval between in-

dex test and reference

standard?

Did all patients receive Yes

the same reference

standard?

Were all patients in-

No

cluded in the analysis?

Low

Wolk 2009

\section{Study characteristics}

Patient sam- $\quad$ Twenty-six patients with $\mathrm{MCl}, 22$ patients with mild Alzheimer's disease and 35 healthy elderly participants. The pling clinical diagnosis for those who entered the University of Pittsburgh Alzheimer's Disease Research Center (ADRC) was made through consensus at a conference. The conference was attended by neurologists, psychiatrists, and neuropsychologists experienced in the diagnosis of dementia. Assessment included medical and neurological history and examination, a semi-structured psychiatric evaluation, and psychometric testing.

We only included data on performance of the index test to discriminate between patients with $\mathrm{MCl}$ who convert to dementia and those who remained stable. $\mathrm{MCl}$ participants were recruited from ADRC. Nine participants already had PiB PET data. No further details of recruitment were reported.

Inclusion criteria: age 40 years or older, proficient English speaker, and a reliable caregiver

${ }^{11} \mathrm{C}$-PIB-PET for the early diagnosis of Alzheimer's disease dementia and other dementias in people with mild cognitive impairment (MCI) 
Wolk 2009 (Continued)

Exclusion criteria: lifetime history of schizophrenia, manic-depressive disorder, or schizoaffective disorder; prior electroconvulsive therapy; current substance abuse/dependence or within 2 years of symptom onset; and any medical condition that could affect neuropsychological testing

Patient characteristics and setting
$26 \mathrm{MCl}$ participants diagnosed by the Petersen 2004 and modified Petersen (Winblad 2004) criteria. MCl-multiple cognitive domain cases were reviewed and subdivided according to the Gauthier et al. scheme (Gauthier 2008). No strict cutoffs on psycho-metric testing were used. Impairment was "generally" less than 1.5 SDs of University of Pittsburgh ADRC age-adjusted norms (13 single-domain amnestic-MCl; 6 multi-domain a-MCl; 7 non-amnestic $\mathrm{MCl}$ ). The clinicians were aware of the previous year's diagnosis at follow-up consensus discussions

Gender: total 7 female and 19 male; 3 of 19 amnestic- $\mathrm{MCl}$ is female, 4 of 7 nonamnestic- $\mathrm{MCl}$ is female

Age: total $70.2 \pm 8.8$ years; amnestic- $\mathrm{MCl}$ is $71.6 \pm 8.0$, noamnestic- $\mathrm{MCl}$ is $69.6 \pm 9.2$

$\underline{\mathrm{APOE}} \in 4$ carrier: total 14 APOE 4 carrier; 9 out of 11 a-MCI Amyloid-Positive; 4 out of 8 a-MCl Amyloid-Negative; 0 out of 3 na-MCIAmyloid-Positive; 1 out of 3 na-MCIAmyloid-Negative. One a-MCI patient did not have ApoE results available

MMSE: total $27.3 \pm 1.9$ (calculated by $\mathrm{ZS}$ ); amnestic-MCI is $27.2 \pm 2.1$; noamnestic- $\mathrm{MCl}$ is $27.7 \pm 1.1$

Education: mean $16.6 \pm 3.3$ years for a-MCl; mean $18.7 \pm 2.6$ years for na-MCl

Sources of referral: not reported

Setting: tertiary setting - Pittsburg Alzheimer's Disease Research Center

Index tests PET imaging was conducted on a Siemens/CTI ECAT HR+(Siemens, Erlangen, Germany). The scanner was equipped with Neuro-insert (CTI PET Systems, Knoxville, TN) to reduce the contribution of scattered photons

Time between PIB injection and PET acquisition: 90 minutes for DVR; 40-60 minutes for SUR

\section{PIB administration dose: $14.3 \pm 2.2 \mathrm{mCi}$}

Threshold:DVR or SUR of region of interest > upper-inner fence of the control subjects. To avoid a strict cutoff, authors defined an intermediate range $2.5 \%$ greater than and less than this cutoff (Aizenstein 2008). Subjects who had a PiB DVR value exceeding the intermediate range in any ROI was defined as amyloid-positive, and those under the intermediate range were defined as amyloid-negative. For the two $\mathrm{MCl}$ patients who did not have DVR values SUV ratios were used to determine cutoffs (these are not described). Threshold determined at baseline.

ROIs were defined on a co-registered magnetic resonance image, as described previously (Price 2005); these included frontal, anterior cingulate, precuneus, lateral temporal, parietal, medial temporal, occipital, and sensorimotor cortices, anterior ventral striatum, subcortical white matter, and pons. A cerebellar ROI served as reference region, and the pons and subcortical white matter ROIs were measures of nonspecific ligand retention. Scanning was performed within approximately 6 months of ADRC evaluation (mean SD, $14.9 \pm 7.3$ weeks)

Index test was conducted at baseline and the results were available for all participants

\section{Target condi- Target condition: conversion from MCl to Alzheimer's disease dementia}

tion and ref-

erence stan-

$\operatorname{dard}(\mathrm{s})$

Reference standard: the clinical diagnosis was made through consensus at a conference, attended by neurologists, psychiatrists and neuropsychologists experienced in the diagnosis of dementia

It was not reported whether the reference standard results were interpreted without knowledge of the results of the index test

\section{Flow and tim- Duration of follow-up: mean $21.2 \pm 16.0$ months subsequent to their PiB scan}

ing

All participants received the same reference standard

Number included in analysis: $23 \mathrm{MCl}: 13$ 'amyloid positive': $5 \mathrm{MCl}-\mathrm{AD}, 8 \mathrm{MCl}-\mathrm{MCl}$; 10 'amyloid negative': $0 \mathrm{MCl}-\mathrm{AD}$; 10 non-converters (7 MCl-MCl; $3 \mathrm{MCl}$-normal)

$T P=5 ; F P=8 ; F N=0 ; T N=10$

${ }^{11} \mathrm{C}$-PIB-PET for the early diagnosis of Alzheimer's disease dementia and other dementias in people with mild cognitive impairment (MCI) 
Wolk 2009 (Continued)

Loss to follow-up: $3 \mathrm{MCl}$ participants; they did not have follow-up assessment; two of those patients did not complete the entire protocol

\section{Comparative}

\section{Notes}

\section{Methodological quality}

\begin{tabular}{llll}
\hline Item & Authors' judgement & Risk of bias & Applicability concerns \\
\hline
\end{tabular}

\section{DOMAIN 1: Patient Selection}

Was a consecu- Unclear

tive or random

sample of pa-

tients enrolled?

\begin{tabular}{ll}
\hline $\begin{array}{l}\text { Was a case- } \\
\text { control design } \\
\text { avoided? }\end{array}$ & Yes \\
\hline $\begin{array}{l}\text { Did the study } \\
\text { avoid inappro- } \\
\text { priate exclu- } \\
\text { sions? }\end{array}$ & \\
\end{tabular}

\begin{tabular}{lll}
\hline & Unclear & Low \\
\hline
\end{tabular}

\section{DOMAIN 2: Index Test All tests}

\section{Were the index Yes}

test results in-

terpreted with-

out knowledge

of the results of

the reference

standard?

If a threshold Yes
was used, was
it pre-speci-
fied?

\begin{tabular}{lll}
\hline & Low & Low \\
\hline
\end{tabular}

\section{DOMAIN 3: Reference Standard}

Is the reference Unclear
standards like-
ly to correctly
classify the tar-
get condition?

Were the refer- Unclear
ence standard
results inter-
preted without
knowledge of

${ }^{11} \mathrm{C}$-PIB-PET for the early diagnosis of Alzheimer's disease dementia and other dementias in people with mild cognitive impairment (MCI) 
Wolk 2009 (Continued)

the results of

the index tests?

\begin{tabular}{lll}
\hline & High & Low \\
\hline
\end{tabular}

\title{
DOMAIN 4: Flow and Timing
}

\begin{abstract}
Was there an
appropriate in-

terval between

index test and

reference stan-

dard?
\end{abstract}

Yes

Did all patients Yes

receive the

same reference

standard?

\section{Were all pa- No}

tients included

in the analysis?

Low

\section{Characteristics of excluded studies [ordered by study ID]}

\begin{tabular}{ll}
\hline Study & Reason for exclusion \\
\hline Choo 2011 & $\begin{array}{l}\text { Target condition: not looking at conversion from MCl to dementia. The focus of the study is the an- } \\
\text { nual change in PIB retention }\end{array}$
\end{tabular}

Driscoll 2011

Target condition: not looking at conversion from MCl to dementia

Ellis $2010 \quad$ Target condition: not looking at conversion from MCl to dementia

\begin{tabular}{ll}
\hline Fagan 2007 & Index test: PIB-PET test performed at follow-up \\
& Target condition: not looking at conversion from MCI to dementia
\end{tabular}

\begin{tabular}{ll}
\hline Kadir 2012 & Target condition: not looking at conversion from MCl to dementia \\
\hline Kadir 2012a & Target condition: not looking at conversion from MCl to dementia \\
\hline Resnick 2010 & $\begin{array}{l}\text { Target condition: not looking at conversion from MCl to dementia. The focus of the study is the as- } \\
\text { sociation abeta deposition and cognitive decline }\end{array}$ \\
\hline
\end{tabular}

Rowe $2010 \quad$ Target condition: not looking at conversion from MCI to dementia

Shinotoh $2011 \quad \begin{aligned} & \text { Index test: threshold not used } \\ & \text { Target condition: not looking at conversion from MCI to dementia. The focus of the study is the } \\ & \text { change in PIB retention over time }\end{aligned}$

Sojkova 2008 Participants: 28 non-demented subjects; only 6 participants with mild cognitive impairment $(\mathrm{CDR}=0.5)$ at baseline

${ }^{11} \mathrm{C}$-PIB-PET for the early diagnosis of Alzheimer's disease dementia and other dementias in people with mild cognitive impairment (MCI)

Copyright $\odot 2014$ The Cochrane Collaboration. Published by John Wiley \& Sons, Ltd. 


\begin{tabular}{ll}
\hline Study & Reason for exclusion \\
\hline & $\begin{array}{l}\text { Target condition: not looking at conversion to dementia. The focus of the study is the annual } \\
\text { change in PIB retention in high and low PIB retention groups }\end{array}$ \\
\hline Sojkova 2011 & $\begin{array}{l}\text { Target condition: not looking at conversion from MCI to dementia. The focus of the study is the an- } \\
\text { nual change in PIB retention over time }\end{array}$ \\
\hline
\end{tabular}

Characteristics of ongoing studies [ordered by study ID]

DeKosky 2006

Trial name or title Human amyloid-imaging studies with Pittsburgh Compound-B in Mild Cognitive Impairment $(\mathrm{MCl})$ : Is $\mathrm{MCl}$ the critical period of amyloid plaque deposition?

\begin{tabular}{ll}
\hline $\begin{array}{l}\text { Target condition and reference } \\
\text { standard(s) }\end{array}$ & $\begin{array}{l}\text { Target condition: conversion from MCl to Alzheimer's disease dementia } \\
\text { Reference standard: not reported }\end{array}$ \\
\hline Index and comparator tests & 11C-PIB-PET \\
\hline Starting date & not reported \\
\hline Contact information & sd3zc@hscmail.mcc.virginia.edu \\
\hline Notes & \\
\hline
\end{tabular}

\section{A T A}

Presented below are all the data for all of the tests entered into the review.

\section{Table Tests. Data tables by test}

\begin{tabular}{llc}
\hline Test & No. of studies & No. of participants \\
\hline $1^{11}$ C-PIB-PET AD dementia & 9 & 274 \\
\hline $2^{11}$ C-PIB-PET All dementia & 4 & 117 \\
\hline
\end{tabular}

Test 1. 11C-PIB-PET AD dementia.

Test 2. 11C-PIB-PET All dementia.

\section{ADDITIONAL TABLES}

${ }^{11} \mathrm{C}$-PIB-PET for the early diagnosis of Alzheimer's disease dementia and other dementias in people with mild cognitive impairment (MCI) 


\begin{tabular}{|c|c|c|c|c|c|c|c|c|}
\hline Study & $\begin{array}{l}\text { N/ Age } \\
n\end{array}$ & $\begin{array}{l}\text { Gender } \\
M(\%)\end{array}$ & $\begin{array}{l}\text { MMSE APOE } \varepsilon 4 \\
\text { score carrier } \\
(\%)\end{array}$ & $\begin{array}{l}\text { Years of edu- } \\
\text { cation/ } \\
\text { Verhage's } \\
\text { classifica- } \\
\text { tion` }\end{array}$ & $\begin{array}{l}\text { MCI diagnos- } \\
\text { tic criteria }\end{array}$ & Sampling & Sources of referral & Setting \\
\hline $\begin{array}{l}\text { Forsberg } 2010 \\
\text { (Sweden) }\end{array}$ & $\begin{array}{c}21 / 2163.3 \\
\pm \\
7.8\end{array}$ & $8(38.1)$ & $28.2 \pm 1.44(66.7)$ & $12.7 \pm 3.1$ & Winblad 2004 & $\begin{array}{l}\text { Not re- } \\
\text { ported }\end{array}$ & $\begin{array}{l}\text { Primary care centers } \\
\text { in community }\end{array}$ & Secondary care: outpatients \\
\hline $\begin{array}{l}\text { Grimmer } 2013 \text { (Ger- } \\
\text { many) }\end{array}$ & $28 / 2867.9 \pm$ & $.44(50)$ & $\begin{array}{r}26.0 \pm 3 . \mathbb{Q} \text { ot re- } \\
\text { ported }\end{array}$ & $\begin{array}{l}11.8 \pm 2.2 \\
\text { (range 8-17) }\end{array}$ & $\begin{array}{l}\text { CDR }=0.5 \text { and } \\
\text { Winbald } 2004\end{array}$ & $\begin{array}{l}\text { Not re- } \\
\text { ported }\end{array}$ & $\begin{array}{l}\text { GP surgeries or spe- } \\
\text { cialists or other insti- } \\
\text { tutions }\end{array}$ & Secondary care: outpatients \\
\hline Jack 2010 (USA) & $53 / 5375$ & $\begin{array}{l}\text { Not re- } \\
\text { ported }\end{array}$ & $\begin{array}{l}\text { Not re- } \\
\text { ported }\end{array}$ & 16 & Petersen 2010 & $\begin{array}{l}\text { ADNI par- } \\
\text { ticipants }\end{array}$ & Mixed & Mixed: 13 different sites \\
\hline $\begin{array}{l}\text { Koivunen } 2011 \text { (Fin- } \\
\text { land) }\end{array}$ & $\begin{array}{c}29 / 2971.3 \\
\pm \\
6.4\end{array}$ & $18(62.1)$ & $26.9 \pm 1.67(58.6)$ & Not reported & Petersen 2004 & $\begin{array}{l}\text { Consecu- } \\
\text { tive sam- } \\
\text { ple }\end{array}$ & Not reported & $\begin{array}{l}\text { Secondary care: outpatients: } \\
\text { memory clinic: }\end{array}$ \\
\hline $\begin{array}{l}\text { Okello } 2009 \text { (UK/ } \\
\text { Finland) }\end{array}$ & $\begin{array}{c}31 / 3169.4 \\
\pm \\
7.9\end{array}$ & $19(61.3)$ & $\begin{array}{r}27.5 \pm 1 . \text { Bot re- } \\
\text { ported }\end{array}$ & Not reported & Petersen 2010 & $\begin{array}{l}\text { Not re- } \\
\text { ported }\end{array}$ & Not reported & Secondary care: inpatients \\
\hline $\begin{array}{l}\text { *Ossenkoppele } \\
2012 \text { (Netherland) }\end{array}$ & $15 / 1267 \pm 7$ & $\begin{array}{l}\text { Not re- } \\
\text { ported }\end{array}$ & $\begin{aligned} & 27 \pm 3 \text { Not re- } \\
& \text { ported }\end{aligned}$ & $\begin{array}{l}\text { median } 6 \\
(\text { range } 3-7)^{\star}\end{array}$ & Petersen 2001 & $\begin{array}{l}\text { Not re- } \\
\text { ported }\end{array}$ & Not reported & Not reported \\
\hline $\begin{array}{l}\text { Ossenkoppele } \\
\text { 2012a (Netherland) }\end{array}$ & $30 / 1264 \pm 9$ & $\begin{array}{l}\text { Not re- } \\
\text { ported }\end{array}$ & $\begin{aligned} & 27 \pm 2 \text { Not re- } \\
& \text { ported }\end{aligned}$ & Not reported & Petersen 1999 & $\begin{array}{l}\text { Not re- } \\
\text { ported }\end{array}$ & Not reported & $\begin{array}{l}\text { Secondary care: outpatients: } \\
\text { memory clinic: }\end{array}$ \\
\hline $\begin{array}{l}\text { Villemagne } 2011 \\
\text { (Australia) }\end{array}$ & $67 / 6573.4 \pm \varepsilon$ & $3.36(55.4)$ & $26.5 \pm 2.91(63)$ & $12.2 \pm 4.3$ & Petersen 1999 & $\begin{array}{l}\text { Not re- } \\
\text { ported }\end{array}$ & $\begin{array}{l}\text { Mixed (advertise- } \\
\text { ments and the Mel- } \\
\text { bourne Healthy Ag- } \\
\text { ing Study }\end{array}$ & $\begin{array}{l}\text { Secondary care: outpatients: } \\
\text { memory clinic: }\end{array}$ \\
\hline Wolk 2009 (USA) & $26 / 2370.2 \pm \varepsilon$ & $\begin{array}{l}\text { Mot re- } \\
\text { ported }\end{array}$ & $\begin{array}{r}27.3 \pm 1 . \text { Hot re- } \\
\text { ported }\end{array}$ & $17.2 \pm 3.2$ & $\begin{array}{l}\text { Petersen } \\
\text { 2004; Winbald } \\
2004\end{array}$ & $\begin{array}{l}\text { Not re- } \\
\text { ported }\end{array}$ & Not reported & $\begin{array}{l}\text { Tertiary setting: Pittsburg } \\
\text { ADRC }\end{array}$ \\
\hline
\end{tabular}




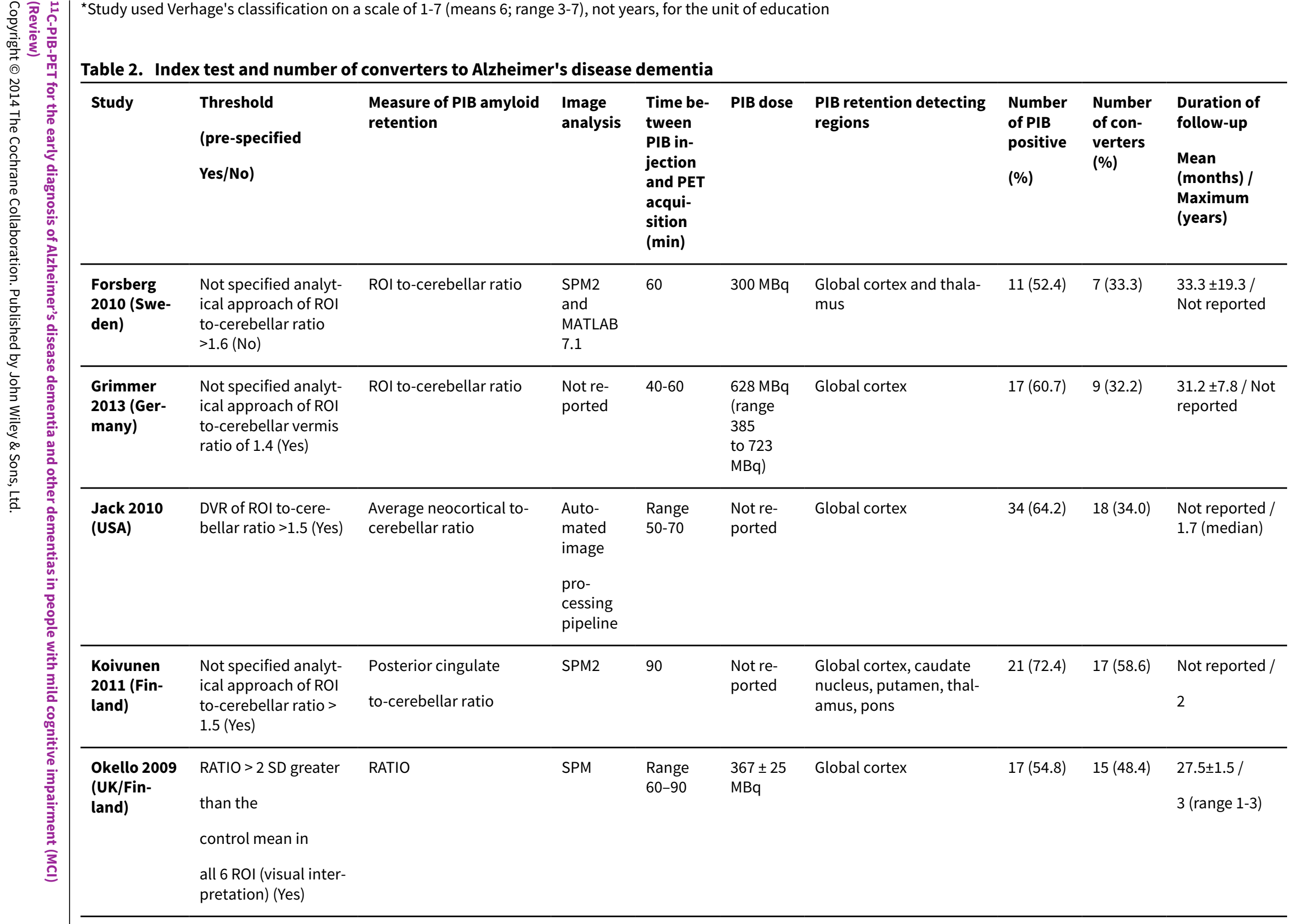




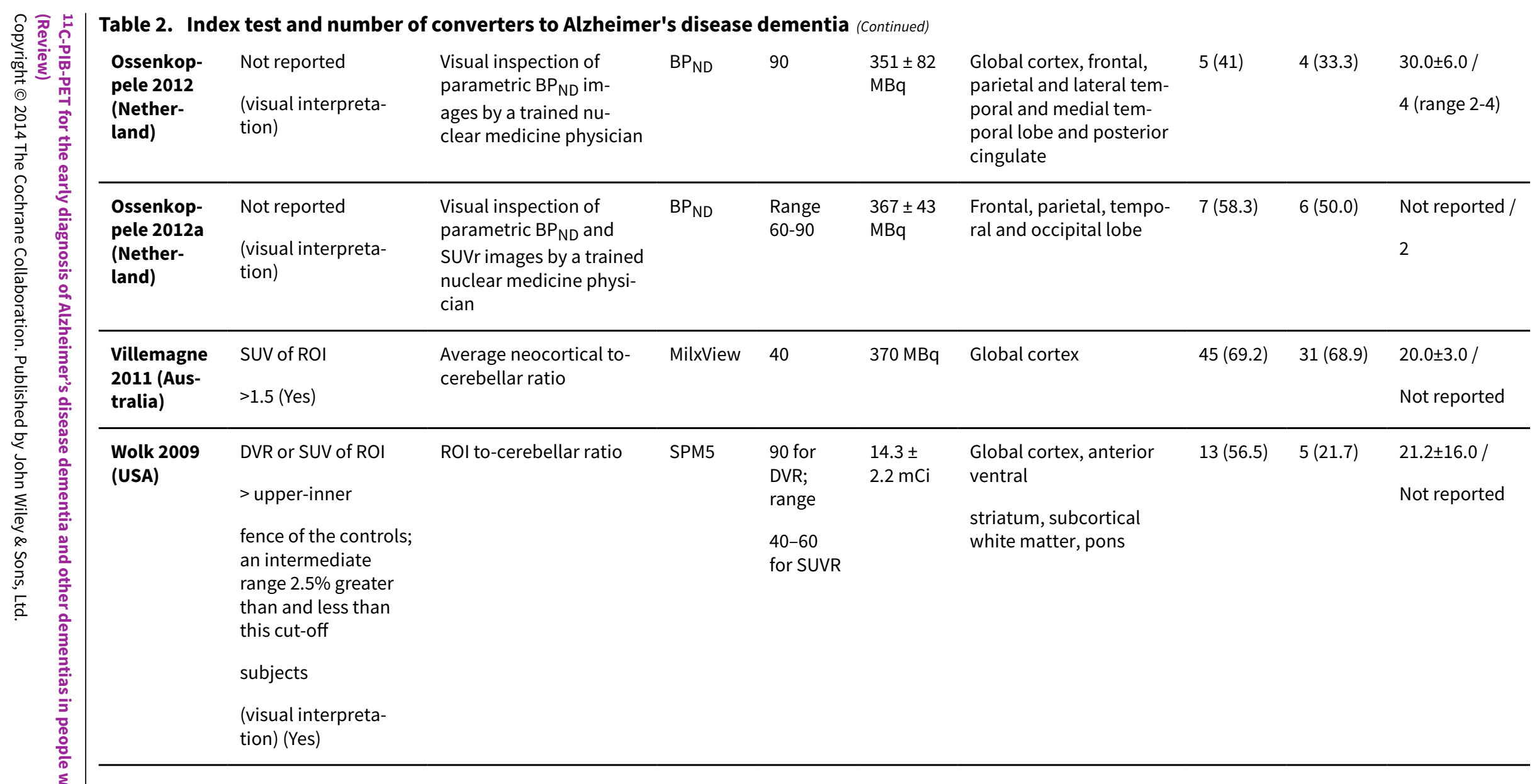


Table 3. Index test: Criteria for quantitative or visual interpretation and PIB retention in brain ROI areas

\section{Threshold for a positive PIB-PET test}

\section{Quantitative interpretation:}

1. DVR (Distribution Volume Ratio) of ROI: >1.5 ( $n=1)$

2. SUVR (Standardised Uptake Volume ratio) of ROI: > 1.5 ( $n=1)$

3. Not specified analytical approach of ROI: $1.4 ;>1.5 ;>1.6(n=3)$

\section{Visual interpretation:}

1. RATIO > 2SD than control mean in 6 ROI $(n=1)$

2. DVR or SVR of ROI > upper-inner fence of the control $(n=1)$

3. Threshold not reported in 2 studies

\begin{tabular}{|c|c|}
\hline Measure of PIB amyloid retention & PIB retention in brain areas ( $\mathrm{ROI})$ \\
\hline \multirow[t]{3}{*}{ 1. ROI to cerebellar ratio $(n=3)$} & Global cortex \\
\hline & Global cortex and thalamus \\
\hline & Global cortex, anterior ventral striatum, subcortical white matter, pons \\
\hline 2. Average neocortical to cerebellar ratio $(n=2)$ & Global cortex \\
\hline 3. Posterior cingulate to cerebellar ratio $(n=1)$ & Global cortex, caudate nucleus, putamen, thalamus, pons \\
\hline 4. RATIO $(n=1)$ & Global cortex \\
\hline 5. Visual inspection of parametric $B P_{N D}$ images $(n=1)$ & $\begin{array}{l}\text { Global cortex, frontal, parietal and lateral temporal and medial temporal } \\
\text { lobe and posterior cingulate }\end{array}$ \\
\hline $\begin{array}{l}\text { 6. Visual inspection of parametric } \mathrm{BP}_{\mathrm{ND}} \text { and SUVR im- } \\
\text { ages }(n=1)\end{array}$ & Frontal, parietal, temporal and occipital \\
\hline
\end{tabular}

Table 4. Sensitivity and likelihood ratios for ${ }^{11}$ C-PIB-PET at fixed values of specificity for Alzhemer's dementia

\begin{tabular}{lllll}
\hline Statistic & $\begin{array}{l}\text { Fixed } \\
\text { value of } \\
\text { specifici- } \\
\text { ty } \%\end{array}$ & $\begin{array}{l}\text { Estimated sensitivity \% } \\
\text { (95\% confidence inter- } \\
\text { val) }\end{array}$ & $\begin{array}{l}\text { Positive likelihood ratio (95\% } \\
\text { confidence interval) }\end{array}$ & $\begin{array}{l}\text { Negative likelihood ratio (95\% } \\
\text { confidence interval) }\end{array}$ \\
& & & &
\end{tabular}

\begin{tabular}{lcccc}
\hline \multicolumn{4}{l}{ All studies $(\mathbf{n}=\mathbf{9}$; cases $=$} & $\mathbf{1 1 2}$; non-cases $=\mathbf{1 6 2})$ \\
\hline Lower quartile & 56 & $96(88,99)$ & $2.19(2.09,2.29)$ & $0.07(0.02,0.23)$
\end{tabular}

${ }^{11 C-P I B-P E T ~ f o r ~ t h e ~ e a r l y ~ d i a g n o s i s ~ o f ~ A l z h e i m e r ' s ~ d i s e a s e ~ d e m e n t i a ~ a n d ~ o t h e r ~ d e m e n t i a s ~ i n ~ p e o p l e ~ w i t h ~ m i l d ~ c o g n i t i v e ~ i m p a i r m e n t ~(M C I) ~}$ 
Table 4. Sensitivity and likelihood ratios for 11C-PIB-PET at fixed values of specificity for Alzhemer's

\begin{tabular}{|c|c|c|c|c|}
\hline Jementia (Continued) & 58 & $96(87,99)$ & $2.29(2.17,2.41)$ & $0.07(0.02,0.24)$ \\
\hline Upper quartile & 81 & $89(68,97)$ & $4.66(4.03,5.39)$ & $0.14(0.05,0.44)$ \\
\hline \multicolumn{5}{|l|}{ Sensitivity analyses } \\
\hline \multicolumn{5}{|c|}{ Reference standard NINCDS-ADRDA only ( $n=7$; cases $=89 ;$ non-cases $=144)$} \\
\hline Lower quartile & 56 & $96(84,99)$ & $2.18(2.06,2.32)$ & $0.07(0.02,0.30)$ \\
\hline Median & 58 & $96(83,99)$ & $2.28(2.14,2.43)$ & $0.07(0.02,0.31)$ \\
\hline Upper quartile & 81 & $88(62,97)$ & $4.62(3.86,5.55)$ & $0.15(0.04,0.56)$ \\
\hline \multicolumn{5}{|c|}{ Threshold pre-specified $(n=7$; cases $=101$; non-cases $=140$ ) } \\
\hline Lower quartile & 56 & $95(84,99)$ & $2.16(2.02,2.30)$ & $0.09(0.03,0.30)$ \\
\hline Median & 58 & $94(83,98)$ & $2.25(2.10,2.41)$ & $0.10(0.03,0.32)$ \\
\hline Upper quartile & 81 & $85(61,95)$ & $4.46(3.67,5.42)$ & $0.19(0.06,0.55)$ \\
\hline
\end{tabular}

The middle $50 \%$ of specificities from the studies are between the lower and upper quartile, i.e. the interquartile range

\section{APPENDICES}

Appendix 1. Searches performed: January 2013, April 2012, September 2011

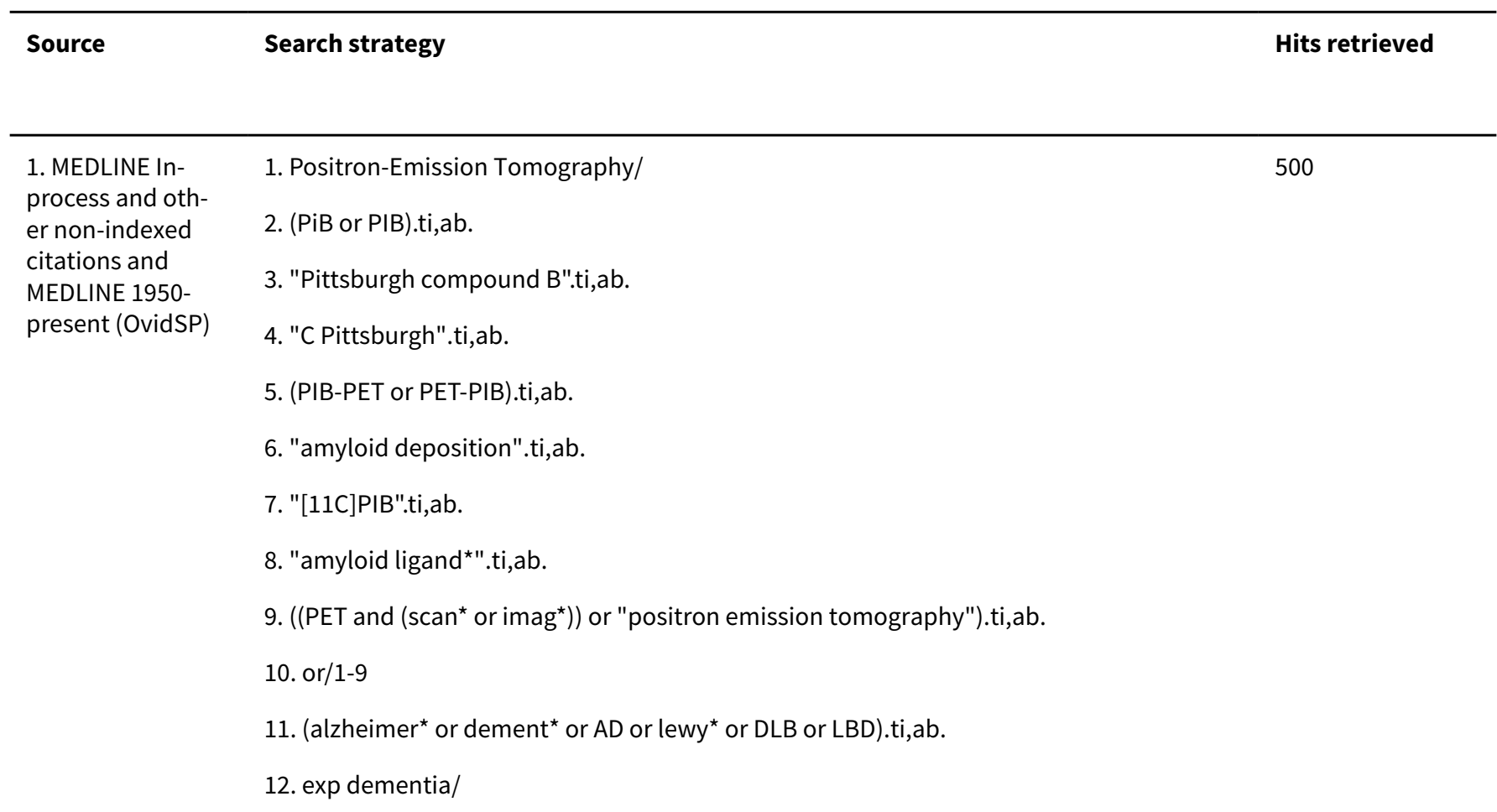

${ }^{11} \mathrm{C}$-PIB-PET for the early diagnosis of Alzheimer's disease dementia and other dementias in people with mild cognitive impairment (MCI) 
(Continued)

13. ((cognit* or memory or cerebr $^{*}$ or mental $\left.{ }^{\star}\right)$ adj3 (declin ${ }^{*}$ or impair ${ }^{\star}$ or los ${ }^{*}$ or deteriorat $^{\star}$ or degenerat* or complain* or disturb* or disorder $\left.\left.{ }^{\star}\right)\right) . t i, a b$.

14. MCl.ti,ab.

15. ACMI.ti,ab.

16. ARCD.ti,ab.

17. SMC.ti,ab.

18. CIND.ti,ab.

19. BSF.ti,ab.

20. AAMI.ti,ab.

21. LCD.ti,ab.

22. QD.ti,ab.

23. AACD.ti,ab.

24. MNCD.ti,ab

25. MCD.ti,ab.

26. (nMCl or aMCl or $\mathrm{mMCl})$.ti,ab.

27. ("N-MCI" or "A-MCI" or "M-MCI").ti,ab.

28. ("CDR 0.5 " or "clinical dementia rating scale 0.5 " or "0.5 CDR").ti,ab.

29. ("GDS 3" or "3 GDS").ti,ab.

30. ("global deterioration scale" and "stage 3").ti,ab.

31. or/11-30

32. 10 and 31

33. (animals not (humans and animals)).sh.

34. 32 not 33

35. $\left(2012^{\star}\right.$ or $\left.2013^{\star}\right) \cdot$ ed.

36. 34 and 35

2. (PiB or PIB).ti,ab. or pittsburgh compound B/

(OvidSP)

3. "Pittsburgh compound B".ti,ab.

4. "C Pittsburgh".ti,ab.

5. (PIB-PET or PET-PIB).ti,ab.

6. "amyloid deposition".ti,ab.

7. "[11C]PIB".ti,ab.

8. "amyloid ligand*".ti,ab.

${ }^{11}$ C-PIB-PET for the early diagnosis of Alzheimer's disease dementia and other dementias in people with mild cognitive impairment (MCI) 
9. ((PET and (scan* or imag $\left.\left.{ }^{\star}\right)\right)$ or "positron emission tomography").ti,ab.

10. or/1-9

11. (alzheimer ${ }^{\star}$ or dement ${ }^{\star}$ or AD or lewy* or DLB or LBD).ti,ab.

12. exp dementia/

13. ((cognit* or memory or cerebr* or mental $\left.^{\star}\right)$ adj3 (declin* or impair ${ }^{\star}$ or los ${ }^{\star}$ or deteriorat $^{\star}$ or degenerat* or complain ${ }^{\star}$ or disturb* or disorder $\left.\left.{ }^{\star}\right)\right) . t i, a b$.

14. $\mathrm{MCl} . \mathrm{ti}, \mathrm{ab}$.

15. ACMI.ti,ab.

16. ARCD.ti,ab.

17. SMC.ti,ab.

18. CIND.ti,ab.

19. BSF.ti,ab.

20. AAMI.ti,ab.

21. LCD.ti,ab.

22. QD.ti,ab.

23. AACD.ti,ab.

24. MNCD.ti,ab.

25. MCD.ti,ab.

26. (nMCl or aMCl or $\mathrm{mMCl}) . t i, a b$.

27. ("N-MCl" or "A-MCl" or "M-MCl").ti,ab.

28. ("CDR 0.5" or "clinical dementia rating scale 0.5 " or "0.5 CDR").ti,ab.

29. ("GDS 3" or "3 GDS").ti,ab.

30. ("global deterioration scale" and "stage 3").ti,ab.

31. or $/ 11-30$

32. 10 and 31

33. $\left(2012^{\star}\right.$ or $\left.2013^{\star}\right) \cdot$ em

34. 32 and 33

3. "Pittsburgh compound B".ti,ab.

4. "C Pittsburgh".ti,ab.

5. (PIB-PET or PET-PIB).ti,ab.

6. "amyloid deposition".ti,ab. 
(Continued)

7. "[11C]PIB".ti,ab.

8. "amyloid ligand*".ti,ab.

9. ((PET and (scan* or imag*)) or "positron emission tomography").ti,ab.

10. or/1-9

11. (alzheimer ${ }^{\star}$ or dement ${ }^{\star}$ or AD or lewy* or DLB or LBD).ti,ab.

12. exp dementia/

13. ((cognit* or memory or cerebr ${ }^{\star}$ or mental $\left.{ }^{\star}\right)$ adj3 (declin ${ }^{\star}$ or impair ${ }^{\star}$ or los ${ }^{\star}$ or deteriorat $^{\star}$ or degenerat $^{\star}$ or complain $^{\star}$ or disturb* or disorder $\left.\left.^{\star}\right)\right)$.ti,ab.

14. MCl.ti,ab.

15. ACMI.ti,ab.

16. ARCD.ti,ab.

17. SMC.ti,ab.

18. CIND.ti,ab.

19. BSF.ti,ab.

20. AAMI.ti,ab.

21. LCD.ti,ab.

22. QD.ti,ab.

23. AACD.ti,ab.

24. MNCD.ti,ab.

25. MCD.ti,ab.

26. (nMCl or aMCl or $\mathrm{mMCl}) . t \mathrm{ti}, \mathrm{ab}$.

27. ("N-MCl" or "A-MCl" or "M-MCl").ti,ab.

28. ("CDR 0.5" or "clinical dementia rating scale 0.5 " or "0.5 CDR").ti,ab.

29. ("GDS 3" or "3 GDS").ti,ab.

30. ("global deterioration scale" and "stage 3").ti,ab.

31. or $/ 11-30$

32. 10 and 31

33. $\left(2012^{\star}\right.$ or $\left.2013^{\star}\right) \cdot$ up.

34. 32 and 33

4. Biosis previews
(ISI Web of Knowl-
edge)

Topic=(PiB OR PIB OR "Pittsburgh compound B" OR "C Pittsburgh" OR "PiB-PET" OR ic=(alzheimer ${ }^{\star}$ OR AD OR dement ${ }^{\star}$ OR lewy OR VAD OR VCI OR cognit ${ }^{\star}$ OR MCI OR memory) AND Year Published $=(2012-2013)$

Timespan=All Years. Databases=BIOSIS Previews.

Lemmatization=On

${ }^{11}$ C-PIB-PET for the early diagnosis of Alzheimer's disease dementia and other dementias in people with mild cognitive impairment (MCI) 


\begin{tabular}{ll}
\hline 5. Web of Science & Topic=(PiB OR PIB OR "Pittsburgh compound B" OR "C Pittsburgh" OR "PiB-PET" OR \\
and conference & "PET-PiB" OR "amyloid ligand*" OR "[11C]PiB" OR "amyloid deposition") AND Top- \\
proceedings & ic=(alzheimer* OR AD OR dement* OR lewy OR VAD OR VCI OR cognit* OR MCI OR memo- \\
(1945-present) & ry) AND Year Published=(2012-2013) \\
& Timespan=All Years. Databases=SCI-EXPANDED, SSCI, A\&HCI, CPCI-S, CPCI-SSH. \\
& Lemmatization=On
\end{tabular}
6. LILACS (BIREME) PiB OR PIB OR "Pittsburgh compound B" OR "C Pittsburgh" OR PiB-PET OR PET-PiB OR 7 "amyloid ligand*" OR "amyloid deposition" [Words]

$\begin{array}{lr}\text { TOTAL before de-duplication } & 2737\end{array}$

\begin{tabular}{|c|c|c|}
\hline Source & Search strategy & Hits retrieved \\
\hline \multirow{13}{*}{$\begin{array}{l}\text { 1. MEDLINE In- } \\
\text { process and oth- } \\
\text { er non-indexed } \\
\text { citations and } \\
\text { MEDLINE 1950- } \\
\text { present (OvidSP) }\end{array}$} & 1. Positron-Emission Tomography/ & \multirow[t]{13}{*}{502} \\
\hline & 2. (PiB or PIB).ti,ab. & \\
\hline & 3. "Pittsburgh compound B".ti,ab. & \\
\hline & 4. "C Pittsburgh".ti,ab. & \\
\hline & 5. (PIB-PET or PET-PIB).ti,ab. & \\
\hline & 6. "amyloid deposition".ti,ab. & \\
\hline & 7. "[11C]PIB".ti,ab. & \\
\hline & 8. "amyloid ligand*".ti,ab. & \\
\hline & 9. ((PET and (scan* or imag*)) or "positron emission tomography").ti,ab. & \\
\hline & 10. or/1-9 & \\
\hline & 11. (alzheimer ${ }^{\star}$ or dement ${ }^{\star}$ or AD or lewy ${ }^{\star}$ or DLB or LBD).ti,ab. & \\
\hline & 12. exp dementia/ & \\
\hline & $\begin{array}{l}\left.\text { 13. ((cognit }{ }^{\star} \text { or memory or cerebr }{ }^{\star} \text { or mental }{ }^{\star}\right) \text { adj3 }\left(\text { declin }^{\star} \text { or impair }{ }^{\star} \text { or } \operatorname{los}^{\star} \text { or deterio- }\right. \\
\left.\left.\text { rat }^{\star} \text { or degenerat } \text { or complain }^{\star} \text { or disturb } \text { or disorder }^{\star}\right)\right) . t i, a b \text {. }\end{array}$ & \\
\hline
\end{tabular}

${ }^{11}$ C-PIB-PET for the early diagnosis of Alzheimer's disease dementia and other dementias in people with mild cognitive impairment (MCI) 
(Continued)

14. MCl.ti,ab.

15. ACMI.ti,ab.

16. ARCD.ti,ab.

17. SMC.ti,ab.

18. CIND.ti,ab.

19. BSF.ti,ab.

20. AAMI.ti,ab.

21. LCD.ti,ab.

22. QD.ti,ab.

23. AACD.ti,ab.

24. MNCD.ti,ab.

25. MCD.ti,ab.

26. (nMCl or aMCl or mMCl).ti,ab.

27. ("N-MCI" or "A-MCI" or "M-MCI").ti,ab.

28. ("CDR 0.5 " or "clinical dementia rating scale 0.5 " or "0.5 CDR").ti,ab.

29. ("GDS 3" or "3 GDS").ti,ab.

30. ("global deterioration scale" and "stage 3").ti,ab.

31. or/11-30

32. 10 and 31

33. (animals not (humans and animals)).sh.

34. 32 not 33

35. $\left(2011^{\star}\right.$ or $\left.2012^{\star}\right) \cdot$ ed

36.34 and 35

2. EMBASE

1. Positron-Emission Tomography/

1154

1980-2012 April $10 \quad$ 2. (PiB or PIB).ti,ab. or pittsburgh compound B/

(OvidSP)

3. "Pittsburgh compound B".ti,ab.

4. "C Pittsburgh".ti,ab.

5. (PIB-PET or PET-PIB).ti,ab.

6. "amyloid deposition".ti,ab.

7. "[11C]PIB".ti,ab.

8. "amyloid ligand*".ti,ab.

9. ((PET and (scan or imag*)) or "positron emission tomography").ti,ab.

10. or/1-9

${ }^{11}$ C-PIB-PET for the early diagnosis of Alzheimer's disease dementia and other dementias in people with mild cognitive impairment (MCI) 
11. (alzheimer ${ }^{\star}$ or dement ${ }^{\star}$ or AD or lewy ${ }^{\star}$ or DLB or LBD).ti,ab.

12. exp dementia/

13. ((cognit ${ }^{\star}$ or memory or cerebr ${ }^{\star}$ or mental $\left.{ }^{\star}\right)$ adj3 (declin ${ }^{\star}$ or impair ${ }^{\star}$ or los ${ }^{\star}$ or deteriorat $^{\star}$ or degenerat ${ }^{\star}$ or complain ${ }^{\star}$ or disturb* or disorder $\left.{ }^{\star}\right)$ ).ti,ab.

14. MCl.ti,ab.

15. ACMI.ti,ab.

16. ARCD.ti,ab.

17. SMC.ti,ab.

18. CIND.ti,ab.

19. BSF.ti,ab.

20. AAMI.ti,ab.

21. LCD.ti,ab

22. QD.ti,ab.

23. AACD.ti,ab.

24. MNCD.ti,ab.

25. MCD.ti,ab.

26. ( $\mathrm{nMCl}$ or aMCl or $\mathrm{mMCl}) \cdot$ ti, ab.

27. ("N-MCI" or "A-MCI" or "M-MCI").ti,ab.

28. ("CDR 0.5" or "clinical dementia rating scale 0.5 " or "0.5 CDR").ti,ab.

29. ("GDS 3" or "3 GDS").ti,ab.

30. ("global deterioration scale" and "stage 3").ti,ab.

31. or/11-30

32. 10 and 31

33. $\left(2011^{\star}\right.$ or $\left.2012^{\star}\right)$.em.

34. 32 and 33

2. (PiB or PIB).ti,ab. or pittsburgh compound B/

2012 (OvidSP)

3. "Pittsburgh compound B".ti,ab.

4. "C Pittsburgh".ti,ab.

5. (PIB-PET or PET-PIB).ti,ab.

6. "amyloid deposition".ti,ab.

7. "[11C]PIB".ti,ab.

8. "amyloid ligand*".ti,ab.

${ }^{11}$ C-PIB-PET for the early diagnosis of Alzheimer's disease dementia and other dementias in people with mild cognitive impairment (MCI) 
9. ((PET and (scan* or imag $\left.\left.{ }^{\star}\right)\right)$ or "positron emission tomography").ti,ab.

10. or/1-9

11. (alzheimer ${ }^{\star}$ or dement ${ }^{\star}$ or AD or lewy* or DLB or LBD).ti,ab.

12. exp dementia/

13. ((cognit* or memory or cerebr* or mental $\left.^{\star}\right)$ adj3 (declin* or impair ${ }^{\star}$ or los ${ }^{\star}$ or deteriorat $^{\star}$ or degenerat ${ }^{\star}$ or complain* or disturb* or disorder $\left.\left.{ }^{\star}\right)\right)$.ti,ab.

14. MCl.ti,ab.

15. ACMI.ti,ab.

16. ARCD.ti,ab.

17. SMC.ti,ab.

18. CIND.ti,ab.

19. BSF.ti,ab.

20. AAMI.ti,ab.

21. LCD.ti,ab.

22. QD.ti,ab.

23. AACD.ti,ab.

24. MNCD.ti,ab.

25. MCD.ti,ab.

26. ( $\mathrm{nMCl}$ or $\mathrm{aMCl}$ or $\mathrm{mMCl}) . t \mathrm{ti}$,ab.

27. ("N-MCI" or "A-MCI" or "M-MCI").ti,ab.

28. ("CDR 0.5" or "clinical dementia rating scale 0.5 " or "0.5 CDR").ti,ab.

29. ("GDS 3" or "3 GDS").ti,ab.

30. ("global deterioration scale" and "stage 3").ti,ab.

31. or/11-30

32. 10 and 31

33. $\left(2011^{\star}\right.$ or $\left.2012^{\star}\right) \cdot$ up.

34.32 and 33

4. Biosis previews
(ISI Web of Knowl-
edge)

Topic=(PiB OR PIB OR "Pittsburgh compound B" OR "C Pittsburgh" OR "PiB-PET" OR

"PET-PiB" OR "amyloid ligand*" OR "[11C]PiB" OR "amyloid deposition") AND Topic=(alzheimer ${ }^{\star}$ OR AD OR dement* OR lewy OR VAD OR VCI OR cognit* OR MCI OR memory) AND Year Published $=(2011-2012)$

Timespan=All Years. Databases=BIOSIS Previews.

Lemmatization=0n

${ }^{11} \mathrm{C}$-PIB-PET for the early diagnosis of Alzheimer's disease dementia and other dementias in people with mild cognitive impairment (MCI) 
(Continued)

\section{SMC.ti,ab.}

18. CIND.ti,ab.

19. BSF.ti,ab.

20. AAMI.ti,ab.

21. LCD.ti,ab.

22. QD.ti,ab.

23. AACD.ti,ab.

24. MNCD.ti,ab

25. MCD.ti,ab.

26. ( $\mathrm{nMCl}$ or aMCl or $\mathrm{mMCl}) \cdot$ ti, ab.

27. ("N-MCI" or "A-MCl" or "M-MCl").ti,ab.

28. ("CDR 0.5" or "clinical dementia rating scale 0.5 " or "0.5 CDR").ti,ab.

29. ("GDS 3" or "3 GDS").ti,ab.

30. ("global deterioration scale" and "stage 3").ti,ab.

31. or/11-30

32. $\left(2003^{\star}\right.$ or $2004^{\star}$ or $2005^{\star}$ or $2006^{\star}$ or $2007^{\star}$ or $2008^{\star}$ or $2009^{\star}$ or $2010^{\star}$ or $\left.2011^{\star}\right)$.ed.

33. 10 and 31 and 32

34. (animals not (humans and animals)).sh.

35.33 not 34

\section{EMBASE}

1. Positron-Emission Tomography/

1980-2011 week

2. (PiB or PIB).ti,ab. or pittsburgh compound B/

34 (OvidSP)

3. "Pittsburgh compound B".ti,ab.

4. "C Pittsburgh".ti,ab.

5. (PIB-PET or PET-PIB).ti,ab.

6. "amyloid deposition".ti,ab.

7. "[11C]PIB".ti,ab.

8. "amyloid ligand*".ti,ab.

9. ((PET and (scan* or imag*)) or "positron emission tomography").ti,ab.

10. or/1-9

11. (alzheimer ${ }^{\star}$ or dement ${ }^{\star}$ or AD or lewy* or DLB or LBD).ti,ab.

12. exp dementia/

13. ((cognit* or memory or cerebr ${ }^{\star}$ or mental $\left.{ }^{\star}\right)$ adj3 (declin ${ }^{\star}$ or impair ${ }^{\star}$ or los ${ }^{\star}$ or deteriorat $^{\star}$ or degenerat* or complain $^{\star}$ or disturb* or disorder $\left.\left.{ }^{\star}\right)\right) . t i, a b$.

14. MCl.ti,ab

${ }^{11} \mathrm{C}-\mathrm{PIB}-\mathrm{PET}$ for the early diagnosis of Alzheimer's disease dementia and other dementias in people with mild cognitive impairment (MCI) 
(Continued)

15. ACMI.ti,ab.

16. ARCD.ti,ab.

17. SMC.ti,ab.

18. CIND.ti,ab.

19. BSF.ti,ab.

20. AAMI.ti,ab.

21. LCD.ti,ab.

22. QD.ti,ab.

23. AACD.ti,ab.

24. MNCD.ti,ab.

25. MCD.ti,ab.

26. (nMCl or aMCl or $\mathrm{mMCl})$.ti,ab.

27. ("N-MCI" or "A-MCI" or "M-MCI").ti,ab.

28. ("CDR 0.5 " or "clinical dementia rating scale 0.5 " or "0.5 CDR").ti,ab.

29. ("GDS 3" or "3 GDS").ti,ab.

30. ("global deterioration scale" and "stage 3").ti,ab.

31. or/11-30

32. 10 and 31

33. $\left(2003^{\star}\right.$ or $2004^{\star}$ or $2005^{\star}$ or $2006^{\star}$ or $2007^{\star}$ or $2008^{\star}$ or $2009^{\star}$ or $2010^{\star}$ or $\left.2011^{\star}\right)$.em.

34. 32 and 33

35. limit 34 to human
3. PsycINFO
1. Positron-Emission Tomography/
1806-February
2. (PiB or PIB).ti,ab. or pittsburgh compound B/
week 22011
(OvidSP)
3. "Pittsburgh compound B".ti,ab.
4. "C Pittsburgh".ti,ab.
5. (PIB-PET or PET-PIB).ti,ab.
6. "amyloid deposition".ti,ab.
7. "[11C]PIB".ti,ab.
8. "amyloid ligand*".ti,ab.
9. ((PET and (scan* or imag*)) or "positron emission tomography").ti,ab.
10. or $/ 1-9$
11. (alzheimer ${ }^{\star}$ or dement ${ }^{\star}$ or AD or lewy* or DLB or LBD).ti,ab.
12. exp dementia/

${ }^{11} \mathrm{C}$-PIB-PET for the early diagnosis of Alzheimer's disease dementia and other dementias in people with mild cognitive impairment (MCI) 
(Continued)

13. ((cognit* or memory or cerebr $^{*}$ or mental $\left.{ }^{\star}\right)$ adj3 (declin ${ }^{*}$ or impair ${ }^{\star}$ or los ${ }^{*}$ or deteriorat $^{\star}$ or degenerat ${ }^{\star}$ or complain ${ }^{\star}$ or disturb* or disorder $\left.\left.{ }^{\star}\right)\right) . t i, a b$.

14. MCl.ti,ab.

15. ACMI.ti,ab.

16. ARCD.ti,ab.

17. SMC.ti,ab.

18. CIND.ti,ab.

19. BSF.ti,ab.

20. AAMI.ti,ab.

21. LCD.ti,ab.

22. QD.ti,ab.

23. AACD.ti,ab.

24. MNCD.ti,ab.

25. MCD.ti,ab.

26. (nMCl or aMCl or $\mathrm{mMCl})$.ti,ab.

27. ("N-MCI" or "A-MCI" or "M-MCI").ti,ab.

28. ("CDR 0.5 " or "clinical dementia rating scale 0.5 " or "0.5 CDR").ti,ab.

29. ("GDS 3" or "3 GDS").ti,ab.

30. ("global deterioration scale" and "stage 3").ti,ab.

31. or/11-30

32. 10 and 31

33. $\left(2003^{\star}\right.$ or $2004^{\star}$ or $2005^{\star}$ or $2006^{\star}$ or $2007^{\star}$ or $2008^{\star}$ or $2009^{\star}$ or $2010^{\star}$ or $\left.2011^{\star}\right)$.up.

34. 32 and 33
4. ISI Web of
Topic=(PiB OR PIB OR "Pittsburgh compound B" OR "C Pittsburgh" OR "PiB-PET" OR ic=(alzheimer ${ }^{*}$ OR AD OR dement* OR lewy OR VAD OR VCI OR cognit* OR MCI OR memo- (1926-present) ry) AND Year Published $=(2003-2011)$
Timespan=2003-2011. Databases=BIOSIS Previews
Lemmatization $=$ On

5. ISI Web of
Knowledge: Cita-
tion Databases:
Science Citation
Index Expanded
(SCI-EXPANDED);
Social Sciences
Citation Index

Topic=(PiB OR PIB OR "Pittsburgh compound B" OR "C Pittsburgh" OR "PiB-PET" OR "PET-PiB" OR "amyloid ligand*" OR "[11C]PiB" OR "amyloid deposition") AND Topic $=($ alzheimer* OR AD OR dement* OR lewy OR VAD OR VCI OR cognit* OR MCI OR memory) AND Year Published $=(2003-2011)$

Timespan=2003-2011. Databases=BIOSIS Previews.

Lemmatization=On

${ }^{11} \mathrm{C}$-PIB-PET for the early diagnosis of Alzheimer's disease dementia and other dementias in people with mild cognitive impairment (MCI) 
(Continued)

(SSCI); Arts \& Hu-

manities Citation

Index (A\&HCl);

Conference Pro-

ceedings Citation

Index-Science

(CPCl-S); Confer-

ence Proceedings

Citation Index- So-

cial Science \& Hu-

manities (CPCl-

$\mathrm{SSH})$

6. LILACs (BIREME) PiB OR PIB OR "Pittsburgh compound B" OR "C Pittsburgh" OR PiB-PET OR PET-PiB OR 187

"amyloid ligand*" OR "amyloid deposition" [Words]

7. Clinicaltrial-

s.gov (www.clini-

caltrials.gov)
$\# 1$ 11-C Pib $=3$

\#2 amyloid ligand OR amyloid ligands = 5

$\# 3$ radioligand $=38$

\#4 Pittsburgh compound $=27$

\section{Appendix 2. Two times two tables}

Table 1: Conversion from MCl to Alzheimer's disease dementia

\begin{tabular}{lll}
\hline Index test information & References standard information & \\
\cline { 2 - 3 } & ADD present & ADD absent \\
\hline Index test positive & PIB+ who convert to ADD (TP) & PIB+ who remain MCl (FP) \& PIB+ who convert to non-ADD (FP) \\
\hline Index test negative & PIB- who convert to ADD (FN) & PIB- who remain MCI (TN) \& PIB- who convert to non-ADD (TN) \\
\hline
\end{tabular}

Table 2: Conversion from MCI to non-Alzheimer's disease dementia

\begin{tabular}{lll}
\hline Index test information & References standard information & \\
\cline { 2 - 3 } & Non-ADD present & Non-ADD absent \\
\hline Index test positive & PIB+ who convert to non-ADD (TP) & PIB+ who remain MCI (FP) \& PIB+ who convert to ADD (FP) \\
\hline Index test negative & PIB- who convert to non-ADD (FN) & PIB- who remain MCI (TN) \& PIB- who convert to ADD (TN) \\
\hline
\end{tabular}

${ }^{11} \mathrm{C}-\mathrm{PIB}-\mathrm{PET}$ for the early diagnosis of Alzheimer's disease dementia and other dementias in people with mild cognitive impairment (MCI) 
Table 3: Conversion from $\mathrm{MCl}$ to any forms of dementia

\begin{tabular}{lll}
\hline Index test information & References standard information & Dementia absent \\
\cline { 2 - 3 } & Any forms of dementia present & PIB+ who remain MCI (FP) \\
\hline Index test positive & PIB+ who convert to any form of dementia (TP) & PIB- who remain MCI (TN) \\
\hline Index test negative & PIB- who convert to any form of dementia (FN) & \\
\hline
\end{tabular}

Appendix 3. Assessment of methodological quality table QUADAS-2 tool

\begin{tabular}{|c|c|c|c|c|}
\hline DOMAIN & PATIENT SELECTION & INDEX TEST & REFERENCE STANDARD & FLOW AND TIMING \\
\hline $\begin{array}{l}\text { Descrip- } \\
\text { tion }\end{array}$ & $\begin{array}{l}\text { Describe methods of pa- } \\
\text { tient selection: describe } \\
\text { included patients (prior } \\
\text { testing, presentation, in- } \\
\text { tended use of index test } \\
\text { and setting) }\end{array}$ & $\begin{array}{l}\text { Describe the index test } \\
\text { and how it was conduct- } \\
\text { ed and interpreted }\end{array}$ & $\begin{array}{l}\text { Describe the reference stan- } \\
\text { dard and how it was conduct- } \\
\text { ed and interpreted }\end{array}$ & $\begin{array}{l}\text { Describe any patients who } \\
\text { did not receive the index } \\
\text { test(s) and/or reference } \\
\text { standard or who were ex- } \\
\text { cluded from the } 2 \times 2 \text { table } \\
\text { (refer to flow diagram): de- } \\
\text { scribe the time interval and } \\
\text { any interventions between } \\
\text { index test(s) and reference } \\
\text { standard }\end{array}$ \\
\hline
\end{tabular}

\begin{tabular}{|c|c|c|c|c|}
\hline \multirow[t]{4}{*}{$\begin{array}{l}\text { Signalling } \\
\text { questions } \\
\text { (yes/no/ } \\
\text { unclear) }\end{array}$} & $\begin{array}{l}\text { Was a consecutive or ran- } \\
\text { dom sample of patients } \\
\text { enrolled? }\end{array}$ & $\begin{array}{l}\text { Were the index test re- } \\
\text { sults interpreted without } \\
\text { knowledge of the results } \\
\text { of the reference stan- } \\
\text { dard? }\end{array}$ & $\begin{array}{l}\text { Is the reference standard } \\
\text { likely to correctly classify the } \\
\text { target condition? }\end{array}$ & $\begin{array}{l}\text { Was there an appropriate } \\
\text { interval between index } \\
\text { test(s) and reference stan- } \\
\text { dard? }\end{array}$ \\
\hline & $\begin{array}{l}\text { Was a case-control design } \\
\text { avoided? }\end{array}$ & \multirow[t]{3}{*}{$\begin{array}{l}\text { If a threshold was used, } \\
\text { was it pre-specified? }\end{array}$} & \multirow{3}{*}{$\begin{array}{l}\text { Were the reference standard } \\
\text { results interpreted without } \\
\text { knowledge of the results of } \\
\text { the index test? }\end{array}$} & $\begin{array}{l}\text { Did all patients receive a } \\
\text { reference standard? }\end{array}$ \\
\hline & $\begin{array}{l}\text { Did the study avoid inap- } \\
\text { propriate exclusions? }\end{array}$ & & & $\begin{array}{l}\text { Did all patients receive the } \\
\text { same reference standard? }\end{array}$ \\
\hline & & & & $\begin{array}{l}\text { Were all patients included } \\
\text { in the analysis? }\end{array}$ \\
\hline $\begin{array}{l}\text { Risk of } \\
\text { bias: } \\
\text { High/low/ } \\
\text { unclear }\end{array}$ & $\begin{array}{l}\text { Could the selection of pa- } \\
\text { tients have introduced } \\
\text { bias? }\end{array}$ & $\begin{array}{l}\text { Could the conduct or in- } \\
\text { terpretation of the in- } \\
\text { dex test have introduced } \\
\text { bias? }\end{array}$ & $\begin{array}{l}\text { Could the reference stan- } \\
\text { dard, its conduct, or its inter- } \\
\text { pretation have introduced } \\
\text { bias? }\end{array}$ & $\begin{array}{l}\text { Could the patient flow have } \\
\text { introduced bias? }\end{array}$ \\
\hline $\begin{array}{l}\text { Concerns } \\
\text { regard- } \\
\text { ing applic- } \\
\text { ability: } \\
\text { High/low/ } \\
\text { unclear }\end{array}$ & $\begin{array}{l}\text { Are there concerns that } \\
\text { the included patients } \\
\text { do not match the review } \\
\text { question? }\end{array}$ & $\begin{array}{l}\text { Are there concerns that } \\
\text { the index test, its con- } \\
\text { duct, or interpretation } \\
\text { differ from the review } \\
\text { question? }\end{array}$ & $\begin{array}{l}\text { Are there concerns that the } \\
\text { target condition as defined } \\
\text { by the reference standard } \\
\text { does not match the review } \\
\text { question? }\end{array}$ & \\
\hline
\end{tabular}

${ }^{11}$ C-PIB-PET for the early diagnosis of Alzheimer's disease dementia and other dementias in people with mild cognitive impairment (MCI) 


\section{Appendix 4. Anchoring statements for quality assessment of PIB-PET diagnostic studies}

Table 4: Review question and inclusion criteria

\begin{tabular}{|c|c|c|}
\hline Category & Review Question & Inclusion Criteria \\
\hline Patients & $\begin{array}{l}\text { Participants with mild cognitive impair- } \\
\text { ment, no dementia }\end{array}$ & $\begin{array}{l}\text { Participants fulfilling the criteria for the clinical diagnosis of } \\
\mathrm{MCl} \text { at baseline }\end{array}$ \\
\hline Index Test & ${ }^{11} \mathrm{C}-\mathrm{PIB}-\mathrm{PET}$ biomarker & ${ }^{11} \mathrm{C}-\mathrm{PIB}-\mathrm{PET}$ biomarker \\
\hline \multirow[t]{2}{*}{ Target Condition } & $\begin{array}{l}\text { Alzheimer's disease dementia (conversion } \\
\text { from } \mathrm{MCl} \text { to Alzheimer's disease dementia) }\end{array}$ & $\begin{array}{l}\text { Alzheimer's disease dementia (conversion from MCl to } \\
\text { Alzheimer's disease dementia) }\end{array}$ \\
\hline & $\begin{array}{l}\text { Any other forms of dementia (conversion } \\
\text { from } \mathrm{MCl} \text { to any other forms of dementia }\end{array}$ & $\begin{array}{l}\text { Any other forms of dementia (conversion from } \mathrm{MCl} \text { to any other } \\
\text { forms of dementia) }\end{array}$ \\
\hline $\begin{array}{l}\text { Reference Stan- } \\
\text { dard }\end{array}$ & $\begin{array}{l}\text { NINCDS-ADRDA; DSM; ICD; McKeith criteria; } \\
\text { Lund criteria; NINDS-ARIEN criteria }\end{array}$ & $\begin{array}{l}\text { NINCDS-ADRDA; DSM; ICD; McKeith criteria; Lund criteria; } \\
\text { NINDS-ARIEN criteria }\end{array}$ \\
\hline Outcome & $\mathrm{N} / \mathrm{A}$ & Data to construct $2 \times 2$ table \\
\hline Study Design & $\mathrm{N} / \mathrm{A}$ & $\begin{array}{l}\text { - Longitudinal cohort studies and } \\
\text { - Nested case-control studies if they incorporate a delayed ver- } \\
\text { ification design (case-control nested in cohort studies) }\end{array}$ \\
\hline
\end{tabular}

\section{Anchoring statements for quality assessment of PIB-PET diagnostic studies}

We provide some core anchoring statements for quality assessment of diagnostic test accuracy review of the PIB-PET biomarker in dementia. These statements are designed for use with the QUADAS-2 tool and are based on the guidance for quality assessment of diagnostic test accuracy reviews of IQCODE in dementia (Quinn 2014)

During the two-day, multidisciplinary focus group and the piloting/validation of the guidance, it was clear that certain issues were key to assessing quality, while other issues were important to record but less important for assessing overall quality. To assist, we describe a 'weighting' system. Where an item is weighted 'high risk' then that section of the QUADAS-2 results table is likely to be scored as high risk of bias. For example in dementia diagnostic test accuracy studies, ensuring that clinicians performing dementia assessment are blinded to results of the index test is fundamental. If this blinding was not present then the item on the reference standard should be scored 'high risk of bias', regardless of the other contributory elements.

In assessing individual items, the score of unclear should only be given if there is genuine uncertainty. In these situations review authors will contact the relevant study teams for additional information.

Table 5: Anchoring statements to assist with assessment for risk of bias

\begin{tabular}{lll}
\hline Question & $\begin{array}{l}\text { Response and } \\
\text { weighting }\end{array}$ & Explanation \\
\hline Patient Selection & & \\
\hline $\begin{array}{l}\text { Was the sampling } \\
\text { method appropri- } \\
\text { ate? }\end{array}$ & No = high risk of bias & $\begin{array}{l}\text { Where sampling is used, the designs least likely to cause bias are consecutive sampling } \\
\text { or random sampling. Sampling that is based on volunteers or selecting subjects from a } \\
\text { clinic or research resource is prone to bias. }\end{array}$
\end{tabular}

${ }^{11} \mathrm{C}$-PIB-PET for the early diagnosis of Alzheimer's disease dementia and other dementias in people with mild cognitive impairment (MCI) 
(Continued)

Unclear = unclear

risk of bias

\begin{tabular}{|c|c|c|}
\hline $\begin{array}{l}\text { Was a case-control } \\
\text { or similar design } \\
\text { avoided? }\end{array}$ & $\begin{array}{l}\text { No }=\text { high risk of bias } \\
\text { Yes = low risk of bias } \\
\text { Unclear = unclear } \\
\text { risk of bias }\end{array}$ & $\begin{array}{l}\text { Designs similar to case control that may introduce bias are those designs where the study } \\
\text { team deliberately increase or decrease the proportion of subjects with the target condi- } \\
\text { tion, which may not be representative. Some case control methods may already be ex- } \\
\text { cluded if they mix subjects from various settings. }\end{array}$ \\
\hline $\begin{array}{l}\text { Are exclusion cri- } \\
\text { teria described } \\
\text { and appropriate? }\end{array}$ & $\begin{array}{l}\text { No }=\text { high risk of bias } \\
\text { Yes = low risk of bias } \\
\text { Unclear = unclear } \\
\text { risk of bias }\end{array}$ & $\begin{array}{l}\text { Study will be automatically graded unclear if exclusions are not detailed (pending con- } \\
\text { tact with study authors). Where exclusions are detailed, the study will be graded as "low } \\
\text { risk" if exclusions are felt to be appropriate by the review authors. Certain exclusions } \\
\text { common to many studies of dementia are: medical instability; terminal disease; alco- } \\
\text { hol/substance misuse; concomitant psychiatric diagnosis; other neurodegenerative con- } \\
\text { dition. Exclusions are not felt to be appropriate if 'difficult to diagnose' patients are ex- } \\
\text { cluded. Post hoc and inappropriate exclusions will be labelled "high risk" of bias. }\end{array}$ \\
\hline
\end{tabular}

\section{Index Test}

Was PIB-PET biomarker's assessment / interpretation performed without knowledge of clinical dementia diagnosis?
No $=$ high risk of bias

Yes $=$ low risk of bias

Unclear = unclear risk of bias

Terms such as "blinded" or "independently and without knowledge of" are sufficient and full details of the blinding procedure are not required. Interpretation of the results of the index test may be influenced by knowledge of the results of reference standard. If the index test is always interpreted prior to the reference standard then the person interpreting the index test cannot be aware of the results of the reference standard and so this item could be rated as 'yes'.

For certain index tests the result is objective and knowledge of reference standard should not influence result, for example level of protein in cerebrospinal fluid, in this instance the quality assessment may be "low risk" even if blinding was not achieved.

Were PIB-PET bio- $\quad$ No $=$ high risk of bias marker's thresholds pre-speciYes = low risk of bias

For scales and biomarkers there is often a reference point (in units or categories) above which subjects are classified as "test positive"; this may be referred to as threshold; clinical cut-off or dichotomisation point. A study is classified high risk of bias if the authors define the optimal cut-off post-hoc based on their own study data because selecting the Unclear = unclear risk of bias threshold to maximise sensitivity and / specificity may lead to overoptimistic measures of test performance.

Certain papers may use an alternative methodology for analysis that does not use thresholds and these papers should be classified as not applicable.

\section{Reference Standard}

\begin{tabular}{ll}
\hline $\begin{array}{l}\text { Is the assessment } \\
\text { used for clinical }\end{array}$ & No = high risk of bias \\
diagnosis of de- & Yes = low risk of bias \\
$\begin{array}{l}\text { mentia accept- } \\
\text { able? }\end{array}$ & $\begin{array}{l}\text { Unclear = unclear } \\
\text { risk of bias }\end{array}$
\end{tabular}

Commonly used international criteria to assist with clinical diagnosis of dementia include those detailed in DSM-IV and ICD-10. Criteria specific to dementia subtypes include but are not limited to NINCDS-ADRDA criteria for Alzheimer's dementia; McKeith criteria for Lewy Body dementia; Lund criteria for frontotemporal dementia; and the NINDSAIREN criteria for vascular dementia. Where the criteria used for assessment is not familiar to the review authors or the Cochrane Dementia and Cognitive Improvement group ('unclear') this item should be classified as "high risk of bias".

\begin{tabular}{|c|c|}
\hline Was clinical as- & No $=$ high risk of bias \\
\hline mentia performed & Yes $=$ low risk of bias \\
\hline $\begin{array}{l}\text { without knowl- } \\
\text { edge of the PIB- } \\
\text { PET biomarker? }\end{array}$ & $\begin{array}{l}\text { Unclear = unclear } \\
\text { risk of bias }\end{array}$ \\
\hline
\end{tabular}

Terms such as "blinded" or "independently and without knowledge of" are sufficient and full details of the blinding procedure are not required. Interpretation of the results of the reference standard may be influenced by knowledge of the results of index test.

\section{Patient flow}

${ }^{11} \mathrm{C}$-PIB-PET for the early diagnosis of Alzheimer's disease dementia and other dementias in people with mild cognitive impairment (MCI) 
(Continued)

Was there an appropriate interval between PIB-PET biomarker and clinical dementia assessment?
No $=$ high risk of bias

Yes $=$ low risk of bias

Unclear = unclear risk of bias
As we test the accuracy of the PIB-PET biomarker for $\mathrm{MCl}$ conversion to dementia, there will always be a delay between the index test and the reference standard assessments. The time between reference standard and index test will influence the accuracy (Geslani 2005 ; Okello 2009 ; Visser 2006 ), and therefore we will note time as a separate variable (both within and between studies) and will test its influence on the diagnostic accuracy. We have set a minimum mean time to follow-up assessment of 1 year. If more than 16\% of subjects of subjects have assessment for $\mathrm{MCl}$ conversion before nine months this item will score 'no'.
Did all subjects get the same assessment for dementia regardless PIB-PET biomarker?

Were all patients who received PIBPET biomarker's assessment included in the final analysis?
No = high risk of bias

Yes $=$ low risk of bias

There may be scenarios where subjects who score "test positive" on index test have a more detailed assessment. Where dementia assessment differs between subjects this should be classified as high risk of bias.

Unclear $=$ unclear

risk of bias

No $=$ high risk of bias

Yes $=$ low risk of bias

Unclear $=$ unclear risk of bias
If the number of patients enrolled differs from the number of patients included in the $2 X 2$ table then there is the potential for bias. If patients lost to drop-outs differ systematically from those who remain, then estimates of test performance may differ.

If drop outs these should be accounted for; a maximum proportion of drop outs to remain low risk of bias has been specified as $20 \%$
Were missing PIBPET biomarker results reported?
No $=$ high risk of bias

Yes $=$ low risk of bias

Unclear $=$ unclear

risk of bias
Where missing or uninterpretable results are reported, and if there is substantial attrition (we have set an arbitrary value of $50 \%$ missing data), this should be scored as 'no'. If those results are not reported, this should be scored as 'unclear' and authors will be contacted

\section{Anchoring statements to assist with assessment for applicability}

Question Explanation

Were included patients representative of the general population of interest?
The included patients should match the intended population as described in the review question. The review authors should consider population in terms of symptoms; pre-testing; potential disease prevalence; setting

If there is a clear ground for suspecting an unrepresentative spectrum the item should be rated poor applicability.

\section{Index test}

Were sufficient data on Plasma and PIB-PET biomarker's application given for the test to be repeated in an independent study?
Variation in technology, test execution, and test interpretation may affect estimate of accuracy. In addition, the background, and training/expertise of the assessor should be reported and taken in consideration. If PIB-PET biomarker was not performed consistently this item should be rated poor applicability.

\section{Reference Standard}

Was clinical diagnosis of dementia made in a manner similar to current clinical practice?
For many reviews, inclusion criteria and assessment for risk of bias will already have assessed the dementia diagnosis. For certain reviews an applicability statement relating to reference standard may not be applicable. There is the possibility that a form of dementia assessment, although valid, may diagnose a far larger proportion of subjects with disease than usual clinical practice. In this instance the item should be rated poor applicability.

${ }^{11}$ C-PIB-PET for the early diagnosis of Alzheimer's disease dementia and other dementias in people with mild cognitive impairment (MCI) 


\section{CONTRIBUTIONS OF AUTHORS}

SZ: contributed to drafting protocol; data extraction; overall responsibility of study selection and data extraction; drafted Discussion and Authors' conclusion sections

$\mathrm{CH}$ : conception, funding, design, reviewing draft protocol and finalising manuscript

RMS: conception, funding, design, reviewing draft protocol and manuscript

ANS: developed search strategy and performed searches; contacted the authors

YT: performed statistical analyses, updated statistical methods section, wrote findings section and reviewed the draft manuscript

NS: designed and drafted protocol; study selection and data-extraction; characteristics of included and excluded studies tables; entered data and data entry check; QUADAS-2 assessment; set up data and analysis tables; created additional tables; drafted manuscript; managed the review process and produced progress reports, attended progress meetings and worked with all review authors to ensure that the review met publication deadlines

\section{DECLARATIONS OF INTEREST}

None known

\section{SOURCES OF SUPPORT}

\section{Internal sources}

- No sources of support supplied

\section{External sources}

- A programme of Diagnostic Test Accuracy(DTA) reviews and of updates of interventionreviews in dementia: 10/4001/05, UK.

This project was funded by the National Institute for Health Research. The views and opinions expressed therein are those of the authors and do not necessarily reflect those of the NIHR, NHS or the Department of Health

\section{N DEX TERMS}

\section{Medical Subject Headings (MeSH)}

*Aniline Compounds; *Carbon Radioisotopes; *Thiazoles; Alzheimer Disease [ ${ }^{\star}$ diagnostic imaging]; Cognitive Dysfunction [ ${ }^{\star}$ diagnostic imaging]; Dementia [*diagnostic imaging]; Disease Progression; Early Diagnosis; Positron-Emission Tomography [*methods]; Prospective Studies; Sensitivity and Specificity

\section{MeSH check words}

Aged; Humans

${ }^{11} \mathrm{C}$-PIB-PET for the early diagnosis of Alzheimer's disease dementia and other dementias in people with mild cognitive impairment (MCI) 